\title{
NEW INSIGHTS ON THE ECOLOGY OF FREE-LIVING, HETEROTROPHIC NANOFLAGELLATES BASED ON THE USE OF \\ MOLECULAR BIOLOGICAL APPROACHES
}

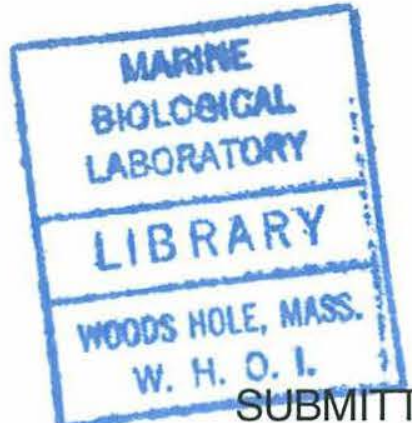

\author{
By \\ Ee Lin Lim \\ B.A., Smith College \\ (1988) \\ SUBMITTED IN PARTIAL FULFILLMENT OF THE REQUIREMENTS \\ FOR THE DEGREE OF
}

W. H. 0.1. I]

DOCTOR OF PHILOSOPHY

at the

MASSACHUSETTS INSTITUTE OF TECHNOLOGY

and the

WOODS HOLE OCEANOGRAPHIC INSTITUTION

March 1997

(C) 1997 Ee Lin Lim

All rights reserved

The author hereby grants to MIT and WHOI permission to reproduce and distribute copies of this thesis document in whole or in part.

Signature of Author

Joint Program in Biological Oceanography $\cap \cap \begin{aligned} & \text { Massachusetts Institute of Technology/ } \\ & \text { 'Noods Hole Oceanographic Institution }\end{aligned}$

Certified by

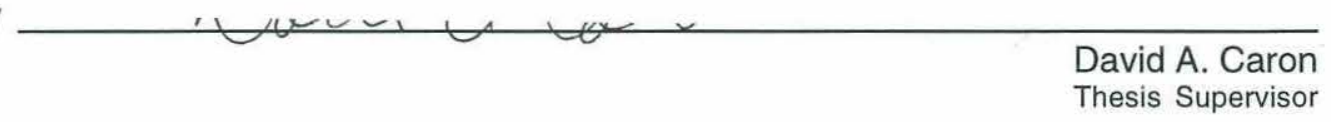

Accepted by

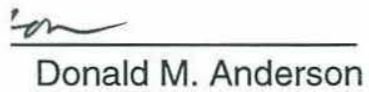

Donald M. Anderson

Chairman, Joint Committee for Biological Oceanography Massachusetts Institute of Technology/

Woods Hole Oceanographic Institution 


\section{Table of Contents}

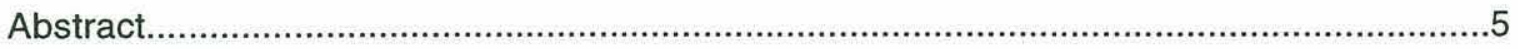

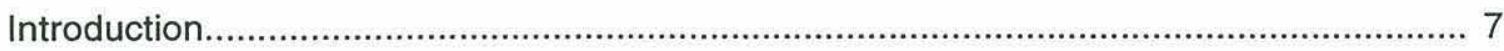

Chapter 1 Molecular Characterization of Heterotrophic Nanoflagellates by

Restriction Fragment Length Polymorphism Analysis of PCR amplified

Small Subunit rRNA Genes..................................................................15

Chapter 2 Application of Ribosomal RNA-Based Probes for Observing Marine

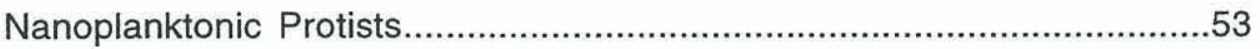

Chapter 3 Development and Field Application of a Quantitative Method for Examining

Natural Assemblages of Protists using Oligonucleotide Probes................85

Chapter 4 The Ecology of Paraphysomomnas imperforata based on Studies Employing

Oligonucleotide Probe Identification of Cells in Coastal Water Samples and

Enrichment Cultures.......................................................................121

Conclusions.

Appendix Molecular Identification of Nanoplanktonic Protists based on Small

Subunit Ribosomal RNA Gene Sequences for Ecological Studies.

175 


\title{
NEW INSIGHTS ON THE ECOLOGY OF FREE-LIVING, HETEROTROPHIC NANOFLAGELLATES \\ BASED ON THE USE OF MOLECULAR BIOLOGICAL APPROACHES
}

\author{
by \\ Ee Lin Lim \\ Submitted in partial fulfillment of the requirements for the degree of \\ Doctor of Philosophy
}

\begin{abstract}
Nanoplanktonic protists comprise a diverse assemblage of flagellate species responsible for various trophic processes in marine and freshwater ecosystems. Current methods for identifying small protists do not readily permit identification and enumeration of nanoplanktonic flagellates in cultures or field samples. The aim of this study was to apply molecular biological techniques for identification and enumeration of nanoflagellate taxa in water samples.

Restriction fragment length polymorphism (RFLP) analysis of small subunit ribosomal DNA (SSU rDNA) amplified by the polymerase chain reaction (PCR) differentiated pure cultures of heterotrophic nanoflagellates according to established taxonomic classification at the generic and species level. In addition, RFLP analysis of amplified SSU rDNA permitted discrimination of polymorphic forms among species of flagellates from the genus Paraphysomonas.

A fluorescent in situ hybridization method that uses rRNA-targeted oligonucleotide probes for counting protists from cultures and environmental water samples was developed. Preserved cells were intensely labeled with multiple
\end{abstract}


eukaryote-specific oligonucleotide probes end-labeled with biotin and detected by fluorescein (FITC)-avidin. This probe hybridization method gave estimates of nanoplankton abundances that were often more representative of natural abundances than estimates obtained by commonly employed fluorochrome stains.

The geographical distribution and seasonal abundance of the cosmopolitan heterotrophic flagellate, Paraphysomonas imperforata was examined in coastal waters using species-specific oligonucleotide probes. $P$. imperforata was found to occur at extremely low abundances in coastal environments, constituting $\leq 1 \%$ of the TNAN. However, $P$. imperforata often dominated the nanoplankton (up to $98 \%$ of TNAN) when water samples were enriched with bacteria. $P$. imperforata appears to be an opportunistic species capable of growing rapidly to high abundances when prey are abundant. Water temperature, small differences in the absolute abundance of $P$. imperforata, and nanoplankton grazers appeared to play a role in determining $P$. imperforata dominance. Results from this study also suggest that enrichment cultivation or perhaps incubations in general can select for nanoflagellates such as $P$. imperforata that may not be representative of abundant oceanic species. 


\section{Introduction1}

1 This introduction contains excerpts from the paper: Lim, E. L. 1996. Molecular identification of nanoplanktonic protists based on small subunit ribosomal RNA gene sequences for ecological studies". J. Euk. Microbiol., 43(2): pp. 101-106 (see Appendix A). This paper was originally presented as part of the symposium on "Protistan Molecular Ecology and Systematics," July 29, 1995, during the 48th Annual Meeting of the Society of Protozoologists, University of Alabama, Tuscaloosa, AL. 
Free-living protists in the nanoplankton size class $(2-20 \mu \mathrm{m})$ are composed primarily of a diverse assemblage of heterotrophic and photosynthetic flagellates (11, $12,16,17)$. Protists in this size category numerically dominate the eukaryotic plankton and are responsible for a variety of trophic processes in planktonic food webs (2, 3, and references therein). Photosynthetic protists often constitute a significant fraction of primary production in aquatic ecosystems while heterotrophic species are the major consumers of picoplankton-sized microorganisms (prokaryotic and eukaryotic cells 0.2 to $2 \mu \mathrm{m}$ in size) $(7,8,13,14)$. The grazing activities of these heterotrophs also result in the release of nutrients and dissolved organic material which are utilized by bacteria and microalgae $(4,6)$. In addition, by virtue of their size and ability to efficiently graze minute microorganisms, protists serve as an important trophic link between the picoplankton and metazoan zooplankton which can capture protists but are unable to consume picoplanktonic cells efficiently (5).

Despite their abundance and vital position in the trophic structure of microbial food webs, relatively little information is available on the population structure and diversity of the nanoplankton assemblage in the water column. Virtually nothing is known about the seasonal and temporal abundance of most species, and the geographical distribution of individual species is also poorly understood. Measurements of nanoplankton production and grazing rates in ecological studies are routinely performed without concomitant identification of the species responsible for these processes. Individual species often are not recognized as functionally and physiologically unique entities but are grouped together by size. This simplistic treatment of protistan community structure is largely a result of difficulties associated with identifying and enumerating small protists in mixed, natural assemblages using existing techniques.

Until recently, electron microscopy has been the most informative method for identifying small protists because of its high resolution. Information on ultrastructural 
organization based on flagella systems, scale morphology, and the structure of mitochondria and chloroplasts for example, has been used for taxonomy and phylogeny. However, electron microscopy is labor-intensive, impractical for analyses of large numbers of samples and has limited applicability for cell enumeration. As a result, the method is not routinely used by ecologists for processing environmental water samples and for viewing natural assemblages of microorganisms. One of the major goals in the application of molecular biological approaches in ecological studies thus, is to provide a new tool that allows both identification and enumeration of small protists in natural water samples.

An approach for examining microbial diversity that has begun to gain wide application in recent years is the use of SSU rRNA sequences and rRNA-based phylogenetic identification techniques $(1,18)$. Ribosomal RNA molecules are suitable molecular markers because they are universally distributed, highly conserved, and functionally and evolutionarily homologous across kingdom lines $(9,15)$. The molecule is interspersed with conserved and variable regions which are useful for sequence alignment and differentiation of compared organisms, respectively. The gene (and gene product) is relatively easy to isolate and characterize, and appears not to undergo lateral gene transfer between species. At present, the SSU rRNA database contains approximately 3000 aligned sequences, of which more than 400 are eukaryotic sequences (10). The database provides a source of sequence information for comparative sequence analysis and the design of oligonucleotide primers and probes. Oligonucleotides of varying specificity ranging from kingdom- to subspecies-level have been designed for numerous microorganisms for use as primers and probes, indicating that the SSU rRNA molecule may be a suitable target to design protistan probes. Another important advantage of working with the rRNA molecule is that the relatively high cellular content of.rRNA provides abundant target sites for probe binding. 
Ribosomal RNA sequences and phylogenetic identification techniques have mostly been employed for the detection and identification of a variety of prokaryotes (1). These techniques have enabled bacteriologists to characterize species in cultures as well as in environmental samples by direct sequence analysis, restriction fragment length polymorphism (RFLP) analyses or by oligonucleotide hybridization probes. The use of PCR to amplify rRNA genes from single cells or minute amounts of template DNA, together with automated sequencing techniques, have made the identification of microbial cells using molecular biological techniques more effective and expedient than traditional culture methods.

The goal of this thesis is to provide a conceptual framework for applying rRNAbased identification techniques to examine free-living nanoflagellate diversity and ecology. Chapter 1 compares morphology-based identifications of heterotrophic heterokont flagellates to molecular characterization by restriction fragment length polymorphism analysis of SSU rRNA genes amplified by the polymerase chain reaction (PCR). This method also allowed discrimination of different species (groups) of flagellates in our culture collection so that appropriate species could be selected for sequencing and probe development. The work in Chapter 2 examines the feasibility of using oligonucleotide probes to detect protists in field samples and sets the stage for Chapter 3, which describes the adaptation of existing hybridization protocols for quantitative analysis of samples by in situ hybridization. The method and results from its application for counting protists in cultures and field samples as well as in an experimental setting are described. In Chapter 4, the methods developed in the two previous chapters are applied in the context of an ecological study. The biogeography and seasonal abundance of the heterotrophic flagellate, Paraphysomonas imperforata, is investigated along with questions concerning the selective growth and control of $P$. imperforata in enrichment cultures. 


\section{References}

1. Amann, R. I., W. Ludwig and S. K-H. 1995. Phylogenetic identification and in situ detection of individual microbial cells without cultivation. Microbiol. Rev. 59:143-169.

2. Azam, F., T. Fenchel, J. G. Field, J. S. Gray, L. A. Meyer-Reil and F. Thingstad. 1983. The ecological role of water-column microbes in the sea. Mar. Ecol. Prog. Ser. 10:257-263.

3. Berninger, U.-G., D. A. Caron, R. W. Sanders and B. J. Finlay. 1991. Heterotrophic flagellates of planktonic communities, their characteristics and methods of study, p. 39-56. In D. J. Patterson and J. Larsen (ed.), The biology of free-living heterotrophic flagellates. vol. Special Volume 45. Clarendon Press, Oxford.

4. Caron, D. A. 1991. Evolving role of protozoa in aquatic nutrient cycles, p. 387415. In P. C. Reid, C. M. Turley and P. H. Burkill (ed.), Protozoa and their role in marine processes. vol. 25. Springer-Verlag, Berlin.

5. Caron, D. A. 1994. Protozoan links in food webs, p. 125-130. In K. Hausmann and N. Hülsmann (ed.), Progress in Protozoology, Proceedings of the IX International Congress of Protozoology, Berlin 1993. Gustav Fischer Verlag, Stuttgart.

6. Caron, D. A. and J. C. Goldman. 1990. Protozoan nutrient regeneration, p. 283-306. In G. M. Capriulo (ed.), Ecology of marine protozoa. Oxford University Press, New York.

7. Caron, D. A., E. L. Lim, G. Miceli, J. B. Waterbury and F. W. Valois. 1991. Grazing and utilization of chroococcoid cyanobacteria and heterotrophic 
bacteria by protozoa in laboratory cultures and a coastal plankton community. Mar. Ecol. Prog. Ser. 76:205-212.

8. Malone, T. C. 1971. The relative importance of nannoplankton and netplankton as primary producers in tropical oceanic and neritic phytoplankton communities. Limnol. Oceanogr. 16:633-639.

9. Olsen, G. J., D. J. Lane, J. Giovannoni and N. R. Pace. 1986. Microbial ecology and evolution: a ribosomal RNA approach. Ann. Rev. Microbiol. 40:337365.

10. Olsen, G. J., R. Overbeek, N. Larsen, T. L. Marsh, M. J. McCaughey, M. A. Maciukenas, W.-M. Kuan, T. J. Macke, Y. Xing and C. R. Woese. 1992. The ribosomal RNA database project. Nucleic Acids Res. 20:2199-2200.

11. Patterson, D. J. 1993. The current status of the free-living heterotrophic flagellates. Journal of Eukaryotic Microbiology 40:606-609.

12. Patterson, D. J. and J. Larsen. 1991. The biology of free-living heterotrophic flagellates. Clarendon Press, Oxford

13. Sherr, B. F., E. B. Sherr and R. D. Fallon. 1987. Use of monodispersed, fluorescently labeled bacteria to estimate in situ protozoan bacterivory. Appl. Environ. Microbiol. 53:958-965.

14. Sherr, E. B., B. F. Sherr and J. McDaniel. 1991. Clearance rates of $<6 \mu \mathrm{m}$ fluorescently labeled algae (FLA) by estuarine protozoa: potential grazing impact of flagellates and ciliates. Mar. Ecol. Prog. Ser. 69:81-92.

15. Sogin, M. L. and J. H. Gunderson. 1987. Structural diversity of eukaryotic small subunit ribosomal RNAs. Ann. N.Y. Acad. Sci. 503:125-139.

16. Vørs, N. 1992. Heterotrophic amoebae, flagellates and heliozoa from the Tvärminne area, Gulf of Finland, in 1988-1990. Ophelia 36:1-109. 
17. Vørs, N. 1993. Marine heterotrophic amoebae, flagellates and heliozoa from Belize (Central America) and Tenerife (Canary Islands), with descriptions of new species, Luffisphaera bulbochaete N. Sp., L. longihastis N. Sp., L. turriformis N. Sp. and Paulinella intermedia N. Sp. Journal of Eukaryotic Microbiology 40:272287.

18. Ward, D. M., M. M. Bateson, R. Weller and A. L. Ruff-Roberts. 1992. Ribosomal RNA analysis of microorganisms as they occur in nature. Adv. Microb. Ecol. 12:219-286. 


\section{Chapter I}

Molecular Characterization of Heterotrophic Nanoflagellates by Restriction Fragment Length Polymorphism Analysis of PCR-Amplified Small Subunit rRNA Genes 


\section{Abstract}

Thirty clones of heterotrophic nanoflagellates isolated from a variety of marine and freshwater environments were examined by restriction fragment length polymorphism (RFLP) analysis of small subunit (SSU) rRNA genes amplified by the polymerase chain reaction (PCR), and compared to electron microscopical identifications of the isolates. Based on morphological identification, sixteen of the thirty clones belonged to the genus Paraphysomonas De Saedeleer, seven to the genus Spumella Cienkowski, four to the genus Oikomonas Kent and three to the genus Cafeteria Fenchel and Patterson. Among these taxa, eleven different combinations of restriction patterns representing eleven SSU rDNA genotypes were detected by RFLP analysis with the enzymes Hinf I, Hae III, Sau3A I and Msp I. Differentiation of nanoflagellate taxa by the PCR-RFLP method was in good agreement with established taxonomic classification at the generic and species level. In addition, RFLP analysis of amplified SSU rDNA permitted discrimination of polymorphic forms among species of Paraphysomonas. RFLP analysis of PCR-amplified SSU rDNA provides a rapid and reliable way to distinguish taxonomic groups of heterotrophic nanoflagellates, and an independent method for resolving ambiguities in taxonomic classification when morphological features are unclear. 


\section{Introduction}

Heterotrophic flagellates are ubiquitous in aquatic environments and constitute a major component of the eukaryotic plankton. They are the primary consumers of bacteria and other picoplankton and serve as important nutrient remineralizers in the water column $(1,2,4,6,7)$. The size of these organisms and their ability to consume bacteria also place the heterotrophic flagellates in a position as trophic links for the transfer of carbon and nutrients from bacteria to higher consumers in planktonic food webs that cannot otherwise utilize the bacterial biomass.

Studies on the diversity and biogeography of heterotrophic flagellates have been hampered by problems with the identification of these minute protists. Flagellate taxa are generally identified on the basis of morphological characters: cell morphology, flagellar number, the presence or absence of cell coverings, etc. Because many of the species are very small $(<20 \mu \mathrm{m})$, the minute morphological and ultrastructural details which distinguish individual taxa can often only be observed by electron microscopy. Electron microscopy, however, demands experience as well as a significant expenditure of time. It is costly and impractical as a tool for analyzing large numbers of samples.

Heterotrophic flagellates are also difficult to discriminate because the majority of species lack obvious cell coverings such as scales and loricas for specific identification. Among the naked flagellates, where only cell morphology and cytoplasmic characters are available (with the exception of cysts), many of the descriptions for species belonging to genera such as Spumella and Oikomonas are often vague because the criteria for identifying species within these groups are not clear. The use of electron microscopy does not help as well for lack of discriminatory criteria. Most of the 
descriptions of known species, consequently, still date back to original light microscopical descriptions which are often inadequate (18).

Identification based on well-defined taxonomic characters such as silica scales which cover some groups of chrysomonad flagellates can also present special problems. Some species such as Paraphysomonas imperforata as well as other members of the genus apparently demonstrate intraspecific variability in scale size and morphology. The polymorphic scales of $P$. imperforata can show up to 4-fold differences in size (15, $23,24)$ while other species may produce imperfect forms. These differences are often present even within a single cell. Several species of Paraphysomonas normally possess at least two types of scales but these species have also been observed with only one type of scale. Whether or not individuals which show such deviations in scale size and morphology should be considered a separate species has become a subject for debate and has rendered species identifications even more tentative $(22,24)$.

Another important question concerning scale variability that has not been well addressed is the effect of environmental conditions such as temperature, salinity and nutrients on scale variability. Silica limitation is known to affect the production of scales but there are no data on the effects silica concentration on variability in scale morphology. These uncertainties further confound the problem of identifying cells with varying scale structure.

A more rapid and reliable identification method would ease the discrimination of flagellate taxa and aid ecological studies of these species. In recent years, rapid identification and classification of microorganisms have been successfully carried out by DNA-based methods. The analysis of small subunit ribosomal RNA (SSU rRNA) gene sequences, the polymerase chain reaction (PCR), oligonucleotide probes and DNA polymorphism assays have been especially useful for characterizing microbial populations $(8,13,14,21,25,26)$. A method based on restriction fragment length 
polymorphisms (RFLP) of rRNA genes amplified by PCR, in particular, has been commonly used for taxonomic characterization of cultivable bacterial species and strains $(9,10)$. This method entails amplification of SSU rRNA genes directly from isolates followed by digestion of the amplified rDNA with restriction enzymes. The digested rDNA of isolates are then analyzed and compared for length polymorphisms by horizontal gel electrophoresis and ethidium bromide staining. Restriction fragment length polymorphism analysis of amplified SSU rDNA has also proven to be useful in the taxonomy of protists to delineate species of vahlkampfiid amoebae, toxic red tide dinoflagellates within the genus Alexandrium and Symbiodinium-like zooxanthellae (3, $19,20)$.

This study examines the use of RFLP analysis of small subunit (SSU) rDNA sequences amplified by PCR to differentiate clonal cultures of heterotrophic flagellates. Differentiation of the flagellate isolates by RFLP analysis was compared to identification of species based on electron microscopical observations of flagella and scale structure (where present).

\section{Materials and methods}

Flagellate cultures. Thirty clonal cultures of flagellates which originated from various freshwater and marine locations along the east coast of the United States, England and Malaysia were examined (Table 1). Isolates selected for this study all possessed a swimming behavior characteristic of chrysomonad-like flagellates. The identity of these species were otherwise unknown at the time that the RFLP analyses were performed with the exception of clone JE1 which was provided by Jacqueline Eccleston and identified as $P$. imperforata. Seven of the clones were isolates from 
Table 1. Small subunit (SSU) rDNA restriction patterns of heterotrophic nanoflagellates grouped by RFLP analysis of PCR-amplified SSU rDNA. M = marine isolate; $F=$ freshwater isolate. " An extra $750 \mathrm{bp}$ band was detected in the PCR product; ** An extra 1000 bp band was detected in the PCR product; † The amplified SSU rDNA was $1900 \mathrm{bp}$. 


\begin{tabular}{|c|c|c|c|c|c|c|c|}
\hline $\begin{array}{l}\text { Identification } \\
\text { (Clone name) }\end{array}$ & $\begin{array}{c}\text { Geographic } \\
\text { origin }\end{array}$ & Source & $\frac{\text { SSU } r}{\text { Hinf I }}$ & $\frac{\text { NA res }}{\text { Hae III }}$ & $\frac{\text { striction pe }}{\text { SauBA I }}$ & $\frac{\text { attern }}{\text { Msp I }}$ & $\begin{array}{l}\text { SSU rDNA } \\
\text { genotype }\end{array}$ \\
\hline \multicolumn{8}{|l|}{ P. imperforata } \\
\hline WB1 & Waquoit Bay, MA & $M$ & 1 & 1 & 1 & 1 & $1^{\star}$ \\
\hline WB2 & Waquoit Bay, MA & $M$ & 1 & 1 & 1 & 1 & $1^{\star}$ \\
\hline WB3 & Waquoit Bay, MA & $M$ & 1 & 1 & 1 & 1 & $1^{\star}$ \\
\hline WB4 & Waquoit Bay, MA & M & 1 & 1 & 1 & 1 & $1^{*}$ \\
\hline WB5 & Waquoit Bay, MA & M & 1 & 1 & 1 & 1 & $1^{*}$ \\
\hline VS1 & Vineyard Sound, MA & M & 1 & 1 & 2 & 2 & ॥ \\
\hline JE1 & England & M & 1 & 1 & 2 & 2 & ॥ \\
\hline \multicolumn{8}{|c|}{ Paraphysomonas sp. } \\
\hline SR3 & Sakonnet River, RI & M & 1 & 1 & 2 & 2 & $\|$ \\
\hline \multicolumn{8}{|l|}{ Spumella spp. } \\
\hline EP1 & Eel Pond, MA & M & 2 & 2 & 2 & 1 & $\mathrm{III}^{* *}$ \\
\hline EP2 & Eel Pond, MA & $M$ & 2 & 2 & 2 & 1 & $\mathrm{III}^{\star \star}$ \\
\hline YP1 & Malaysia & $\mathrm{F}$ & 2 & 2 & 2 & 3 & IV \\
\hline CRP1 & Washington, DC & $\mathrm{F}$ & 3 & 3 & 3 & 4 & V \\
\hline LW1 & Winnepesaukee, NH & $\mathrm{F}$ & 3 & 3 & 3 & 4 & V \\
\hline LBMS1 & Malaysia & $\mathrm{F}$ & 3 & 3 & 3 & 4 & V \\
\hline MR1 & Merrimac River, MA & $\mathrm{F}$ & 3 & 3 & 3 & 5 & $\mathrm{VI}$ \\
\hline \multicolumn{8}{|l|}{ P. vestita } \\
\hline PV10 & England & $\mathrm{F}$ & 4 & 4 & 4 & 6 & vIIt \\
\hline DB1 & Kyle's Pond, MD & $\mathrm{F}$ & 4 & 4 & 4 & 6 & VIIt \\
\hline \multicolumn{8}{|c|}{ P. vestita (small-scaled) } \\
\hline WH1 & Woods Hole, MA & M & 5 & 5 & 5 & 7 & VIII \\
\hline WH4 & Woods Hole, MA & M & 5 & 5 & 5 & 7 & VIII \\
\hline SS & Sargasso Sea & M & 5 & 5 & 5 & 7 & VIII \\
\hline WH1a & Woods Hole, MA & M & 5 & 5 & 5 & 7 & VIII \\
\hline Hflag & Sargasso Sea & M & 5 & 5 & 5 & 7 & VIII \\
\hline \multicolumn{8}{|l|}{$P$. butcheri } \\
\hline DB4 & Patuxant River, MD & M & 6 & 6 & 6 & 8 & $\mathrm{IX}^{\star}$ \\
\hline \multicolumn{8}{|l|}{ Cafeteria sp. } \\
\hline SR4 & Sakonnet River, RI & M & 7 & 7 & 7 & 9 & $\mathrm{x}$ \\
\hline SR6 & Sakonnet River, RI & M & 7 & 7 & 7 & 9 & $\mathrm{X}$ \\
\hline Cflag & Woods Hole, MA & M & 7 & 7 & 7 & 9 & $x$ \\
\hline \multicolumn{8}{|l|}{ Oikomonas sp. } \\
\hline NB1 & Narragansett Bay, RI & $M$ & 8 & 8 & 8 & 10 & $x$ \\
\hline NB2 & Narragansett Bay, RI & M & 8 & 8 & 8 & 10 & $x$ \\
\hline SR1 & Sakonnet River, RI & M & 8 & 8 & 8 & 10 & $x$ \\
\hline SR5 & Sakonnet River, RI & $M$ & 8 & 8 & 8 & 10 & $x$ \\
\hline
\end{tabular}


freshwater (CRP1, DB1, LBMS1, LW1, PV10 and YP1) and the remainder originated from marine localities. The clonal cultures designated as $\mathrm{WH} 1, \mathrm{WH} 1 \mathrm{a}, \mathrm{WH} 4$ and $\mathrm{SS}$ were obtained from John B. Waterbury (Woods Hole Oceanographic Institution, MA), PV10 from Robert W. Sanders (Temple University, PA) and DB1 and DB4 from Delma Bratvold (George Mason University, VA). The remaining clonal cultures were isolated from enrichment cultures of natural water samples according to the method in Caron (5) and the procedure briefly described below.

One hundred $\mathrm{ml}$ of a water sample was supplemented with sterile yeast extract to a final concentration of $0.01 \%$ to promote bacterial growth. These cultures were kept in the dark at room temperature for approximately 7 days to enrich for a mixed assemblage of heterotrophic protists on the bacteria. These enrichments were viewed with a Wild M-10 dissecting microscope and individual flagellate cells were picked with a micropipet from a drop of culture. Individual cells were transferred through successive drops of sterile water (to ensure selection of a single cell), and finally transferred into a tube containing a dilute culture of bacteria. After about 2 weeks, these clonal attempts were checked for growth of flagellates. All the clonal cultures from the collection of David A. Caron with the same letter prefixes originated from the same enrichment culture and the number following the letters refers to individual clones that were isolated from that enrichment culture.

All the flagellate cultures were maintained on either freshwater or seawater supplemented with $0.005 \%$ yeast extract and bacteria at room temperature. Cultures were harvested for microscopy and molecular analyses when the flagellates reached early stationary growth phase.

DNA preparation. Cells from $1.5 \mathrm{ml}$ of culture were pelleted and resuspended in $50 \mu$ of $1 X \mathrm{PCR}$ buffer $(50 \mathrm{mM} \mathrm{KCl}, 10 \mathrm{mM}$ Tris- $\mathrm{HCl} \mathrm{pH} 8.3,2 \mathrm{mM} \mathrm{MgCl}$, $0.001 \%$ gelatin) supplemented with $0.5 \%$ NP40. The cell suspension was then 
incubated at $95^{\circ} \mathrm{C}$ for $10 \mathrm{~min}$. to lyse the cells. The supernatant was directly used as template for PCR amplification.

PCR amplification. Primers derived from conserved regions flanking the SSU rRNA genes of eukaryotes, designated as Primer A and Primer $\mathrm{B}$, were used for PCR amplification (12). Each PCR reaction consisted of $50 \mathrm{mM} \mathrm{KCl}, 10 \mathrm{mM}$ Tris- $\mathrm{HCl} \mathrm{pH}$ $8.3,2 \mathrm{mM} \mathrm{MgCl} 2,0.001 \%$ gelatin, $0.05 \% \mathrm{NP} 40,200 \mu \mathrm{M}$ of each dNTP, $1 \mathrm{ng} \mu^{-1}$ of each primer, $0.5 \mu \mathrm{l}$ of Taq DNA polymerase (Promega, Madison, WI) and $3 \mu \mathrm{l}$ of cell lysate ( template) in a total volume of $100 \mu \mathrm{l}$. DNA amplification was performed in a Perkin-Elmer Thermocycler for 30 cycles with the following temperature profile: denaturation at $92^{\circ} \mathrm{C}$ for $1 \mathrm{~min}$. $30 \mathrm{sec}$., annealing at $55^{\circ} \mathrm{C}$ for $1 \mathrm{~min}$. $30 \mathrm{sec}$. and extension at $72^{\circ} \mathrm{C}$ for $2 \mathrm{~min}$. Amplified DNA was analyzed by horizontal gel electrophoresis in $1 \%$ agarose gels.

RFLP analysis. Amplified SSU rDNA was digested with the restriction enzymes Hae III, Hinf I, Msp I and Sau3A I (New England Biolabs, Beverly, MA). The digestions were performed with $1 \mathrm{U}$ of enzyme in $8 \mu \mathrm{l}$ of PCR product and incubated for 2 hours at $37^{\circ} \mathrm{C}$. Digested DNA was analyzed by horizontal gel electrophoresis in $3 \%$ low melting point agarose (Sigma, St. Louis, MO). Gels were stained in a solution of ethidium bromide (5 $\left.\mathrm{ng} \mathrm{ml}^{-1}\right)$ and photographed under UV illumination. Restriction fragment sizes were calculated from migration distances for each flagellate clone relative to a 1 kb DNA fragment size marker (GIBCO BRL, Gaithersburg, MD) by using the Bio Image Whole Band Analysis program on a Sun Sparc 10 workstation.

Transmission Electron Microscopy. Cells in late exponential or stationary phase of growth were fixed with glutaraldehyde to a final concentration of $1 \%$. Fixed cells (approximately $1.5 \mathrm{ml}$ ) were concentrated to a small volume (by centrifugation and discarding all but approximately $50 \mu \mathrm{l}$ of supernatant to resuspend the cell pellet), and a drop of concentrate was placed on a formvar-coated copper grid (400-mesh). 
After allowing the cells to settle for about $10 \mathrm{~min}$., the drop was blotted away with a piece of Whatman filter paper and the grid was air-dried. The cells were then negativestained with $1 \%$ uranyl acetate for $2 \mathrm{~min}$. Grids were subsequently rinsed by quickly immersing them into distilled water to remove excess stain and salt crystals (marine samples), and then air-dried. Microscopy was carried out using a Zeiss 10 transmission electron microscope. The heterotrophic flagellates were identified by flagellar morphology and scale structure (if present), and measurements of their cell size and flagella length were made from electron micrographs. Isolates were identified to genus and species where possible.

\section{Results}

Identification of flagellate clones. All the flagellates examined in this study are heterotrophic (i.e. lack chloroplast) and possess heterokont flagellation, a short flagellum that is smooth and a second (usually the longer flagellum) which has tripartite hairs. Sixteen of the thirty clones belonged to the genus Paraphysomonas De Saedeleer, seven to the genus Spumella Cienkowsky, four to the genus Oikomonas Kent and three belonged to the genus Cafeteria Fenchel and Patterson. A brief description of each group along with species descriptions (where identification was possible) are provided in the following paragraphs.

Paraphysomonas De Saedeleer. Paraphysomonas cells possess a long hairy flagellum and a short, smooth one. Species in this genus are identified by the siliceous scales which cover the cell. The group has been extensively described by Preisig and Hibberd in a series of three papers and detailed information can be found in these papers for, identifying Paraphysomonas species (15-17). A brief description of the species 
included in this study is given below (following the references above). More detailed descriptions are provided for isolates that are different from the type material and could not be clearly identified.

Three species of Paraphysomonas, $P$. imperforata (7 isolates), $P$. vestita (2 isolates) and $P$. butcheri ( 1 isolate) were identified. Five isolates were temporarily identified as a variant of $P$. vestita possessing short spines and one isolate has not been identified with certainty but resembles the genus Paraphysomonas. These identifications have been confirmed by $\mathrm{H}$. R. Preisig (personal communication).

P. imperforata Lucas (Fig $1 \mathrm{~A}$ and $\mathrm{B}$ ). P. imperforata is characterized by scales which consist of a flat baseplate without a thickened rim. A spine arises from the center of the baseplate and ends in an abruptly pointed tip. The clones WB1-5 and VS 1 were identified as $P$. imperforata (the strain, JE1, was identified as $P$. imperforata by J. Eccleston) (Table 1). All were marine isolates which originated from two locations in Massachusetts, USA and from England.

Paraphysomonas sp. (Fig. 1C and D). The scale type produced by the marine isolate, SR3, is different from any described species of Paraphysomonas although the general features of the cell, (cell size $\approx 3 \mu \mathrm{m}$, colorless, heterokont flagellation with one long, hairy flagellum and a short, smooth flagellum) resembles the genus Paraphysomonas. The scales are more or less spherical $(\approx 1 \mu \mathrm{m})$ without distinct processes or often with a central accumulation of scale material. These scales resemble the aberrant scale forms sometimes produced by $P$. gladiata, although the aberrant scales of $P$. gladiata have a rim (15, Fig. 5). Preisig found cells covered with scales similar to clone SR3 in several English lakes and suggested that they may belong to a new species (15). However, more detailed studies are needed before a new specific name can be assigned. 
Figure $1 \mathrm{~A}$ and B. Paraphysomonas imperforata. A: Whole cell, $\mathrm{x} 9000$. B: Group of scales, x 17,000. Figure 1C and D. 

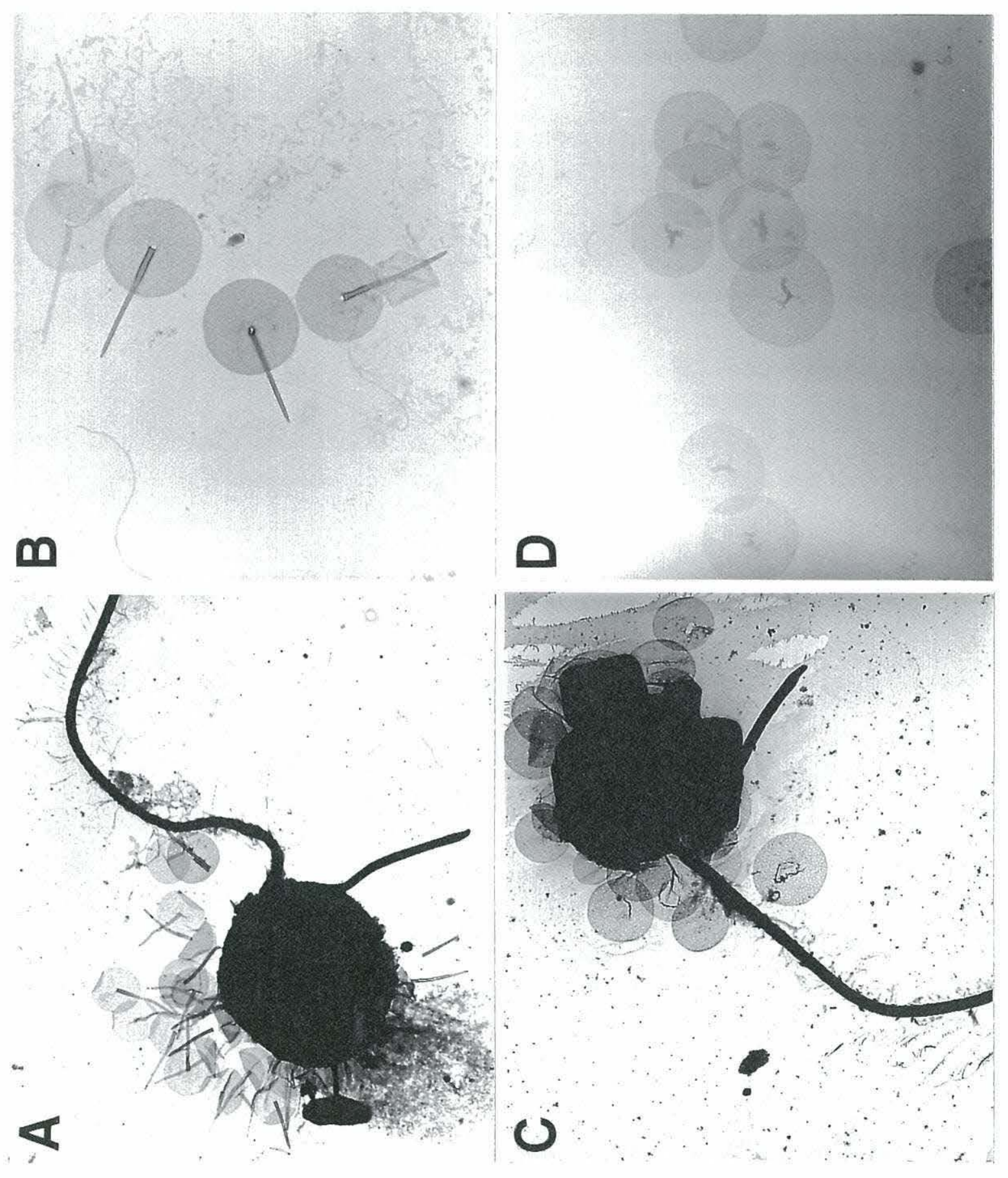
P. vestita (Stokes) de Saedeleer (Fig. $2 A$ and B). The scales of this species consist of a baseplate with a slightly thickened rim; a tapering spine with an acute tip arises from the center of the baseplate. The spines are generally longer relative to the base plate than the spines of $P$. imperforata (Fig. 1B). Two clones, PV10 and DB1, which originated from England and Maryland, USA, respectively, were identified as $P$. vestita. Both are freshwater isolates (Table 1).

P. vestita (small-scaled) (Fig. $2 \mathrm{C}$ and $\mathrm{D})$. Scales from marine strains $\mathrm{WH} 1$, WH1a, WH4, SS and Hflag have a baseplate with a thickened rim and a central spine arising from the base plate that ends in a rounded tip. The morphology of the scales resembles that of $P$. bandaiensis Takahashi although it was suggested by Preisig to consider these strains as small-scaled $P$. vestita (personal communication) on the following basis: i) Small-scaled forms of $P$. vestita may be very similar to $P$. bandaiensis and it is not always possible to distinguish the two species; ii) $P$. vestita was previously reported to have scales with a base diameter as small as $0.4 \mu \mathrm{m}$ and a spine length as short as $1.3 \mu \mathrm{m}$ whereas $P$. bandaiensis usually have scales with a base diameter of $0.2-0.8 \mu \mathrm{m}$ and a spine length of 0.2-1.1 $\mu \mathrm{m}$ (15). The scales of clone WH1, WH1a, WH4, SS and Hflag have a base diameter that measures $\approx 0.6 \mu \mathrm{m}$ and a spine length, $\approx 1.0-1.3 \mu \mathrm{m}$ and appear to be intermediate between $P$. vestita and $P$. bandaiensis; because typical $P$. bandaiensis cells have never been recorded in marine environments, the clones are tentatively identified as small-scaled $P$. vestita.

P. butcheri Pennick and Clarke (Fig. $3 A$ and B). This species produces two types of scales. The plate scales are round to elliptical with a meshwork structure while the crown scales consist of a proximal ring from which a series of five arches arise. These distal arches are connected in the middle by a meshwork structure. The marine isolate DB4 was identified as $P$. butcheri in this study. 
Figure 2A and B. Paraphysomonas vestita. A: Whole cell, x 5500. B: Group of scales, x 20,000. Figure 2C and D. Small$\underset{\omega}{\omega} \quad$ scaled Paraphysomonas vestita. C: Whole cell, $x 8000$. D: Group of scales, $x$ 32,000. 


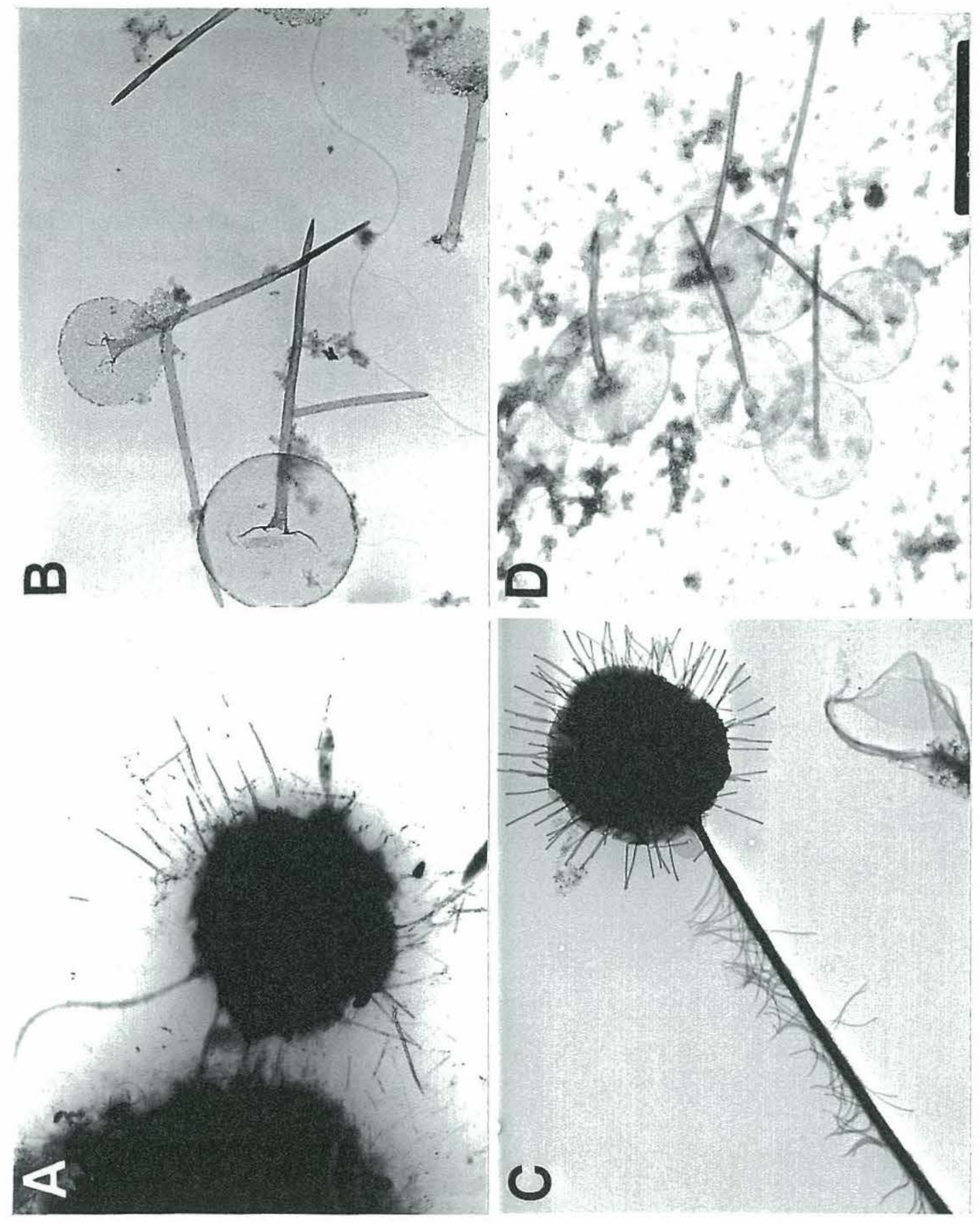


Figure 3 A and B. Paraphysomonas butcheri. A: Whole cell, $x 9000$. B: Single crown scale (top) and plate scale (bottom), $\mathrm{x}$

20,000. Figure $3 C$ and D. Spumella spp. C: Clone EP1, x 12,000. D: Clone YP1, x 13,000. 

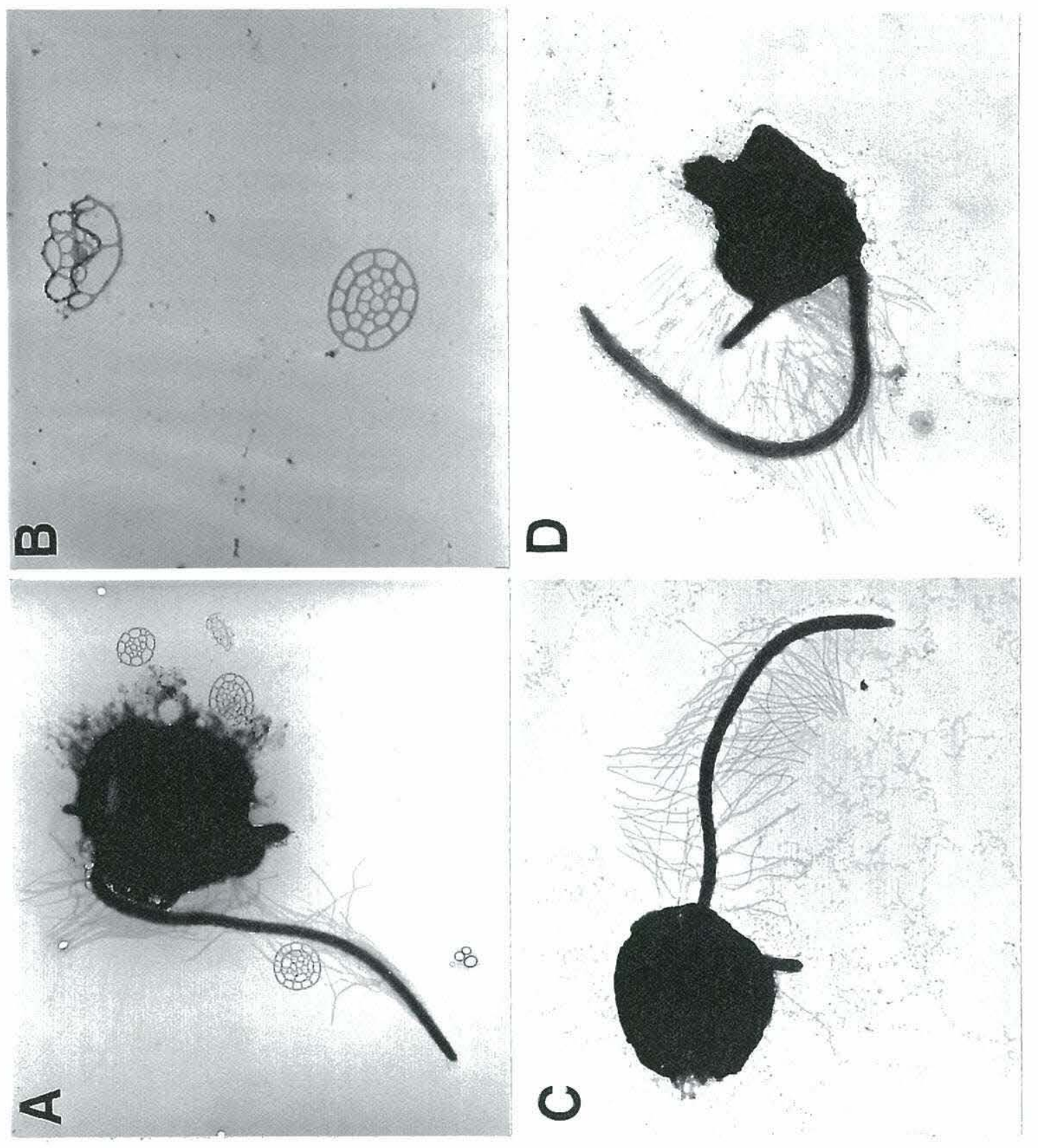
Spumella Cienkowsky (Fig 3C; D, Fig. 4A, B, C and D). Identification of the naked, chrysomonad flagellates is generally very difficult because there are few obvious morphological criteria to separate species. The problem of identifying these naked flagellates is further confounded by the lack of informative taxonomic keys as guidelines. Most of the descriptions of this group still date back to original, light microscopical observations from the last century. Identification of the clonal cultures in this study represent the best possible identifications based on current literature.

Isolates identified as Spumella are naked, and the long, hairy flagellum and short, smooth flagellum are both visible. Two of the clones were marine isolates (EP1 and EP2) from Massachusetts while the other five (YP1, CRP1, LW1, LBMS1 and MR1) originated from freshwater localities. These latter five cultures came from lakes in District of Columbia, New Hampshire, Malaysia and a river in Massachusetts, respectively. Cells from clone EP1, EP2, YP1 and MR1 were $\approx 2 \mu \mathrm{m}$ in diameter with a flagellum length of $\approx 5-6 \mu \mathrm{m}$ for isolates EP1, EP2 and YP1, but the long flagellum of clone MR1 was $\approx 10 \mu \mathrm{m}$. The cell diameter of isolates CRP1, LW1 and LBMS1 was $\approx 4$ $\mu \mathrm{m}$ and the length of their long flagellum was $\approx 7-10 \mu \mathrm{m}$. These latter three isolates have a cell bodies that are uniformly covered by an amorphous material that cannot be readily identified from negative-stained preparations (Fig. 4A, B and C). This cell covering gives the outline of the cell body an uneven appearance.

Cafeteria Fenchel and Patterson (Fig. 5A and B). A description of this genus and its members based on light microscopical observations of live samples can be found in Larsen and Patterson (11). Three clones (SR4, SR6 and Cflag) were identified as belonging to this genus. The generic identity of strain Cflag was confirmed by D. J. Patterson based on observations of live samples. Cells from strain SR 4 and SR6 have a spherical to D-shaped cell body, $2-3 \mu \mathrm{m}$ in diameter. The cells possess two flagella of approximately equal length: the hairy flagellum is $6-8 \mu \mathrm{m}$ long and the smooth 
Figure 4. Spumella spp. A: Clone CRP1, x 8000. B: several cells of Clone LW1, x 5000. C: Clone LBMS1, x 5500. D: Clone MR1, x 8500 . 


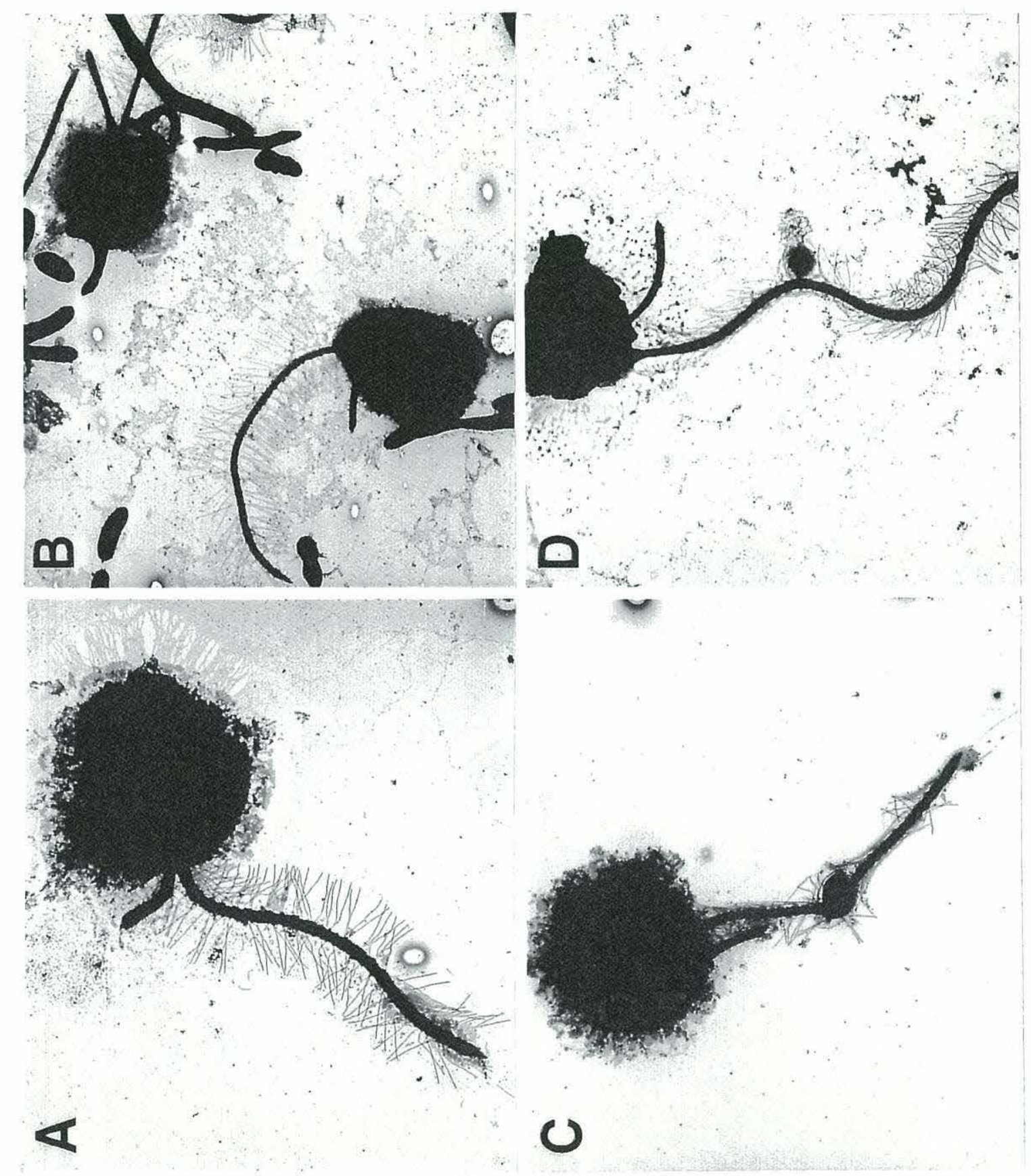


Figure 5A and B. Cafeteria sp. A: several cells of Clone SR4, x 4500. B: Clone SR6, x 9000. Figure 5C and D. Oikomonas sp. C: several cells of Clone NB1, x 5500. D: two cells of Clone SR1, x 5500 . 


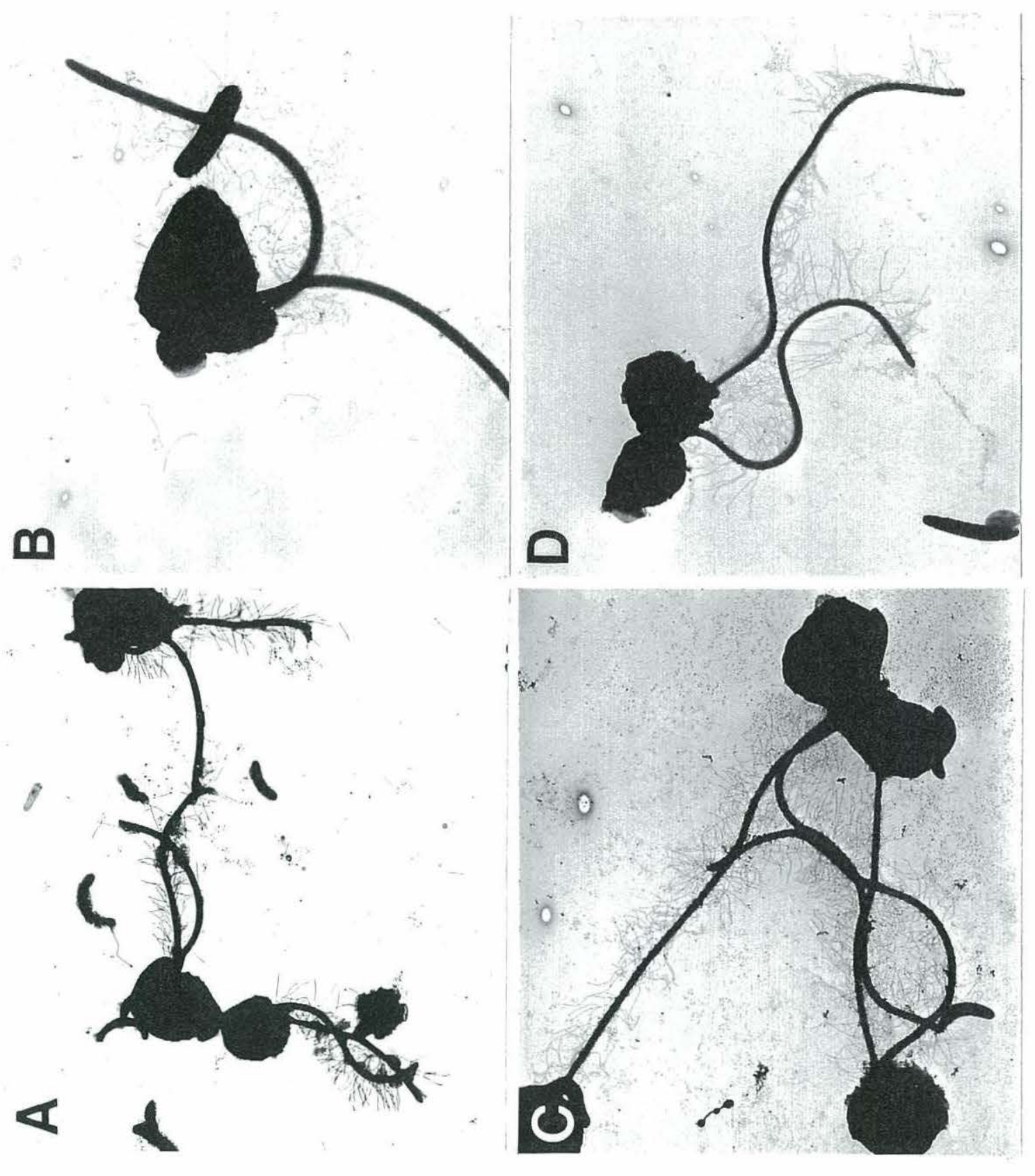


flagellum is about $7 \mu \mathrm{m}$ long. All three isolates are from marine localities in Rhode Island and Massachusetts.

Oikomonas Kent (Fig. $5 \mathrm{C}$ and D). This genus is described with a single emergent flagellum which distinguishes it from Spumella which possess two visible flagella (18). Clones NB1, NB2, SR1 and SR5 all have only one long, hairy flagellum visible. Cells belonging to the NB clones are $\approx 3 \mu \mathrm{m}$ in diameter with flagella that range from $12-15 \mu \mathrm{m}$ in length whereas cells from the SR clones are $\approx 2-3 \mu \mathrm{m}$ in diameter and have flagella that are $\approx 13 \mu \mathrm{m}$ long. All the clones originated from marine water samples in Rhode Island, USA.

PCR amplification of SSU rRNA genes. The rDNA primers amplified the DNA of all the thirty isolates tested and produced a single band of approximately $1800 \mathrm{bp}$ except for clones WB1-5, EP1, EP2 and PV10, DB1 and DB4. Amplification of clones WB1-5 and DB4, produced a second band of $\approx 750$ bp in addition to the 1800 bp band, and in EP1 and EP2, a second band of $\approx 1000 \mathrm{bp}$ was produced. The rDNA amplified from clones PV10 and DB1 were $\approx 1900 \mathrm{bp}$ in size.

RFLP analysis of amplified SSU rDNA. Eight restriction patterns were obtained with the enzymes Hinf I, Hae III and Sau3A I and 10 restriction patterns were obtained with Msp I for all the isolates analyzed (Table 1). Figure 6 shows one representative of each RFLP pattern generated by the enzymes Hinf I and Msp I. Eleven different combinations of patterns representing eleven different SSU rDNA genotypes were detected in the thirty isolates analyzed by RFLP using Hinf I, Hae III and Sau3A I and Msp I (Table 1).

The combination of four enzymes discriminated the Paraphysomonas species, $P$. imperforata, $P$. vestita and $P$. butcheri. Two genotypes were found among the $P$. imperforata isolates, and one of the $P$. imperforata genotypes was shared by the unidentified Paraphysomonas isolate, SR3. The five $P$. imperforata clones from Waquoit 
Figure 6. Restriction patterns of PCR-amplified rDNA digested with the enzymes Hinf I and Msp I. The figures for each enzyme represents a composite image of lanes obtained from three gels. Migration distances were normalized to the molecular weight markers on each side of the composite gels. The lane assignments (lanes 1-8 for Hinf I and 1-10 for Msp I) correspond to the restriction patterns given in Table 1 for each of the enzymes. Lane M refers to the GIBCO BRL $1 \mathrm{~kb}$ molecular weight marker. 
$\stackrel{\leftrightarrow}{\omega}$

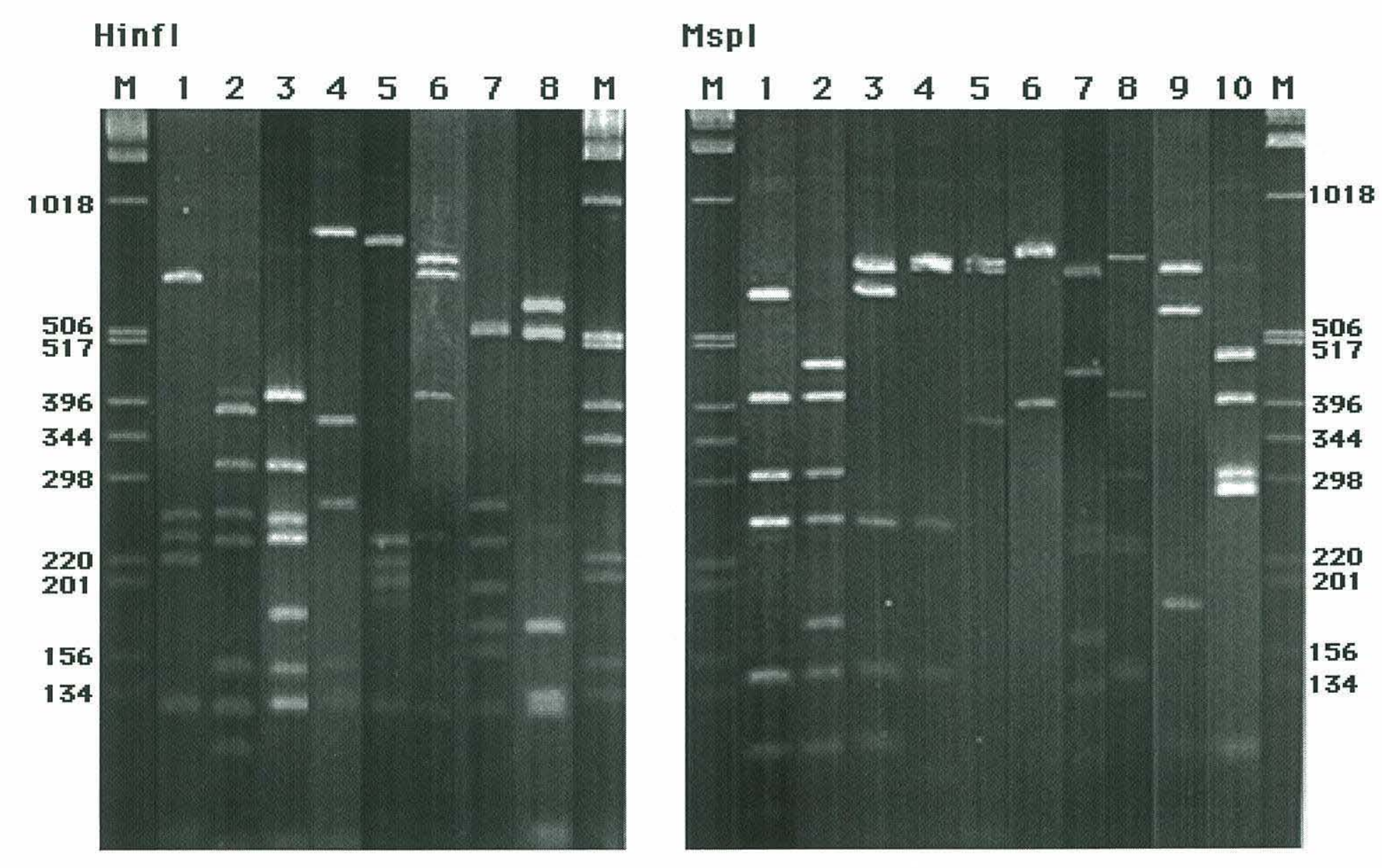


Bay, MA (WB1-5), were assigned to genotype I while two other P. imperforata clones, VS1 and JE1 from Vineyard Sound, MA and England, along with clone SR3 from Sakonnet River, RI, belonged to genotype II. Variations in the SSU rDNA sequences of these clones were detected by the enzymes Sau3A I and Msp I but not Hinf I and Hae III (Table 1). Based on restriction patterns generated by Msp I, the two genotypes of $P$. imperforata only differed at one restriction site (Fig. 6, lanes 1 and 2). The two different forms of P. vestita ("normal" vs. small-scaled) corresponded to two distinct genotypes (genotype VII and VIII, respectively) while $P$. butcheri was assigned to genotype IX.

The three genera of naked chrysomonads, Spumella, Cafeteria and Oikomonas were separated into genotypes distinct from each other and from the scaled chrysomonads. Within the genus Spumella, the seven clones were differentiated into four genotypes. Clones EP1 and EP2 were identified as having genotype III, YP1 as genotype IV, clones CRP1, LWI and LBMS1 as genotype V, and MR1 as genotype VI. The three clones ascribed to the genus Cafeteria were assigned to genotype $X$ and the four clones of Oikomonas to genotype XI.

A minimum of two enzymes, Msp I together with either Hinf I, Hae III or Sau3A I could provide the same resolving power as the combination of four enzymes. The use of the enzyme Msp I was only slightly less discriminating than the combination of Msp I and one of the other three enzymes. RFLP analysis with the enzymes Hinf I and Hae III separated and grouped the Paraphysomonas isolates tested into mophologically-defined species with the exception of an unidentified Paraphysomonas isolate, clone SR3, which grouped with $P$. imperforata even though its scales were different. 


\section{Discussion}

Identification of flagellate taxa in cultures and environmental water samples are often lacking because of the time and experience needed to distinguish behavioral and morphological features characteristic of the different taxa by light and electron microscopy. RFLP analysis of amplified SSU rDNA from cultured heterotrophic flagellates provides a rapid and reliable means for differentiating cultures of heterotrophic nanoflagellates. The PCR-RFLP approach may also be used as an independent method for resolving ambiguities in taxonomic classification when morphological features are unclear or atypical.

The SSU rRNA gene sequences within the genus Paraphysomonas were sufficiently varied to permit discrimination of $P$. imperforata, $P$. butcheri and $P$. vestita (as well as other genera from Paraphysomonas species) by RFLP analysis. PCR-RFLP analysis of SSU rDNA was also able to distinguish $P$. vestita and the small-scaled variant of $P$. vestita. The discrimination of these two groups was likely related to the size of the SSU rRNA gene of $P$. vestita $(\approx 1900 \mathrm{bp})$ compared to small-scaled $P$. vestita (Table 1$)$. The SSU rRNA gene of $P$. vestita has been sequenced in our lab (data not shown) and insertions of a number of "TA-rich" segments that contributed to the larger size of the SSU rDNA of $P$. vestita were found throughout the gene. These insertions were present in both isolates of $P$. vestita (and may be a general feature of this species), but not in any of the small-scaled $P$. vestita isolates. Because the SSU rDNA signatures of these two morphotypes are so different, based on RFLP analysis and sequencing information, it is valid to consider these two forms as separate species. The small-scaled $P$. vestita clones

should therefore be reconsidered as $P$. bandaiensis. Direct comparison with a freshwater $P$. bandaiensis type specimen would resolve this question. 
The unidentified clone of Paraphysomonas (SR3) was found to share the same genotype as $P$. imperforata clones even though the scales of clone SR3 were morphologically different from those of $P$. imperforata. The SSU rRNA genes of clone SR3 and $P$. imperforata clone VS1 have been sequenced in our laboratory (data not shown) and the sequence data are consistent with the result of the RFLP analysis showing that clone SR3 and clone VS1 are identical based on their SSU rRNA gene sequences.

There is evidence from the literature that clone SR3 is merely a morphological variant of $P$. imperforata. In a study on ultrastructural variability among Paraphysomonas species from freshly collected water samples, Thomsen frequently observed cells similar to $P$. imperforata but covered by spineless scales reminescent of clone SR3 scales (23, Fig. 12) (Fig. 1C and D). Thomsen also recorded the presence of groups of "normally" developed P. imperforata scales occurring together with spineless scales, indicating that cells covered by spineless scales are likely to be clonal variants of typical P. imperforata cells (23, Fig. 13). These results indicate that RFLP analysis of PCR-amplified SSU rDNA can be useful for detecting polymorphic forms of flagellate species or when discrepancies exist between type descriptions and isolates under investigation.

Intraspecific variation was observed in the rDNA sequences of $P$. imperforata clones. Two genotypes were detected among the seven morphologically identical isolates of $P$. imperforata. Clones from Waquoit Bay, MA formed one genotypes while the second genotype consisted of clones from Vineyard Sound, MA and England. The Vineyard Sound clone originated from a location approximately 4 miles away from Waquoit Bay (which connects to Vineyard Sound), indicating that the SSU rDNA sequences of clones originating from relatively close geographical locations can be heterogenous. The amount of heterogeneity that exists in the SSU rDNA sequences of $P$. imperforata clones cannot be estimated based on the few isolates examined by RFLP analysis in this study. 
The SSU rRNA gene of $P$. imperforata clones would have to be analyzed with more enzymes or preferably, sequenced in order to adequately examine sequence heterogeneity among $P$. imperforata clones.

The variability in rDNA gene sequences among isolates of Spumella, Cafeteria and Oikomonas was sufficient to distinguish the different genera of naked, heterokont flagellates tested in this study. Four genotypes were detected among the Spumella isolates while all the isolates within the genus Cafeteria and Oikomonas were assigned to two unique genotypes, respectively. The ability of the PCR-RFLP method to discriminate species of naked flagellates could not be adequately examined because it was not possible to identify the isolates at the species level.

Isolates of Spumella with similar morphological characteristics based on cell size and flagellar length, nevertheless, could be correlated to distinct SSU rDNA genotypes identified by RFLP analysis. Cells from clones EP1, EP2, YP1 and MR1 were distinguished from clones CRP1, LW1 and LBMS1 based on cell size: the cell diameter of the former group was $\approx 2 \mu \mathrm{m}$ while the latter group of flagellates measured $\approx 4 \mu \mathrm{m}$ in diameter and formed a unique genotype (Fig. 3C, D, Fig. 4 and Table 1). The hairy flagellum of MR1 is almost twice the length of clones EP1, EP2 and YP1, thus MR1 can be morphologically and genotypically discriminated from these three isolates (Fig. 4D and Table 1). Altogether, these observations provide some evidence to support the hypothesis that RFLP analysis can also discriminate species of Spumella, although only a limited number of clones within each genotype was measured for morphological comparisons.

The genera Oikomonas and Cafeteria were comprised of isolates which clustered into two genotypes, respectively. The isolates within each genotype were also morphologically very similar based on overall cell dimensions and flagellar structure. These results further suggest the association of morphologically similar isolates with a 
particular genotype among the naked, heterokont flagellates. Until these isolates can be identified more accurately, it may well be justified to consider isolates which cluster into one genotype within each genus as individual species. The ability of RFLP analysis to distinguish the naked, heterotrophic nanoflagellates is important because identification of pure cultures by electron microscopy is still very difficult among species of Spumella, Oikomonas and Cafeteria.

Restriction fragment length polymorphism of PCR-amplified SSU rRNA genes appears to be a rapid and reliable tool for the differentiation of heterotrophic nanoflagellates from the genus Paraphysomonas, Spumella, Oikomonas and Cafeteria. This method was also able to discriminate species of Paraphysomonas, and possibly Spumella, tested in this study. Our results also suggest that RFLP analysis of amplified SSU rDNA was more informative than morphology-based identifications and permitted discrimination of polymorphic forms among species of Paraphysomonas. Molecular information therefore provides an independent criterion to clarify the validity of distinctions (or lack of) between individual taxa when morphological characteristics are ambiguous or atypical. Finally, the results of this study have important implications with regard to future applications of molecular techniques to study these taxa. The ability of the PCR-RFLP method to distinguish the heterotrophic nanoflagellates indicates that the rDNA sequences of these flagellates is sufficiently varied to design species- or genus-specific rRNA-based oligonucleotide probes for ecological studies. Detection of these flagellate taxa by in situ hybridization with oligonucleotide probes will enable studies of their natural abundances and distribution, and thus, their importance in an environment. 


\section{Acknowledgements}

I thank John Waterbury, Jacqueline Eccleston, Robert Sanders and Delma Bratvold for cultures. I also thank H. R. Preisig and D. J. Patterson for help and advice with the identifications of Paraphysomonas and Cafeteria, John Waterbury for the electron micrograph in Fig. $2 \mathrm{C}$ and Dawn Moran for assistance with preparation of samples for elecron microscopy.

\section{References}

1. Azam, F., T. Fenchel, J. G. Field, J. S. Gray, L. A. Meyer-Reil and F. Thingstad. 1983. The ecological role of water-column microbes in the sea. Mar. Ecol. Prog. Ser. 10:257-263.

2. Berninger, U.-G., D. A. Caron, R. W. Sanders and B. J. Finlay. 1991. Heterotrophic flagellates of planktonic communities, their characteristics and methods of study, p. 39-56. In D. J. Patterson and J. Larsen (ed.), The biology of free-living heterotrophic flagellates. vol. Special Volume 45. Clarendon Press, Oxford.

3. Brown, S. and J. De Jonckheere. 1994. Identification and phylogenetic relationships of Vahlkampfia spp. (free-living amoebae) by riboprinting. FEMS Microbiol. Lett. 115:241-246.

4. Caron, D. A. 1991. Evolving role of protozoa in aquatic nutrient cycles, p. 387415. In P. C. Reid, C. M. Turley and P. H. Burkill (ed.), Protozoa and their role in marine processes. vol. 25. Springer-Verlag, Berlin. 
5. Caron, D. A. 1993. Enrichment, isolation, and culture of free-living heterotrophic flagellates, p. 77-89. In P. F. Kemp, B. F. Sherr, E. B. Sherr and J. J. Cole (ed.), Handbook of methods in aquatic microbial ecology. Lewis Publishers, Boca Raton.

6. Caron, D. A., E. L. Lim, G. Miceli, J. B. Waterbury and F. W. Valois. 1991. Grazing and utilization of chroococcoid cyanobacteria and heterotrophic bacteria by protozoa in laboratory cultures and a coastal plankton community. Mar. Ecol. Prog. Ser. 76:205-212.

7. Fenchel, T. 1982. Ecology of heterotrophic microflagellates. IV. Quantitative occurrence and importance as bacterial consumers. Mar. Ecol. Prog. Ser. 9:3542.

8. Grimont, F. and P. A. D. Grimont. 1986. Ribosomal ribonucleic acid gene restriction patterns as potential taxonomic tools. Ann. Inst. Pasteur/ Microbiol. $137: 165-175$.

9. Laguerre, G., M. Allard, F. Revoy and N. Amarger. 1994. Rapid identification of rhizobia by restriction fragment length polymorphism analysis of PCR-amplified 16S rRNA genes. Appl. Environ. Microbiol. 60:56-63.

10. Laguerre, G., P. Mavingui, M. Allard, M. Charnay, P. Louvrier, S. Mazurier, L. Rigottier-Gois and N. Amarger. 1996. Typing of rhizobia by PCR DNA fingerprinting and PCR-restriction fragment length polymorphism analysis of chromosomal and symbiotic gene regions: application to Rhizobium leguminosarum and its different biovars. Appl. Environ. Microbiol. 62:20292036.

11. Larsen, J. and D. J. Patterson. 1990. Some flagellates (Protista) from tropical marine sediments. J. Nat. His. 24:801-937. 
12. Medlin, L., H. J. Elwood, S. Stickel and M. L. Sogin. 1988. The characterization of enzymatically amplified eukaryotic 16S-like rRNA-coding regions. Gene 71:491-499.

13. Muyzer, G., E. C. de Waal and A. G. Uitterlinden. 1993. Profiling of complex microbial populations by denaturing gradient gel electrophoresis analysis of polymerase chain reaction-amplified genes coding for 16S rRNA. Appl. Environ. Microbiol. 59:695-700.

14. Olsen, G. J. 1988. Phylogenetic analysis using ribosomal RNA, p. 793-812. In H. F. Noller Jr. and K. Moldave (ed.), Methods in Enzymology. Ribosomes. vol. 164. Academic Press, San Diego.

15. Preisig, H. R. and D. J. Hibberd. 1982. Ultrastructure and taxonomy of Paraphysomonas (Chrysophyceae) and related genera 1. Nord. J. Bot. 2:397-420.

16. Preisig, H. R. and D. L. Hibberd. 1982. Ultrastructure and taxonomy of Paraphysomonas (Chrysophyceae) and related genera 2. Nord. J. Bot. 2:601-638.

17. Preisig, H. R. and D. L. Hibberd. 1983. Ultrastructure and taxonomy of Paraphysomonas (Chrysophyceae) and related genera 3. Nord. J. Bot. 3:695-723.

18. Preisig, H. R., N. Vørs and G. Hällfors. 1991. Diversity of heterotrophic heterokont flagellates, p. 361-399. In D. J. Patterson and J. Larsen (ed.), The Biology of Free-living Heterotrophic Flagellates. vol. 45. Clarendon Press, Oxford.

19. Rowan, R. and D. A. Powers. 1991. Molecular genetic identification of symbiotic dinoflagellates (Zooxanthellae). Mar. Ecol. Prog. Ser. 71:65-73.

20. Scholin, C. A. and D. M. Anderson. 1994. Identification of group- and strain-specific genetic markers for globally distributed Alexandrium (Dinophyceae). 1. RFLP analysis of SSU rRNA genes. J. Phycol. 30:744-754. 
21. Stahl, D. A. and R. Amann. 1991. Development and application of nucleic acid probes, p. 205-248. In E. Stackebrandt and M. Goodfellow (ed.), Nucleic acid techniques in bacterial systematics. John Wiley \& Sons Ltd., Chichester, England.

22. Takahashi, E. 1976. Studies on genera Mallomonas and Synura, and other plankton in freshwater with the electron microscope X. The genus Paraphysomonas (Chrysophyceae) in Japan. Br. Phycol. J. 11:39-48.

23. Thomsen, H. A. 1975. An ultrastructural survey of the Chrysophycean genus Paraphysomonas under natural conditions. Br. Phycol. J. 10:113-127.

24. Vørs, N., B. Johansen and H. Havskum. 1990. Electron microscopical observations on some species of Paraphysomonas (Chrysophyceae) from Danish lakes and ponds. Nova Hedwigia 50:337-354.

25. Welsh, J. and M. McClelland. 1990. Fingerprinting genomes using PCR with arbitrary primers. Nucleic Acids Res. 18:7213-7218.

26. Williams, J. G. K., A. R. Kubelik, K. J. Livak, J. A. Rafalski and S. V. Tingey. 1990. DNA polymorphisms amplified by arbitrary primers are useful as genetic markers. Nucleic Acids Res. 18:6531-6535. 


\section{Chapter II}

\section{Application of Ribosomal RNA-Based Probes For Observing Marine Nanoplanktonic Protists 1}

${ }^{1}$ Published in Appl. Environ. Microbiol. 59(5): pp. 1647-1655, 1993. E. L. Lim, L. A. Amaral, D. A. Caron and E. F. DeLong. 


\section{Abstract}

The use of small subunit rRNA-based oligonucleotides as probes for detecting marine nanoplanktonic protists was examined with a ciliate (Uronema sp.), a flagellate (Cafeteria sp.,), and with mixed assemblages of protists from enrichment cultures and natural seawater samples. Flow cytometry and epifluorescence microscopy analyses demonstrated that hybridizations employing fluorescein-labeled, eukaryote-specific probes intensely stained logarithmically growing protists, whereas these same protist strains in late stationary growth were barely detectable. The fluorescence intensity due to probe binding was significantly enhanced by the use of probes end-labeled with biotin, which were detected by fluorescein-labeled avidin. The degree of signal amplification ranged from 2 to 5 fold for cultured protists in both logarithmic and stationary growth phases. Mixed assemblages of heterotrophic protists from enrichment cultures also were intensely labeled by rRNA-targeted oligonucleotide probes using the biotin/avidin detection system. Protists in late stationary growth phase, and natural assemblages of protists that were otherwise undetectable when hybridized with fluorescein-labeled probes, were easily visualized using this approach. In the latter samples, hybridization with multiple, biotin-labeled probes was necessary for detection of naturallyoccurring marine protists using epifluorescence microscopy. The signal amplification obtained with the biotin-avidin system should increase the utility of rRNA-targeted probes for identifying protists and facilitate characterization of their population structure and distribution in aquatic environments. 


\section{Introduction}

Nanoplanktonic protists ( 2 to $20 \mu \mathrm{m}$ in diameter) are recognized as fundamental components of aquatic ecosystems because of their multiple ecological roles (5). Within planktonic food webs, these microorganisms function as primary producers, nutrient remineralizers and intermediaries in the transfer of energy to higher trophic levels. Photosynthetic and heterotrophic species within this assemblage are typically present at similar abundances $\left(10^{2}\right.$ to $\left.10^{3} \mathrm{ml}^{-1}\right)$ in plankton communities (7). Phototrophic protists often dominate total primary production (24) while the heterotrophic protists typically are the primary consumers of bacteria, cyanobacteria and microalgae $(5,9$, $28,29)$. Because of their high metabolic activity and their ability to ingest significant amounts of particulate organic material, heterotrophic protists have also been implicated as major nutrient remineralizers in the marine environment $(5,8,10)$.

Although the ecology of the nanoplankton has been fairly well characterized, our knowledge of the population structure and species composition of this assemblage remains very limited. The biogeography of most nanoplanktonic species has been poorly studied and thus the spatiotemporal distributions of many species are virtually unknown. These shortcomings stem primarily from the difficulties associated with identifying protists in natural water samples. Nanoplankton are typically enumerated by direct counting procedures using epifluorescence microscopy and fluorochrome staining $(7,18,27)$. With this method, phototrophic (chloroplast-bearing) species are distinguished from non-pigmented protists by the autofluorescence of chlorophyll a $(7,12)$. Other than this crude separation, however, epifluorescence microscopy cannot

provide enough detail for the identification of even the broad taxonomic affinities of most small protists. Sufficient criteria for taxonomic characterization of these 
microorganisms must still be obtained using electron microscopy, but this method is time-consuming, expensive and impractical for analyses of large numbers of samples. Other cytological techniques for taxonomic studies are technically complicated and not feasible for routine examination of samples.

An alternative to conventional methods for identifying protistan taxa is the use of nucleic acid hybridization probes. Nucleic acid probes have long been used to detect specific DNA or RNA sequences in tissue sections or intact cells $(6,11,16,22)$. Small subunit ribosomal RNA-based oligonucleotide probes in particular are becoming an increasingly useful tool for characterizing microbial cells in cultures as well as in clinical or environmental samples $(1,3,13,15,17,32)$. The ubiquity, intermediate size, and variable sequence conservation of the small subunit ribosomal RNA facilitate the design of probes capable of distinguishing various phylogenetic groupings, ranging from domains (17), to species $(2,14,31)$. Because these probes are short oligonucleotides (18-20 base pairs long), formalin-fixed cells are relatively permeable to the probes. Moreover, the relatively high cellular content of rRNA provides reasonably abundant target sites for probe binding.

The use of rRNA probes to discriminate numerous bacterial species is now common $(3,19,21,23,33)$, but rRNA probes have not yet been designed for planktonic protists. Protists are potentially more amenable to detection with oligonucleotide probes than bacteria because they are larger and likely to contain more ribosomes and higher concentrations of rRNA. This is especially important in nonradioactive detection systems because they are generally less sensitive than radiolabeled probes. Furthermore, non-radioactive probes such as fluorescently-labeled rRNA probes (14) are well suited for studies with protists because methods for sample preparation and detection are adaptable to epifluorescence microscopical techniques commonly used to count protists in ecological studies. 
This study was designed to test the suitability of eukaryote-specific, fluorescently-labeled rRNA probes to label protists for detection and enumeration. Preliminary hybridization experiments demonstrated that fluor-labeled oligonucleotide probes intensely labeled ciliates and flagellates in the logarithmic growth phase. However, the fluorescence due to probe binding in stationary growth phase cells was relatively weak. These results stimulated us to investigate alternative labeling and detection methods to amplify the fluorescent signal, so that cells would be labeled regardless of their physiological state. Amplification of signal strength was achieved using biotin-labeled probes, whose binding was detected by subsequent treatment with fluorescein-labeled avidin. Cultured species of protists in late stationary growth phase, as well as natural assemblages of protists that were otherwise undetectable when hybridized with fluorescein-labeled probes, were readily visualized using this biotin/avidin detection system.

\section{Materials and methods}

Oligonucleotide synthesis and labeling. In situ hybridizations were performed with oligonucleotide probes complementary to discrete regions of eukaryotic small subunit rRNA. The following eukaryote-targeted probes were used (numbers correspond to the corresponding E. coli sequence position): EUK 1209R (5'-GGG CAT CAC AGA CCT G-3') (17), EUK 502R (5'-ACC AGA CTT GCC CTC C-3') (2), EUK 309R (5'TCA GGC TCC CTC TCC GG-3') (30) and EUK B (5'-TGA TCC TTC TGC AGG TTC ACC TAC-

$\left.3^{\prime}\right)$ (25). A eubacterial probe, EUB 338 (2), and a negative control probe that binds the coding strand of the small subunit rRNA gene (17), served as controls for nonspecific binding to eukaryotic cells. 
The oligonucleotides were synthesized on an Applied Biosystems DNA synthesizer. An amino group was attached to the $5^{\prime}$ end of the oligonucleotide in the last stage of synthesis (Aminolink II, Applied Biosystems). The 5'-aminohexyl oligonucleotides were labeled with either fluorescein or biotin as previously described (14), with some modifications. The labeling reaction $(250 \mu \mathrm{l})$ contained $100 \mu \mathrm{g}$ of $5^{\prime}$-aminohexyl oligonucleotide, $100 \mathrm{mM}$ carbonate buffer $(\mathrm{pH} 9.2)$, and $40 \mu \mathrm{l}$ of a stock solution of 10 $\mathrm{mg} \mathrm{ml}^{-1}$ FITC (Molecular Probes, Inc., Eugene OR), or $33 \mu \mathrm{l}$ of $100 \mathrm{mg} \mathrm{ml}^{-1}$ biotinXX succinimidyl ester (Molecular Probes, Inc., Eugene OR). Reaction mixtures were incubated at room temperature for 16 hours in the dark. Oligonucleotides were separated from unincorporated dye, or biotin, by passing the reaction mixture through a Sephadex G-25 column equilibrated with $10 \mathrm{mM}$ Tris- $\mathrm{HCl}(\mathrm{pH}$ 8.0). Eluted fractions containing the labeled oligonucleotides were subsequently lyophilized and resuspended with sterile double distilled $\mathrm{H}_{2} \mathrm{O}$ to a final volume of $50 \mu \mathrm{l}$. Separation of labeled oligonucleotides from unlabeled oligonucleotides was accomplished by electrophoresis on a $20 \%$ non-denaturing polyacrylamide gel. The band of labeled oligonucleotides was visualized by UV fluorescence, and excised from the gel. Oligonucleotides were eluted in $1 \mathrm{ml}$ of sterile double distilled $\mathrm{H}_{2} \mathrm{O}$ on a rotary shaker and filtered through $0.2 \mu \mathrm{m}$ pore size Acrodisc filters (Gelman Sciences). The labeled oligonucleotides were lyophilized

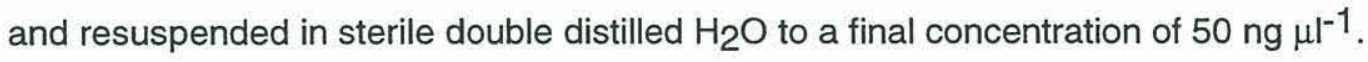

Hybridization with fluorescein-labeled probes. The suitability of fluorescently-labeled eukaryote probes for detecting protists was evaluated by flow cytometry and epifluorescence microscopy. Flow cytometric analyses were performed on a ciliate, Uronema sp., sampled over its growth cycle and hybridized with a eukaryote-specific probe (EUK 1209R) (17). Ciliates were grown in sterile seawater enriched with $0.05 \%$ yeast extract and inoculated with bacteria. Cultures were sampled every 6 hours over a 48 hour period, and every 24 hours thereafter, until the culture 
was well into the stationary phase of growth. Samples were fixed in formaldehyde to a final concentration of $3.7 \%$, and stored at $4^{\circ} \mathrm{C}$. Cell counts were performed on subsamples using a Fuchs-Rosenthal or Reichert hemocytometer. The remainders of the samples $(15 \mathrm{ml})$ were concentrated by centrifugation to approximately $1 \mathrm{ml}$ and used for flow cytometric analyses.

Separate cultures of the ciliate and a flagellate, Cafeteria sp., were also grown as described above for hybridization and examination by epifluorescence microscopy and photometry. Cells were harvested in the logarithmic phase of growth and in the late stationary phase of growth, concentrated by centrifugation, and fixed by resuspending the pellet in cold, fresh $3.7 \%$ formaldehyde. Cell suspensions were stored at $4^{\circ} \mathrm{C}$ and used for hybridizations within 24 hours after fixation. The cells were hybridized with 1 probe (EUK 309R), or a combination of 2 probes (EUK 309R and EUK 502R), or 3 probes (EUK 309R, EUK 502R and EUK 1209R). A probe complementary to the coding strand of the rRNA gene served as a negative control for non-specific binding.

In situ hybridization of protists was performed as follows. Cell concentrates (10 $\mu \mathrm{l})$ were spotted in the wells of gel-subbed, teflon-coated slides (Cel-Line Associates, Inc.) and allowed to air-dry. After dehydration in a series of $50 \%, 75 \%$ and $100 \%$ ethanol washes (2 min. each), $10 \mu \mathrm{l}$ of hybridization buffer $(750 \mathrm{mM} \mathrm{NaCl}, 100 \mathrm{mM}$ tris- $\mathrm{HCl}$ ( $\mathrm{pH} 7.8$ ), $5 \mathrm{mM}$ EDTA, 0.1\% SDS) was added to each cell smear, followed by the addition of the oligonucleotide probe to a final concentration of $5 \mathrm{ng}^{-1}$. The slides were placed in air-tight chambers containing a piece of buffer-saturated tissue paper and incubated at $40^{\circ} \mathrm{C}$ for 3 hours. The slides were then washed in $(30 \mathrm{mM} \mathrm{NaCl}, 4 \mathrm{mM}$ tris- $\mathrm{HCl}(\mathrm{pH} 7.8), 0.2 \mathrm{mM}$ EDTA) at $45^{\circ} \mathrm{C}$ for $10 \mathrm{~min}$, air-dried and mounted with Citifluor (Citifluor, Ltd., London). The cells were observed using a Zeiss Axioskop 20 epifluorescence microscope fitted with Omega optical (Brattleboro, Vermont) filters [DAPI (excitation, U340; emission, GG 420; dichroic beamsplitter, 400 DCLP @ 45); 
fluorescein (excitation, 470 DF 40; emission, 520 EF LP; dichroic beamsplitter, 505 DR LP @ 45ํ); Texas red (excitation 560 DF 40; emission, 635 DF 60; dichroic beamsplitter, 595 DR LP @ 45 $)$ ]. Phase contrast and epifluorescence micrographs of the samples were taken with a Zeiss MC 100 camera and Ektachrome 200 ASA color film.

Modifications to the hybridization procedure were made for flow cytometric analysis as follows. Approximately $300 \mu \mathrm{l}$ of cell concentrate was pelleted in a microfuge tube and resuspended in absolute ethanol. The cells were pelleted again and mixed with $20 \mu \mathrm{l}$ of hybridization buffer followed by $5 \mu \mathrm{l}$ of probe (EUK 1209R). The hybridization mixture was gently vortexed and incubated in a $40^{\circ} \mathrm{C}$ water bath. After 12 hours, the hybridization mixture was brought up to $300 \mu \mathrm{l}$ with phosphate-buffered saline $(\mathrm{pH} 7.4)$ and immediately analyzed.

Hybridization with biotin-labeled probes. In situ hybridization of fixed Uronema and Cafeteria cells were repeated with both fluorescein and biotin-labeled probes, and analyzed by a combination of epifluorescence microscopy and photometry. The following additions were made to the procedure using biotin-labeled probes. After hybridization, the slides were air-dried and $10 \mu \mathrm{l}$ of fluorescein avidin solution $(20 \mu \mathrm{g}$ $\mathrm{ml}^{-1}$ in $100 \mathrm{mM}$ carbonate-buffered saline, $\mathrm{pH}$ 8.2) was added to each cell smear. The slides were incubated in the dark at $4^{\circ} \mathrm{C}$ for $10-20 \mathrm{~min}$. and subsequently washed three times with cold buffered saline. Cells incubated with only fluorescein-labeled avidin, but no oligonucleotide probe, served as controls for non-specific binding of avidin.

Flow cytometric analyses. Flow cytometric analyses were performed using a Coulter EPICS-V flow cytometer (Coulter Electronics Inc., Hialeah, FL) equipped with a single 6-W argon ion laser. The $488 \mathrm{~nm}$ laser line was used for excitation with 250 $\mathrm{mW}$ of power focused to a spot size of $16.5 \times 131 \mu \mathrm{m}$. Cells were passed through a 150 $\mu \mathrm{m}$ diameter jet-in air and FITC fluorescence was measured at wavelengths of $515-590$ 
$\mathrm{nm}$. The signals were amplified with 3 decade log amps and normalized to $2.02 \mu \mathrm{m}$ diameter calibration beads (Polysciences, Inc., Warrington, PA). Data were collected in "list mode" (individual measurements of fluorescence per cell were collected and stored) and mean fluorescence values were compared and analyzed.

Photometer measurements. FITC fluorescence of cells hybridized with fluorescein and biotin probes were compared by measuring fluorescence on a Nikon P1 photometer system attatched to a Zeiss IM 35 inverted epifluorescence microscope (FITC filter set). The system was interfaced with a computer and equipped with a shutter (Vincent Associates, Inc.) on the 50W mercury light source, and another on the photomultiplier tube. Individual cells of interest were located and aligned in the center of the viewing field, and the light path to the photometer restricted by a filter with a 1.0 $\mathrm{mm}$ "pinhole", to admit light from the selected cell. The sample was illuminated for 800 msecs. Total fluorescent light was converted to relative fluorescence units using commercially available software (Phoscan, Nikon). Mean fluorescence $\pm 1 S D$ in relative fluorescence units was calculated from measurements of 20 randomly chosen cells for each treatment at $1000 \mathrm{X}$ magnification.

\section{Detection of mixed assemblages of protists from enrichment} cultures and natural water samples. The ability of probes to label a wide range of naturally-occurring protist cells was tested with mixed assemblages from enrichment cultures, or natural water samples. To enrich for mixed populations of heterotrophic protists from seawater samples, yeast extract was added at a final concentration of $0.05 \%$ to $200 \mathrm{ml}$ of Sargasso Sea seawater or Vineyard Sound seawater. The cultures were kept in the dark at room temperature to selectively enrich for a mixed assemblage of heterotrophic protists. After 7 days, the cells were pelleted and fixed as described above. Samples were hybridized with EUK 1209R, labeled with either fluorescein or biotin. 
Natural samples of small protists from Eel Pond, Woods Hole, MA, were collected by prefiltering $150 \mathrm{ml}$ of seawater through $5 \mu \mathrm{m}$ or $10 \mu \mathrm{m}$ Nitex screening. Samples were preserved with formaldehyde at a final concentration of $3.7 \%$ and stored at $4^{\circ} \mathrm{C}$. After fixation for a minimum of 2 hours, the samples were vacuum-filtered onto $1 \mu \mathrm{m}$ polycarbonate filters (Nuclepore) on a Millipore filtration apparatus until approximately $1 \mathrm{ml}$ remained in the funnel. These crude concentrates of cells were transferred from the funnel to microfuge tubes and centrifuged at $6000 \mathrm{rpm}$ for $5 \mathrm{~min}$. The supernatants were discarded, except for approximately $100 \mu \mathrm{l}$, which was used to resuspend the concentrated cells. Combinations of three or four biotin probes (EUK 309R, EUK 502R, EUK 1209R and EUK B) were used for fluorescent detection of naturally occurring protists.

\section{Results}

\section{Flow cytometric analyses of protistan growth cycle and}

hybridization signal. Because the rRNA content of some microorganisms is known to be proportional to their growth rate (26) we expected that the physiological condition of protists would affect the amount of probe bound, and therefore the hybridization signal (14). This effect was apparent in flow cytometric analyses of the ciliate, Uronema sp., sampled over its life cycle (Fig. 1A). The fluorescent signal from the ciliates expressed as the cell:bead ratio, was highest in cells harvested during the early- to midlogarithmic phase of growth (Fig. 1B). A distinct peak in this signal occurred during early logarithmic growth. During stationary growth, the fluorescence signal due to probe binding was only slightly above background fluorescence resulting from nonspecific probe binding or autofluorescence. 
Figure 1. Growth curve of the ciliate, Uronema sp. (A), and flow cytometric analysis the ciliate hybridized with the fluorescein-labeled, EUK1209R probe (B). Fluorescence per cell was normalized to calibration beads. Sample numbers in (B) correspond to sample numbers next to the data points on the growth curve in (A). 

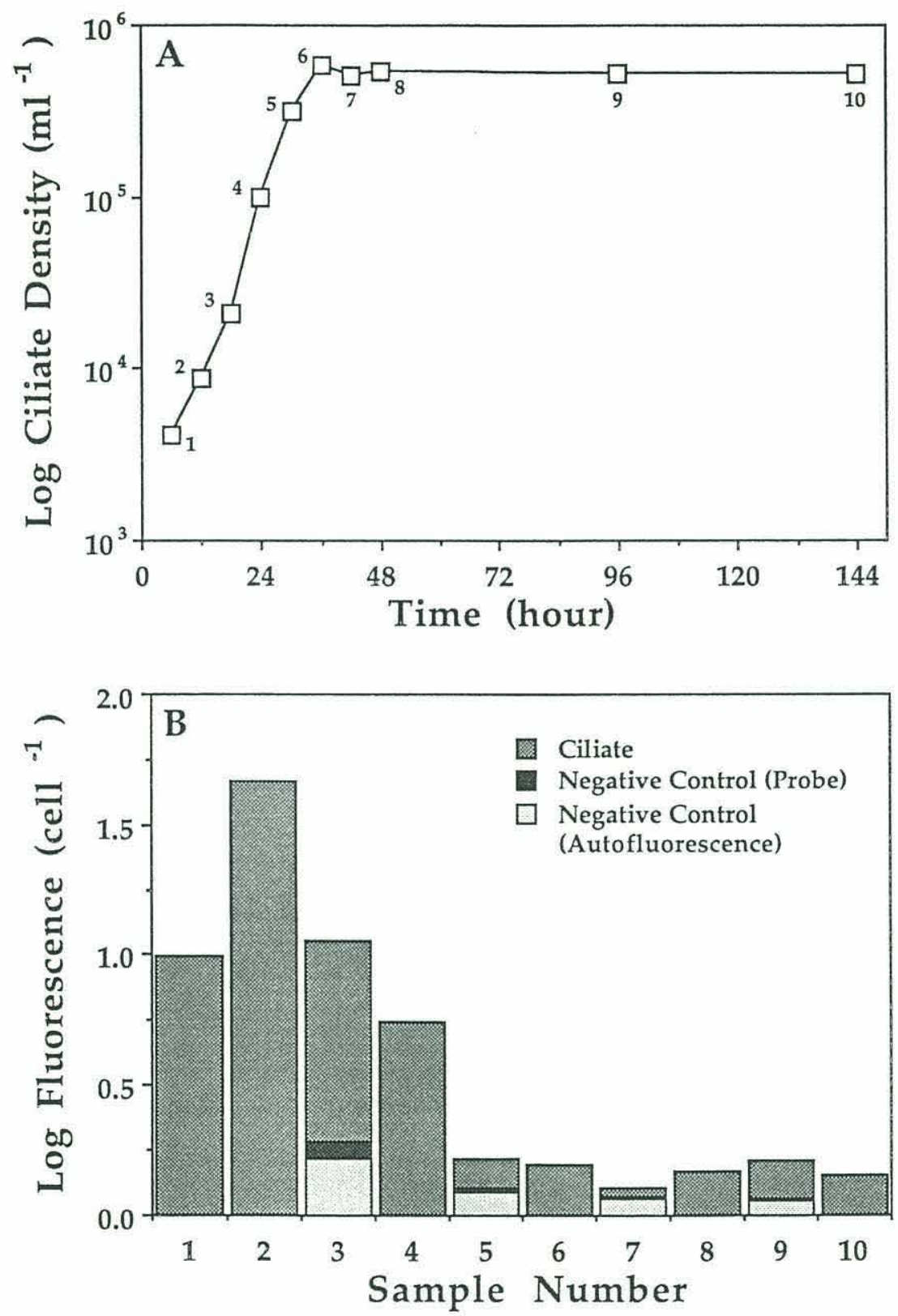
Amplification of hybridization signal. Based on the results of the flow cytometric analyses, we attempted to amplify the fluorescence signal of probed cells by using 1) biotin-labeled probes with fluorescein-labeled avidin and 2) multiple probes. The rationale behind these attempts was to ensure that cells would be detectable in natural samples regardless of their physiological condition. Comparison of fluorescent intensities in these and subsequent hybridization experiments were based on average relative fluorescence units. These values were obtained by subtracting the controls from the experimental values, in order to discount autofluorescence and non-specific binding of the probes and fluorescein-labeled avidin.

The fluorescence of protists hybridized with the biotin/avidin system was significantly greater than that of cells labeled with oligonucleotide probes covalently linked to a single fluorescein moiety (three way ANOVA, $p<0.01$; "shaded" vs. "open" columns in Fig. 2). This result was true for cells harvested in the logarithmic and stationary growth phases. The fluorescent signal with the biotin/avidin system was 2-5 fold higher than the signal from the single fluorescein moiety over all the treatments tested. Fluorescence resulting from the binding of one biotin probe was also greater than that obtained from simultaneous labeling with three fluorescein-labeled probes targeting different sites in the eukaryotic ssu rRNA. The flagellate Cafeteria sp., however, displayed a high background fluorescence, due to the binding of fluor-labeled avidin, which was localized in the food vacuoles of this protist.

The use of a combination of probes complementary to different target sites in the ssu rRNA was expected to additively increase the fluorescent signal proportionally to the number of probes added. The use of either two (EUK 309R and EUK 502R) or three (EUK 309R, EUK 502R and EUK 1209R) fluorescein probes or biotin probes versus a single probe (EUK 309R), however, did not significantly enhance the fluorescence of the ciliates (three way ANOVA, $p=0.07$ ) or flagellates (three way ANOVA, $p=0.04$ ) at the 
Figure 2. The effect of probe label (biotin with fluorescein-labeled avidin vs. fluorescein), multiple probes (EUK 309R; EUK 309R + EUK 502; EUK 309R + EUK $502+$ EUK 1209R) and growth phase (logarithmic, A and C, vs. stationary, B and D) on fluorescence intensity in the ciliate, Uronema sp. (A, B) and the flagellate, Cafeteria sp. (C, D). Fluorescence intensity is expressed in relative units. The fluorescence of the flagellates were measured on a scale $1000 \mathrm{X}$ more sensitive than the ciliates. 
a

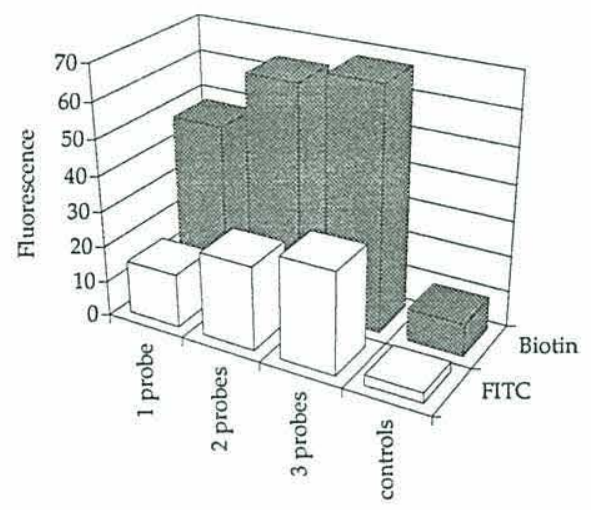

C

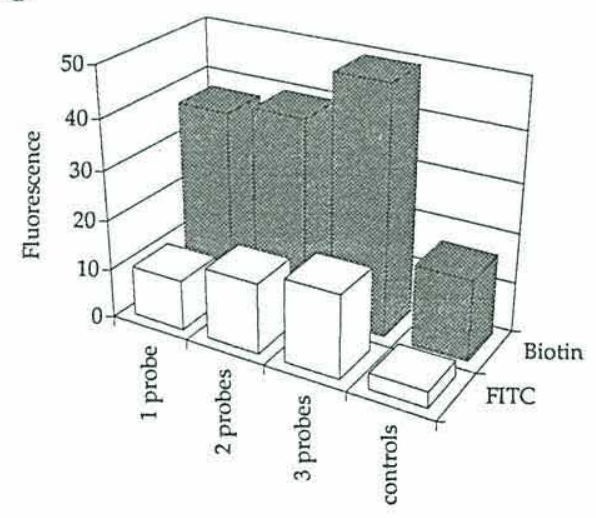

b

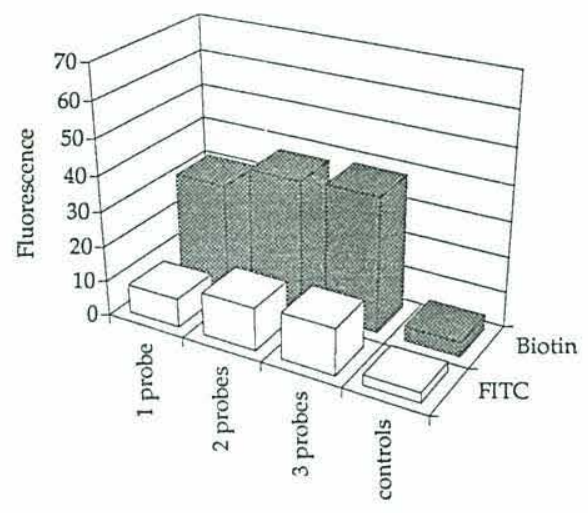

d

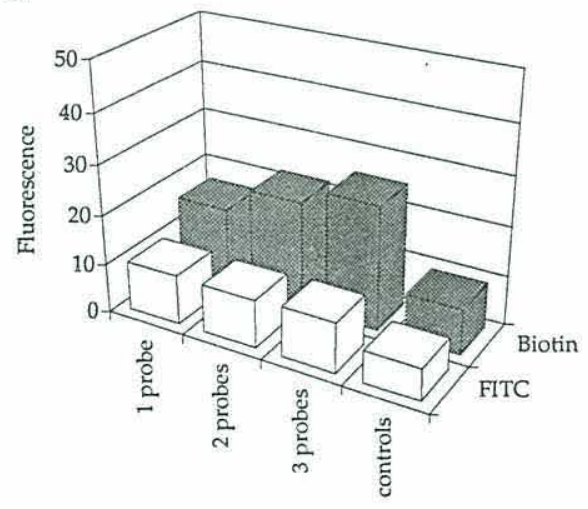


$a=0.01$ significance level (Fig. 2). The lack of a significant difference among these treatments was due to the high standard deviation associated with the mean fluorescence values $(10-30 \%$ of the means). Despite this high variability, there was a trend of increasing fluorescence with the use of multiple probes in all cases except the flagellates sampled during the stationary growth phase and hybridized with fluorescein-labeled oligonucleotide probes (Fig. 2D). The fluorescent signal in this latter treatment was only slightly above that of negative controls, regardless of the number of fluorescein probes used.

\section{Effect of growth phase on hybridization signal (photometer} analyses). The fluorescent intensity due to probe binding in ciliates and flagellates was significantly greater when the cultures were in the logarithmic growth phase $(p<$ 0.01). The fluorescence of ciliates in logarithmic growth (Fig. 2A) was approximately 2 fold greater than that of cells in stationary phase (Fig. 2B). The flagellates showed approximately a three fold increase in fluorescent intensity between cells in logarithmic and stationary growth phases (Fig. 2C and Fig. 2D, respectively). These results agreed closely with the flow cytometric data (Fig. 1), when samples taken from corresponding time points were compared. The fluorescence (cell:bead ratio) of the 24 hour sample (no. 4 in Fig. 1) taken at mid-logarithmic growth phase was approximately $3 X$ greater than the 6 day sample (no. 10 in Fig. 1) taken during the late stationary growth phase (average fluorescence values minus control fluorescence values were compared).

The effectiveness of biotinylated probes detected with fluorescein-labeled avidin can clearly be seen in epifluorescent micrographs of the ciliate (Fig. 3A-C). Fluorescence resulting from the binding of a fluorescein-labeled probe (EUK 1209R) was quite bright in logarithmically growing ciliates, (Fig. $3 \mathrm{~A}$ ) whereas ciliates in stationary growth were barely visible (Fig. 3B). In contrast, ciliates from the same sample in the stationary growth phase were intensely stained by the same probe (EUK 
Figure 3. Ciliates in mid-exponential phase (A) and, in late stationary growth phase (B) hybridized with the fluorescein-labeled, EUK 1209R probe. The same sample of ciliate as (B) hybridized with the biotin-labeled, EUK 1209RR probe and fluoresceinlabeled avidin $(C)$. Marker bars in $(A)-(C)=30 \mu \mathrm{m}$. Phase-contrast micrograph of a mixed population of heterotrophic flagellates from Sargasso seawater enrichment cultures (D), and epifluorescence micrographs of the flagellates hybridized with the fluorescein-labeled, EUK 1209R probe (E), biotin-labeled EUK 1209R probe (F), and controls hybridized with fluorescein-labeled avidin only (G). Marker bars in (D)-(G) $=10 \mu \mathrm{m}$. Protists from $5 \mu \mathrm{m}$ and $10 \mu \mathrm{m}$ filtrates of natural seawater samples collected from Vineyard Sound, Woods Hole, Massachusetts (H-M). Phase contrast micrograph of protists hybridized with a combination of three biotin-labeled eukaryote probes $(H)$, and with a mixture of four biotin-labeled eukaryote probes and fluorescein avidin ( $\mathrm{I}$, J). Corresponding epifluorescence micrographs (K-M) of the protists in $(H),(I)$ and (J). Marker bars in $(H)-(M)=10 \mu \mathrm{m}$. All exposure times were kept constant at 30 seconds (A-C), 120 seconds $(D-G)$ and 60 seconds $(H-M)$ to facilitate a direct comparison of the treatments. 

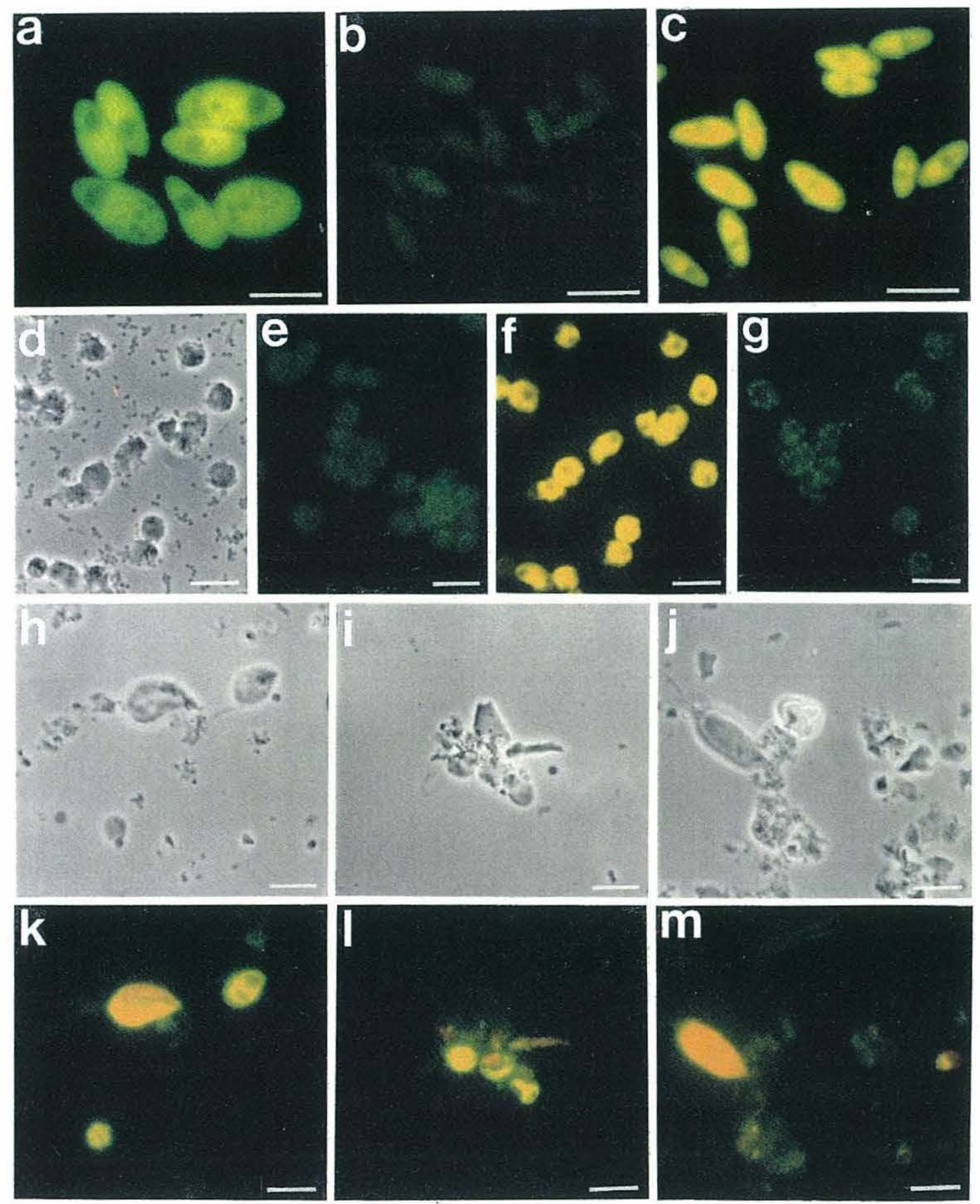
1209R), when it was biotinylated and detected using fluorescein-labeled avidin (Fig. $3 C)$.

Examination of natural, mixed assemblages of protists. Experiments using fluorescein- and biotin-labeled probes were repeated with mixed assemblages of protists from enrichments of seawater samples, as well as untreated, natural seawater samples. The goal of these experiments was simply to test the ability of these probes to label a wide variety of naturally-occurring protists. Enrichment of seawater with yeast extract promoted the growth of bacteria in the water sample initially. After approximately 2 days in continuous darkness, a bacterivorous ciliate dominated the culture. This was followed by a chrysomonad-like flagellate assemblage, and then bodonid-like flagellates. The Sargasso Sea seawater enrichment culture appeared to contain at least 3 co-dominant types of flagellates after 2 weeks. The cells were approximately $6 \mu \mathrm{m}$ in diameter and included a chrysomonad-like species and two species of bodonid-like flagellates. The fluorescence due to the binding of a fluoresceinlabeled probe (EUK 1209R) to the flagellates was weak (Fig. 3E), but the same cells were intensely stained with the same probe, biotinylated and detected with fluoresceinlabeled avidin (Fig. 3F). These cells were easily distinguished from the control which consisted of cells incubated with only fluorescein-labeled avidin (Fig. 3G). Because specific binding of fluorescein-labeled avidin consistently gave the highest background fluorescence compared to autofluorescence and negative control probes (eubacterial and complements of the eukaryote probes), the fluorescein-labeled avidin controls are the only controls presented in our results.

Protozoa from enrichments of Vineyard Sound seawater also were tested with fluorescein- and biotin-labeled oligonucleotide probes, as described above. Results of hybridizations were similar to the Sargasso Sea seawater enrichment cultures, except that the flagellate assemblage was dominated by tiny chrysomonad-like flagellates 
approximately $3 \mu \mathrm{m}$ in diameter. These minute protists were readily visualized using the biotin probes and fluorescein-labeled avidin (not shown).

Natural seawater samples were concentrated approximately $300 \mathrm{X}$ in order to accommodate the small volume of the in situ hybridizations. The mixed assemblage of protists was hybridized with a single, biotin-labeled probe initially, but the fluorescence of the protistan assemblage was weak. Experiments were repeated using a combination of three or four biotin-labeled probes (EUK 309R, EUK 502R, EUK 1209R and EUK B), which significantly enhanced the fluorescent signal. A variety of protists

from several different taxonomic groups were labeled by the biotin probes and fluorescein-labeled avidin (Fig. 3H-M). These cells were easily distinguished from background fluorescence, which was mainly associated with particulate detrital material. Cells associated with particulate material that were not apparent under transmitted light also were readily visualized with the biotin-labeled probes (Fig. $3 \mathrm{~L}$ ). Chlorophyll autofluorescence could still be detected in some of the flagellates as well (Fig. 3L-M).

\section{Discussion}

Planktonic protists are a ubiquitous and taxonomically diverse group of aquatic microorganisms. The identification of these species in natural samples is often difficult due to their small size and the lack of distinctive morphological features that are easily distinguishable at the level of the light microscope. Rapid, sensitive methods for identifying and enumerating these species are needed to facilitate studies of their population dynamics, community diversity and biogeography. In this study, we tested the suitability of rRNA-based oligonuceotide probes for detecting several protist species. 
The use of fluorescein or biotin-labeled, eukaryote-specific probes allowed detection by epifluorescence microscopy of a variety of protists in preserved seawater samples. Our results demonstrate the feasibility of employing oligonucleotide probes for identifying and enumerating protist species, coupled with fluorescence methods for detecting the probe-binding cells.

A major obstacle in the application of oligonucleotide probes to natural samples of microorganisms has been the intensity of the probe signal in these cells. Increased sensitivity is necessary for labeling all target cells, because their rRNA content (and hence fluorescence due to probe binding) may vary widely as a function of their physiological state (14). In addition, sensitive methods of detection are required to maximize hybridization signal relative to background signal which can be caused by non-specific binding of probes or fluorochromes, or natural autofluorescence. Although other non-radioactive detection systems have been tested with bacteria, such as digoxigenin-labeled oligonucleotides detected with fluorescent anti-digoxigenin antibodies, these failed to increase the fluorescent signal resulting from probe binding (34). Enzymatically labeled probes have also recently been used for in situ hybridization and identification of prokaryotic cells (4). These probes are potentially more sensitive than fluorescently-labeled probes, but pretreatment with enzymes or detergent may be necessary to improve permeability of the cells. These pretreatments may prove to be too harsh for some delicate nanoplanktonic species.

Attempts at using other methods of signal amplification have produced variable results. Prior to our application of a biotin/avidin detection system, we tested oligonucleotides labeled with multiple fluors, and poly-thymidine-tailed probes detected with short, fluor-labeled poly-adenine oligonucleotides. Oligonucleotides labeled with multiple flours were inefficient in hybridization reactions, mainly due to nonspecific binding to cell surfaces and slides. Poly-adenine-tailed oligonucleotides were 
successfully applied, but these appeared to be differentially permeable to different cell types.

The hybridization procedure with biotin probes and fluorescein-avidin described here is sensitive to cells in different physiological states, reasonably quick and requires minimal sample manipulation. Treatment with Proteinase-K or lysozyme was not necessary for the fluorescein-labeled avidin to penetrate freshly-fixed cells. The interior of labeled protist cells was intensely fluorescent, except for the nucleus which appeared as a dim circle within the cytoplasm. Unlabeled nuclei were good indicators of the probe specificity for cytoplasmic rRNA. The food vacuoles of cultured protists were often clearly unlabeled as well (Fig. $3 \mathrm{~A}$ ) but control cells incubated with fluoresceinlabeled avidin and no oligonucleotide often contained fluorescent food vacuoles (Fig. 3G). The fluorescence of these controls results from the retention of fluorescein-labeled avidin in food vacuoles which was probably due to the presence of endogenous biotin obtained from ingested bacteria. We have routinely observed bacteria in the food vacuoles of protozoa fluorescing brightly when fluorescein-labeled eubacterial probes were used as control probes for non-specific binding to the protozoa. Nevertheless, the fluorescence from these fluorescein-labeled avidin controls was much weaker than fluorescence in the probed cells (Fig. 3F). It may be possible to reduce this background with the use of unlabeled avidin as a blocking reagent prior to hybridization.

In this study, we demonstrated the fluorescent in situ hybridization of natural assemblages of protists using biotinylated probes and fluorescein-labeled avidin. Further refinements of in situ hybridization will allow the procedure to be applied to natural samples filtered onto polycarbonate filters. In a recent study, bacteria growing in highly eutrophic artificial ponds were simultaneously hybridized with rRNA targeted oligonucleotide probes and stained with the DNA binding fluorochrome DAPI (20). Although the cells examined in these artificial, eutrophic ponds were likely growing 
rapidly, and so contained relatively large amounts of rRNA, only about 60 percent of the DAPI-stained bacteria could be detected using eubacterial-specific rRNA probes (20). Further development of signal amplification methods, such as that described in this report, should help alleviate some of this problem.

Increasing the sensitivity of oligonucleotide probes by methods such as biotinlabeling and fluorescein-avidin detection facilitates the application of oligonucleotide probes for identifying and quantifying protists in natural samples. Growing data bases of small subunit and large subunit rRNA sequences should allow for the future development of species- or genus-specific probes to detect and identify natural assemblages of protists. The application of these probes in ecological studies will lead to a greater understanding of the abundances and distributions of different taxonomic groups of protista in natural ecosystems, and the role that they play in energy flow in aquatic ecosystems.

\section{Acknowledgements}

This study was supported by a Woods Hole Oceanographic Institution Independent Study Award, a grant from the Florence and John Schumann Foundation, the NOAA National Sea Grant College Program Office, Department of Commerce, under Grant No. NA90-AA-D-SG480, Woods Hole Oceanographic Institution Sea Grant project No. R/B114-PD (to DAC), the Woods Hole Oceanographic Institution Education Program, and an ONR Young Investigator Award N00014-90-J-1917 (to EFD). The authors thank Robert J. Olson and Erik Zettler for use of the flow cytometer, Donald M. Anderson for use of the photometer, Andrew R. Solow for assistance with the statistical analyses and David J. Patterson for identification of the flagellate, Cafeteria sp. 


\section{References}

1. Amann, R., N. Springer, W. Ludwig, H.-D. Görtz and K.-H. Schleifer. 1991. Identification in situ and phylogeny of uncultured bacterial endosymbionts. Nature 351:161-164.

2. Amann, R. I., B. J. Binder, S. W. Olson, R. Devereux and D. A. Stahl. 1990b. Combination of 16S rRNA-targeted oligonucleotide probes with flow cytometry for analyzing mixed microbial populations. Appl. Environ. Microbiol. 56:1919-1925.

3. Amann, R. I., L. Krumholz and D. A. Stahl. 1990a. Fluorescentoligonucleotide probing of whole cells for determinative, phylogenetic, and environmental studies in microbiology. J. Bacteriol. 172:762-770.

4. Amann, R. I., B. Zarda, D. A. Stahl and K. Schleifer. 1992. Identification of individual prokaryotic cells by using enzyme-labeled, rRNA-targeted oligonucleotide probes. Appl. Environ. Microbiol. 58:3007-3011.

5. Azam, F., T. Fenchel, J. G. Field, J. S. Gray, L. A. Meyer-Reil and F. Thingstad. 1983. The ecological role of water-column microbes in the sea. Mar. Ecol. Prog. Ser. 10:257-263.

6. Buongiorno-Nardielli, M. and F. Amaldi. 1970. Autoradiographic detection of molecular hybrids between rRNA and DNA in tissue sections. Nature 225:946948.

7. Caron, D. A. 1983. Technique for enumeration of heterotrophic and phototrophic nanoplankton, using epifluorescence microscopy, and comparison with other procedures. Appl. Environ. Microbiol. 46:491-498. 
8. Caron, D. A. 1991. Evolving role of protozoa in aquatic nutrient cycles, p. 387415. In P. C. Reid, C. M. Turley and P. H. Burkill (ed.), Protozoa and their role in marine processes. vol. 25. Springer-Verlag, Berlin.

9. Caron, D. A., E. L. Lim, G. Miceli, J. B. Waterbury and F. W. Valois. 1991. Grazing and utilization of chroococcoid cyanobacteria and heterotrophic bacteria by protozoa in laboratory cultures and a coastal plankton community. Mar. Ecol. Prog. Ser. 76:205-212.

10. Caron, D. A. and J. C. Goldman. 1990. Protozoan nutrient regeneration, p. 283-306. In G. M. Capriulo (ed.), Ecology of marine protozoa. Oxford University Press, New York.

11. Cox, K. H., D. V. DeLeon, L. M. Angerer and R. C. Angerer. 1984. Detection of mRNAs in sea urchin embryos by in situ hybridization using asymmetric RNA probes. Devel. Biol. 101:485-502.

12. Davis, P. G. and J. M. Sieburth. 1982. Differentiation of phototrophic and heterotrophic nanoplankton in marine waters using epifluorescence microscopy. Ann. Inst. Océanogr., Paris 58(S):249-260.

13. DeLong, E. F. and J. Shah. 1990. Fluorescent, ribosomal RNA probes for clinical application: a research review. Diagnos. Clinc. Test. 28:41-44.

14. DeLong, E. F., F. S. Wickham and N. R. Pace. 1989. Phylogenetic stains: ribosomal RNA-based probes for the identification of single cells. Science 243:1360-1363.

15. Distel, D. L., E. F. DeLong and J. B. Waterbury. 1991. Phylogenetic characterization and in situ localization of the bacterial symbiont of shipworms (Teredinidae: Bivalvia) by using $16 \mathrm{~S}$ rRNA sequence analysis and oligodeoxynucleotide probe hybridization. Appl. Environ. Microbiol. 57:23762382. 
16. Gall, J. G. and M. L. Pardue. 1969. Formation and detection of RNA-DNA hybrid molecules in cytological preparations. Proc. Natl. Acad. Sci. 63:378-383.

17. Giovannoni, S. J., E. F. DeLong, G. J. Olsen and N. R. Pace. 1988. Phylogenetic group-specific oligodeoxynucleotide probes for identification of single microbial cells. J. Bacteriol. 170:720-726.

18. Haas, L. W. 1982. Improved epifluorescence microscopy for observing planktonic micro-organisms. Ann. Inst. Océanogr., Paris 58(S):261-266.

19. Hahn, D., M. J. C. Starrenburg and A. D. L. Akkermans. 1990. Oligonucleotide probes that hybridize with rRNA as a tool to study Frankia stains in root nodules. Appl. Environ. Microbiol. 56:1342-1346.

20. Hicks, R. E., R. I. Amann and D. A. Stahl. 1992. Dual staining of natural bacterioplankton with 4', 6-diamidino-2-phenylindole and fluorescent oligonucleotide probes targeting kingdom-level 16S rRNA sequences. Appl. Environ. Microbiol. 58:2158-2163.

21. Jurtshuk, R. J., M. Blick, J. Bresser, G. E. Fox and P. Jurtshuk Jr. 1992. Rapid in situ hybridization technique using 16S rRNA segments for detecting and differentiating the closely related gram-positive organisms Bacillus polymyxa and Bacillus macerans. Appl. Environ. Microbiol. 58:2571-2578.

22. Lichter, P., C.-J. Chang Tang, K. Call, G. Hermanson, G. A. Evans, D. Housman and D. C. Ward. 1990. High-resolution mapping of human chromosome 11 by in situ hybridization with cosmid clones. Science 247:64-69.

23. Lovell, C. R. and Y. Hui. 1991. Design and testing of a functional groupspecific DNA probe for the study of natural populations of acetogenic bacteria. Appl. Environ. Microbiol. 57:2602-2609. 
24. Malone, T. C. 1971. The relative importance of nannoplankton and netplankton as primary producers in tropical oceanic and neritic phytoplankton communities. Limnol. Oceanogr. 16:633-639.

25. Medlin, L., H. J. Elwood, S. Stickel and M. L. Sogin. 1988. The characterization of enzymatically amplified eukaryotic 16S-like rRNA-coding regions. Gene 71:491-499.

26. Neidhardt, F. C. and B. Magasanik. 1960. Studies on the role of ribonucleic acid in the growth of bacteria. Biochim. Biophys. Acta 42:99-116.

27. Sherr, B. and E. Sherr. 1983. Enumeration of heterotrophic microprotozoa by epifluorescence microscopy. Estuar. Coast. Shelf Sci. 16:1-17.

28. Sherr, B. F., E. B. Sherr and R. D. Fallon. 1987. Use of monodispersed, fluorescently labeled bacteria to estimate in situ protozoan bacterivory. Appl. Environ. Microbiol. 53:958-965.

29. Sieburth, J. M. 1984. Protozoan bacterivory in pelagic marine waters, p. 405-444. In J. E. Hobbie and P. J. I. Williams (ed.), Heterotrophic activity in the sea. Plenum Press, New York.

30. Sogin, M. L. and J. H. Gunderson. 1987. Structural diversity of eukaryotic small subunit ribosomal RNAs. Ann. N.Y. Acad. Sci. 503:125-139.

31. StahI, D., B. Flesher, H. R. Mansfield and L. Montgomery. 1988. Use of phylogenetically based hybridization probes for studies of ruminal microbial ecology. Appl. Environ. Microbiol. 54:1079-1084.

32. Stahl, D. A. and R. Amann. 1991. Development and application of nucleic acid probes, p. 205-248. In E. Stackebrandt and M. Goodfellow (ed.), Nucleic acid techniques in bacterial systematics. John Wiley \& Sons Ltd., 
33. Tsien, H. C., B. J. Bratina, K. Tsuji and R. S. Hanson. 1990. Use of oligodeoxynucleotide signature probes for identification of physiological groups of methylotrophic bacteria. Appl. Environ. Microbiol. 56:2858-2865.

34. Zarda, B., R. Amann, G. Wallner and K.-H. Schleifer. 1991. Identification of single bacterial cells using digoxigenin-labelled, rRNA-targeted oligonucleotides. J. Gen. Microbiol. 137:2823-2830. 


\section{Chapter III}

\section{Development and Field Application of a Quantitative Method for Examining Natural Assemblages of Protists using Oligonucleotide Probes 1}

1 Published in Appl. Environ. Microbiol. 62(4): pp. 1416-1423, 1996. E. L. Lim, D. A. Caron, and E. F. DeLong. 


\section{Abstract}

A fluorescent in situ hybridization method is described that uses rRNA-targeted oligonucleotide probes for counting protists in cultures and environmental water samples. Filtration, hybridization and enumeration of fixed cells with biotinylated eukaryote-specific probes and FITC-avidin (fluorescein isothiocyanate conjugated avidin) were performed directly on $0.4 \mu \mathrm{m}$ polycarbonate filters of Transwell cell culture inserts (Costar Corp., Cambridge, Mass.). Counts of various species of cultured protists using this probe hybridization method were not significantly different from counts obtained using the 4', 6-diamidino-2-phenylindole (DAPI) and acridine orange (AO) staining methods. However, counts of total nanoplankton (TNAN) based on probe hybridizations in several field samples and in samples collected from a mesocom experiment were frequently higher than TNAN counts obtained by staining with DAPI or AO. Based on these results, $25 \%$ to $70 \%$ of the TNAN determined using probes were not detectable by DAPI or AO staining. The underestimation of TNAN abundances in samples stained with DAPI or AO was attributed to the existence of small nanoplanktonic cells which could be detected using probes but not DAPI or AO, and the difficulty associated with distinguishing DAPI- or AO-stained protists attached to or embedded in aggregates. We conclude from samples examined in this study that enumeration of TNAN with oligonucleotide probes provide estimates of natural TNAN abundances that are at least as high as (and in some cases higher than) counts obtained using commonly employed fluorochrome stains. The quantitative in situ hybridization method we have described here enables the direct enumeration of free-living protists in water samples using oligonucletide probes. When combined with species-specific probes, this method will enable quantitative studies of the abundance and distribution of specific protistan taxa. 


\section{Introduction}

Protists in the nanoplankton size class $(2-20 \mu \mathrm{m})$ are integral components of marine and freshwater ecosystems. They numerically dominate the eukaryotic plankton and are responsible for important trophic processes in planktonic food webs $(4,5$, and references therein, 7). The photosynthetic nanoplankton (PNAN), which consists of a variety of pigmented flagellates, chlorophytes and some small diatoms, often dominates total primary production in oceanic environments. The heterotrophic nanoplankton (HNAN) is comprised of colorless flagellates, amoeboid forms and smaller ciliates. These heterotrophs are the primary consumers of bacteria, cyanobacteria and small algae $(9,19,21,24,26,30)$ and have also been implicated as major nutrient remineralizers in aquatic environments $(6,8)$.

Although the significance of nanoplanktonic protists in aquatic food webs has been well established, relatively little information is available on the population structure and diversity of the nanoplankton in the water column. Ecological studies demonstrating the role of nanoplanktonic protists in microbial food webs tend to ignore the diversity of this group and imply that all species (aside from the distinction between photosynthetic and heterotrophic species) have a similar ecological function. The spatial and temporal distribution of taxa within this group are also poorly known. These shortcomings in our view and understanding of protistan ecology result largely from our limited ability using existing techniques to identify and enumerate individual species of naturally occurring protists.

Electron microsopy and epifluorescence microscopy are the current methods used for examining protists in natural samples. Both methods possess inherent advantages and disadvantages. Electron microscopy provides details of ultrastructure for identification of protists that are not apparent using light microscopy. This method, 
however, is impractical for analyzing large numbers of samples because it is timeconsuming and expensive. Electron microscopy also does not permit accurate estimates of cell abundance. In contrast, epifluorescence microscopy is relatively rapid, and routinely used to quantify nanoplankton abundances. A variety of fluorochrome dyes such as 4', 6-diamidino-2-phenylindole (DAPI), acridine orange (AO), primulin, fluorescein isothiocyanate (FITC) or proflavin are used to stain prokaryotic and eukaryotic cells in water samples for visualization by epifluorescence microscopy (25). While this method is versatile for counting nanoplanktonic cells, ultrastructural features that are vital for species identification are generally not apparent at the magnifications employed.

Another approach that has recently been applied for detecting and identifying microbial cells employs oligonucleotide probes complementary to specific sequences on the ribosomal RNA (29). Oligonucleotide probes have been designed that can discriminate between microorganisms at the kingdom- to subspecies-level $(2,3,11$ 13). When these probes are labeled with fluorescent dyes (either directly or indirectly), they can be used for the detection of target organisms by epifluorescence microscopy, confocal laser scanning microscopy or flow cytometry $(1,10,20,27)$.

Hybridization methods applying oligonucleotide probes have been largely qualitative to date. Probe hybridizations are performed with preserved cells either attached to glass slides coated with gelatin or in solution $(1,13,18)$. Cells processed "in solution" must undergo several centrifugation and resuspension steps which may cause cell loss. Similarly, repeated washes of gelatin-coated slides typically removes some portion of the attached cells. Because of potential cell losses at these steps, hybridization procedures with oligonucleotide probes, whether for culture samples or field samples, have not been quantitative, although some attempts at relative quantitation have been performed $(15,17,22)$. 
This paper describes a new quantitative method for in situ hybridization and detection of marine and freshwater protists that employs eukaryote-specific rRNA targeted probes. Hybridization, detection and enumeration of protists with biotinylated probes and FITC-avidin were performed with samples concentrated onto polycarbonate filters of Transwell cell culture inserts. Nanoplankton cell counts of cultures and field samples obtained using this probe hybridization technique were compared to cell counts obtained using the DAPI and AO methods. Probe counts of the nanoplankton by our quantitative in situ hybridization method were comparable to, and in many cases higher than, DAPI or AO counts. We conclude that the detection of TNAN with oligonucleotide probes may provide a more representative estimate of natural TNAN abundances than has been previously possible. More importantly, we present a quantitative method for applying oligonucleotide probes as a tool for examining and enumerating natural nanoplankton assemblages.

\section{Materials and methods}

Cell Cultures. Three heterotrophic flagellates, Paraphysomonas imperforata (chrysophyte: Clone A obtained from J. Eccleston, Lancaster University, Lancaster, UK), Paraphysomonas bandaiensis (chrysophyte: Clone WH1 obtained from J. Waterbury, Woods Hole Oceanographic Inst., Woods Hole, MA) and Cafeteria sp. (bicosoecid: Clone Cflag from our culture collection; isolated from seawater aquarium), and a ciliate, Uronema sp. (Clone BBcil from our culture collection; isolated from Buzzards Bay, Woods Hole, MA) were grown in liquid cultures of the marine bacterium, Halomonas halodurans (ATCC 29686). The phytoplankton cultures used were Minutocellus polymorphus (diatom: from our culture collection; isolated from Great South Bay, Long 
Island, NY), Chrysochromulina ericina (prymnesiophyte: Clone NEPCC109A obtained from the Center for Culture of Marine Phytoplankton [CCMP], Bigelow Laboratory of Ocean Sciences, Bigelow, ME), Ochromonas sp. (chrysophyte: Clone VT1 from CCMP) and Alexandrium minutum (dinoflagellate: Clone 1 obtained from D. Anderson, Woods Hole Oceanographic Inst., Woods Hole, MA). These phytoplankton were grown on f/2 medium in natural seawater (14). Cultures in the late exponential growth phase were preserved with formaldehyde to a final concentration of $3.7 \%$ and stored at $4^{\circ} \mathrm{C}$. Samples were processed between 2 hours to 3 days after fixation.

Sampling locations of field survey. Water samples were collected from three sites around the southwestern part of Cape Cod, Massachusetts and from one site in the Sargasso Sea, in October 1994. The sampling locations were Deep Pond (Hatchville), Great Harbor (Woods Hole) and Sippiwissett Marsh (West Falmouth) in Massachusetts, and the site of the Bermuda Atlantic Time-Series station in the Sargasso Sea. At each site, samples were collected at approximately $0.1-0.2 \mathrm{~m}$ depth and preserved with formaldehyde to a final concentration of $3.7 \%$. Preserved samples were stored in the dark at $4^{\circ} \mathrm{C}$ and processed within 3 days.

Field Experiment. Samples were collected from a mesocosm experiment conducted as part of a Land Margin Ecosystem Research (LMER) project by the Marine Biological Laboratory Ecosystems Center, Woods Hole, Massachusetts. This experiment was designed to examine the interaction of dissolved organic carbon (DOC) and dissolved inorganic nutrients (DIN) on the dynamics of coastal pelagic food webs. The experiment was run for 3 weeks in September 1994 off the Northeast Marine Fisheries Services jetty in Woods Hole, MA. Each treatment consisted of $\approx 7.5 \mathrm{~m}^{3}$ of seawater contained in polypropylene bags incubated in situ. The experimental treatments were: 1) no 
addition of DOC and DIN (control); 2) batch addition of DOC in the form of leaf litter leachate at a final concentration of $\approx 350 \mu \mathrm{M} \mathrm{C}$; 3) daily additions of DIN which consisted of a final concentration of $5 \mu \mathrm{M} \mathrm{KNO} 3,0.5 \mu \mathrm{M} \mathrm{KH} \mathrm{KHO}_{4}$ and $7 \mu \mathrm{M} \mathrm{NaSiO}{ }_{3} \cdot 9 \mathrm{H}_{2} \mathrm{O}$; 4) addition of DOC and DIN as in treatments "2" and "3" above. One mesocosm was established for each treatment. Samples from each treatment were collected and preserved with formaldehyde (final concentration of $3.7 \%$ ) for nanoplankton counts at the start of the experiment and on days $2,3,4,6,8$ and 10.

Oligonucleotide synthesis and labeling. The following probes were used for detection and enumeration of nanoplankton cells (the numbers correspond to Escherichia coli $16 \mathrm{~S}$ rRNA sequence positions): Euk 1209 (5'-GGG CAT CAC AGA CCT G3') (13), Euk 502 (5'-ACC AGA CTT GCC CTC C-3') (1), and Euk 309 (5'-TCA GGC TCC CTC TCC GG-3') (28). These probes are complementary to regions on the SSU rRNA that are conserved for all eukaryotes.

The oligonucleotides were synthesized with an amino group at the 5 -terminus (Euk 502 and Euk 309 by Protein and Nucleic Acid Center, Woods Hole, MA; Euk 1209 by Operon Technologies, Inc., Alameda, CA). The amino group of the oligonucleotides were coupled with biotin (Molecular Probes, Inc., Eugene, OR), purified through Sephadex G-25 columns and finally by polyacrylamide gel electrophoresis as described in Lim et al. (18).

\section{Sample processing for enumeration of protists by oligonucleotide}

probes. The in situ hybridization procedure for counting protists is summarized diagramatically in Fig. 1. The basis of this method is described in Lim et al. (18) for hybridization of protists using biotinylated probes and FITC-avidin on glass slides. The present technique entails adapting that method for performing in situ hybridizations using Transwell cell culture inserts (Costar Corp., Cambridge, Mass.). The feasibility 
Figure 1. Flow diagram of the quantitative in situ hybridization method using biotinylated probes and FITC-avidin. 
1. Vacuum filter water sample onto transwell membrane

Formaldehyde-preserved sample

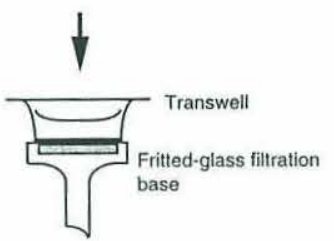

$\downarrow$

2. Dehydrate samples in $\mathrm{EtOH}$ series. Remove $\mathrm{EtOH}$ using vacuum between each wash. Air dry filters.

3. Put transwell in tissue culture tray. Add hybridization buffer onto filter. Prehybridize at $40^{\circ} \mathrm{C}$ for $45 \mathrm{~min}$.

4. Add probes to transwells. Hybridize overnight at $40^{\circ} \mathrm{C}$.

5. Add $0.2 \times$ SET prewarmed to $45^{\circ} \mathrm{C}$. Incubate at $45^{\circ} \mathrm{C}$ for $10 \mathrm{~min}$. Wash $3 X$ with $0.2 X$ SET.

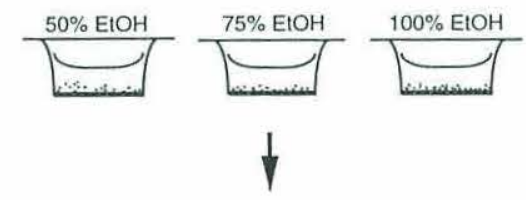

6. Add FITC-avidin and incubate at $4^{\circ} \mathrm{C}$ for $20 \mathrm{~min}$.

Wash $3 \mathrm{X}$ with cold $\mathrm{NaHCO}_{3}$ buffer. Air dry filters.
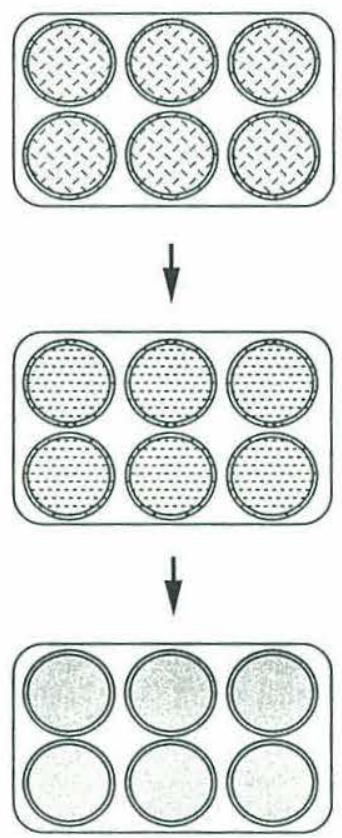

$\downarrow$

7. Cut out filter from transwell

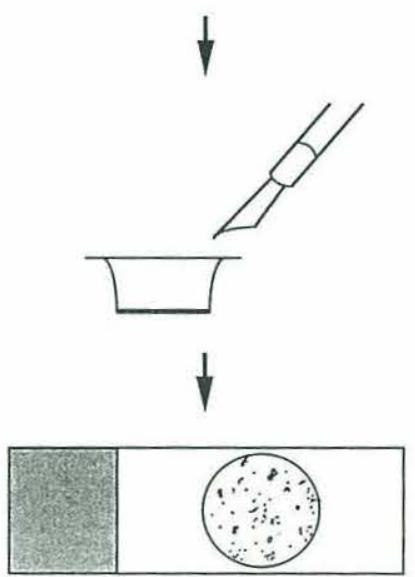

8. Mount filter on glass slide and view using epifluorescence microscope 
of enumerating protists in culture samples and in field samples by this method was examined. A combination of two eukaryote-specific probes was used in hybridizations of cultured protists, and three eukaryote-specific probes were used for natural assemblages of protists.

Preserved samples (2 to $25 \mathrm{mls}$ ) were drawn down onto polycarbonate filters (25mm, $0.4 \mu \mathrm{m}$ pore size) of Transwells at a vacuum no greater than $200 \mathrm{~mm} \mathrm{Hg}$. A $3.0 \mu \mathrm{m}, 25 \mathrm{~mm}$ Millipore filter was placed between the Transwell and the fritted-glass filtration base (Millipore) to promote even dispersion of cells on the filters of the Transwell. Transwells containing the concentrated samples were then transferred to 6well tissue culture dishes and $400 \mu \mathrm{l}$ of $50 \%$ ethanol was added to each Transwell, incubated for $2 \mathrm{~min}$, and removed by gentle vacuum. This process was sequentially repeated with $75 \%$ and $100 \%$ ethanol to dehydrate the samples. The Transwells were similarly placed in tissue culture trays during subsequent incubations and solutions were drawn away by vacuum filtration following each incubation throughout the hybridization procedure. After dehydration, the Transwells were air dried in the tissue culture tray, and $200 \mu \mathrm{l}$ of hybridization buffer (10X Denhardt's solution, $0.1 \mathrm{mg} \mathrm{ml}^{-}$ 1 polyadenylic acid, $5 X$ SET buffer $[750 \mathrm{mM} \mathrm{NaCl}, 100 \mathrm{mM}$ Tris- $\mathrm{HCl}$ [pH 7.8], $5 \mathrm{mM}$ EDTA], $0.1 \%$ sodium dodecyl sulfate) was added to each Transwell. Each tray of Transwells was then placed in a zip-lock bag that contained a piece of buffer-saturated tissue paper at the bottom of the bag and incubated at $40^{\circ} \mathrm{C}$ for $45 \mathrm{~min}$. Following this prehybridization step, $1 \mu \mathrm{l}$ of each probe (stock concentration of $0.5 \mu \mathrm{g} \mu \mathrm{l}^{-1}$ ) was added to each Transwell to obtain a final probe concentration of $2.5 \mathrm{ng} \mu \mathrm{l}^{-1}$, and allowed to hybridize at $40^{\circ} \mathrm{C}$ overnight. The trays were occasionally shaken during hybridization to ensure that the surface of the filters remained wet. At the completion of probe hybridization, each filter was washed by adding $2 \mathrm{ml}$ of $0.2 \mathrm{X}$ SET buffer ( $30 \mathrm{mM}$ $\mathrm{NaCl}, 4 \mathrm{mM}$ Tris- $\mathrm{HCl}[\mathrm{pH} 7.8]$, and $0.2 \mathrm{mM}$ EDTA) prewarmed to $45^{\circ} \mathrm{C}$ and incubating 
for $10 \mathrm{~min}$. The filters were then rinsed once with $0.2 X$ SET buffer and allowed to airdry. To detect the probed cells, $200 \mu \mathrm{l}$ of FITC-avidin solution $\left(20 \mu \mathrm{g} \mathrm{ml}^{-1}\right.$ in $100 \mathrm{mM}$ $\mathrm{NaHCO}_{3}$ buffered saline [pH 8.2]; Vector Laboratories, Inc., Burlingame, CA.) was added to each Transwell and incubated in the dark for $10 \mathrm{~min}$. at $4^{\circ} \mathrm{C}$. Samples were subsequently washed three times with cold $\mathrm{NaHCO}_{3}$-buffered saline $(100 \mathrm{mM})$ and allowed to air-dry in the dark.

To examine the samples, filters were cut out of the Transwells with a dissecting knife and placed as flat as possible on glass slides coated with a thin film of immersion oil (Citifluor, Ltd., London). One drop of Citifluor was then placed on the center of each filter followed by a coverslip. The filters were flattened by inverting the slide onto a flat surface and pressing gently. Cells were observed and counted with a Zeiss standard microscope equipped for epifluorescence microscopy. The area of the fritted-glass filtration base was used as the area covered by the samples for calculating cell density. Filter sets used for fluorescence observations were as follows: for DAPI, a G365 exciter filter, an FT420 chromatic beam splitter, and an LP418 barrier filter; and for AO and FITC, a BP450-490 exciter filter, an FT510 chromatic beam splitter, and an LP520 barrier filter. Epifluorescence micrographs of the samples were taken with an Olympus OM-4T camera using Ektachrome 200 ASA color film.

Duplicate hybridizations were performed with each culture examined, and triplicate hybridizations were conducted with each of the samples collected from different locations in the field survey. Only one hybridization was carried out for each sample collected during the mesocosm experiment due to the large number of samples that had to be processed in a short period. To enumerate the nanoplankton cells, approximately 15 to 40 fields were observed. The total number of cells counted ranged from approximately 35 (Sargasso Sea samples) to 1000 cells (culture and enriched mesocosm samples). 


\section{Sample processing for enumeration of protists by DAPI and acridine}

orange staining. Probe counts of protists were compared to counts obtained using the conventional DAPI and AO staining methods to examine the accuracy of cell counting by the quantitative in situ hybridization method. The procedures for fluorochrome staining were as described by Sherr et al. (25). Briefly, preserved water samples were vacuum filtered onto $0.8 \mu \mathrm{m}$ blackened polycarbonate filters (Nuclepore) and stained with either DAPI or AO for $10 \mathrm{~min}$. and $3 \mathrm{~min}$., respectively. The final concentration of DAPI used was $5 \mu \mathrm{g} \mathrm{ml}^{-1}$. In addition, all the field samples were stained with DAPI at a final concentration of $50 \mu \mathrm{g} \mathrm{ml}^{-1}$ and counted to ensure that the $5 \mu \mathrm{g} \mathrm{ml}^{-1}$ concentration was sufficient to thoroughly stain the nanoplanktonic cells. The final concentration of acridine orange used was $0.01 \%$.

Enumeration of TNAN by each of the three labeling techniques (probes, $A O$ and DAPI) were performed on slides prepared from subsamples of the same preserved sample. Several samples were also dual stained with probes and DAPI for taking photographs. DAPI and AO counts were performed on all the samples collected and processed for cell counts by probe hybridization with one exception. In the mesocosm experiment, acridine orange counts were only performed on the final samples of the experiment (day 10). The number of slides prepared and fields examined for each sample were otherwise the same as that described for the hybridization method.

Because filters with two different pore sizes were used for enumerating protists (0.4 $\mu \mathrm{m}$ for the in situ hybridization method versus $0.8 \mu \mathrm{m}$ filters for the DAPI and AO method), counts of TNAN were compared using $0.4 \mu \mathrm{m}$ and $0.8 \mu \mathrm{m}$ filters to ensure that both types of filters trap the same number of cells. A seawater sample collected from Eel Pond, Woods Hole, MA was stained with DAPI, and a culture of a Nannochloris-like alga (Clone BT3, isolated from Great South Bay, Long Island, NY), 1-3 $\mu \mathrm{m}$ in diameter, 
was stained with 5-(4,6-dichlorotriazin-2-YL)-aminofluorescein (DTAF) and enumerated.

\section{Results}

Quantitative in situ hybridization of protists with probes. The key to this quantitative technique was the use of Costar's Transwell cell culture. The Transwell is essentially a small chamber with a porous polycarbonate membrane filter at the base. This design allowed the insert to serve as a filtration cup in which samples could be concentrated and processed without cell loss due to rinsing. The Transwells were used directly without pretreatment of the filters to reduce background fluorescence, a routine procedure in epifluorescence microscopy (16). However, it was crucial to include a prehybridization step using hybridization buffer which contained 10X Denhardt's reagent and $0.1 \mathrm{mg} \mathrm{ml}^{-1}$ polyadenylic acid (23). These blocking agents suppressed non-specific binding of the probes to the filter and thus greatly reduced background fluorescence. The following points were also found to be important: a volume of $200 \mu \mathrm{l}$ adequately covered the surface of the filters with hybridization buffer or FITC-avidin solution yet minimized the amount of each probe added so that the procedure remained economical; the hybridization time could be reduced to 3 hours without noticeable loss in the fluorescence intensity of probed cells.

Samples were typically processed and enumerated from 1 to 3 days after preservation in formaldehyde. However, the fluorescence of individual cells as well as the nanoplankton counts of field samples preserved for up to 10 days were not different from the fluorescence intensity and the counts obtained when they were probed one day after preservation (data not shown). The signal to noise ratios of the probed samples 
were very high and protists could be clearly visualized against a dark background by epifluorescence microscopy (Fig. $2 a-d, f$ and $j$ ). A variety of protists including small flagellates, dinoflagellates, ciliates, amoebae and diatoms could be distinguished in the field samples. Bacteria and cyanobacteria were not labeled by the probes and nonspecific staining of detrital material was extremely low. This combination of factors made enumerating probed nanoplankton cells easy and rapid. It was not possible to obtain reliable estimates of the percentage of nanoplankton cells that were photosynthetic in natural water samples (i.e. separate them from the heterotrophic nanoplankton) because the ethanol washes extracted the chlorophyll from some of the small photosynthetic cells. Therefore, only total nanoplankton counts were obtained in this study. In future, this problem might be circumvented by counting autofluorescent cells in samples processed without ethanol dehydration.

Comparison of cell counts by hybridization probes, DAPI and acridine orange staining: (i) Cell cultures. Eight cultures of protists representing a range of sizes and taxonomic groups were selected for enumeration by in situ hybridization, DAPI and acridine orange staining. All the cultures tested were easily counted but the fluorescence signal of probed cells varied among the species tested owing largely to differences in cell size and perhaps physiological state (which may affect ribosome number). Cell densities obtained by each of the three methods (expressed as the percentage of cells detected by eukaryote-specific probes relative to DAPI and acridine orange staining) were not significantly different (two-way analysis of variance [ANOVA], $P=0.14$ ) at the $a=0.01$ significance level (Fig. 3 ). The use of eukaryote-specific probes and the filter hybridization method thus gave counts of cultured protists that were comparable to DAPI and acridine orange staining. 
Figure 2. Epifluorescence micrographs of naturally occurring protists in the DOC + DIN treatment of the mesocosm experiment at day 10. A variety of protists hybridized with eukaryote-specific biotinylated oligonucleotide probes and FITC-avidin showing FITC fluorescence (a to $d, f$ and $j$ ) including a diatom (arrow in "a"), a dinoflagellate (b), and an amoeba (d). Probed protists, dual-stained with DAPI and FITC-avidin, irradiated with UV light (e) to preferentially excite DAPI and blue light (f) to preferentially excite FITC. Note the $2 \mu \mathrm{m}$ cell at the bottom of the micrograph (arrow in "f") that is easily distinguished by its FITC fluorescence but not by its DAPI fluorescence (arrow in "e"). AO-stained preparations of free-living protists $(\mathrm{g})$ and an aggregate with associated protists (h). DAPI (i) and corresponding FITC (j) fluorescence of aggregateassociated protists in a dual-stained preparation. Note that protists associated with aggregates are clearly distinguished by oligonucleotide probes. Scale bars $=5 \mu \mathrm{m}$. 

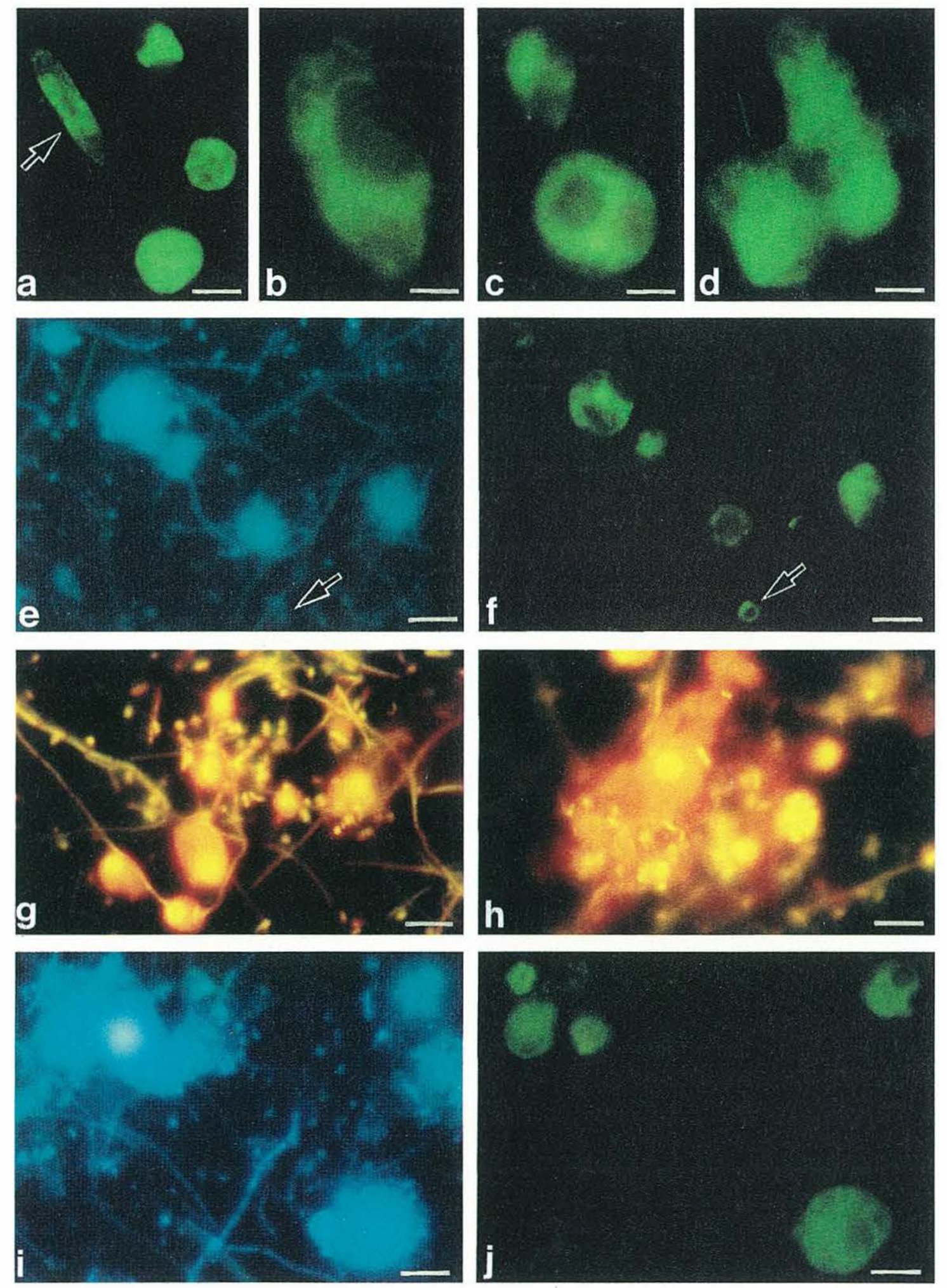
Figure 3. Percentage of cultured heterotrophic flagellates (Paraphysomonas imperforata, P. bandaiensis, Cafeteria sp.), algae (Ochromonas sp., Chrysochromulina ericina, Alexandrium minutum, Minutocellus polymorphus) and a ciliate (Uronema sp.) labeled by in situ hybridization with eukaryote-specific probes. All cell abundances obtained by eukaryote-specific proßbes were normalized to cell counts obtained by (A) DAPI and (B) acridine orange staining. 


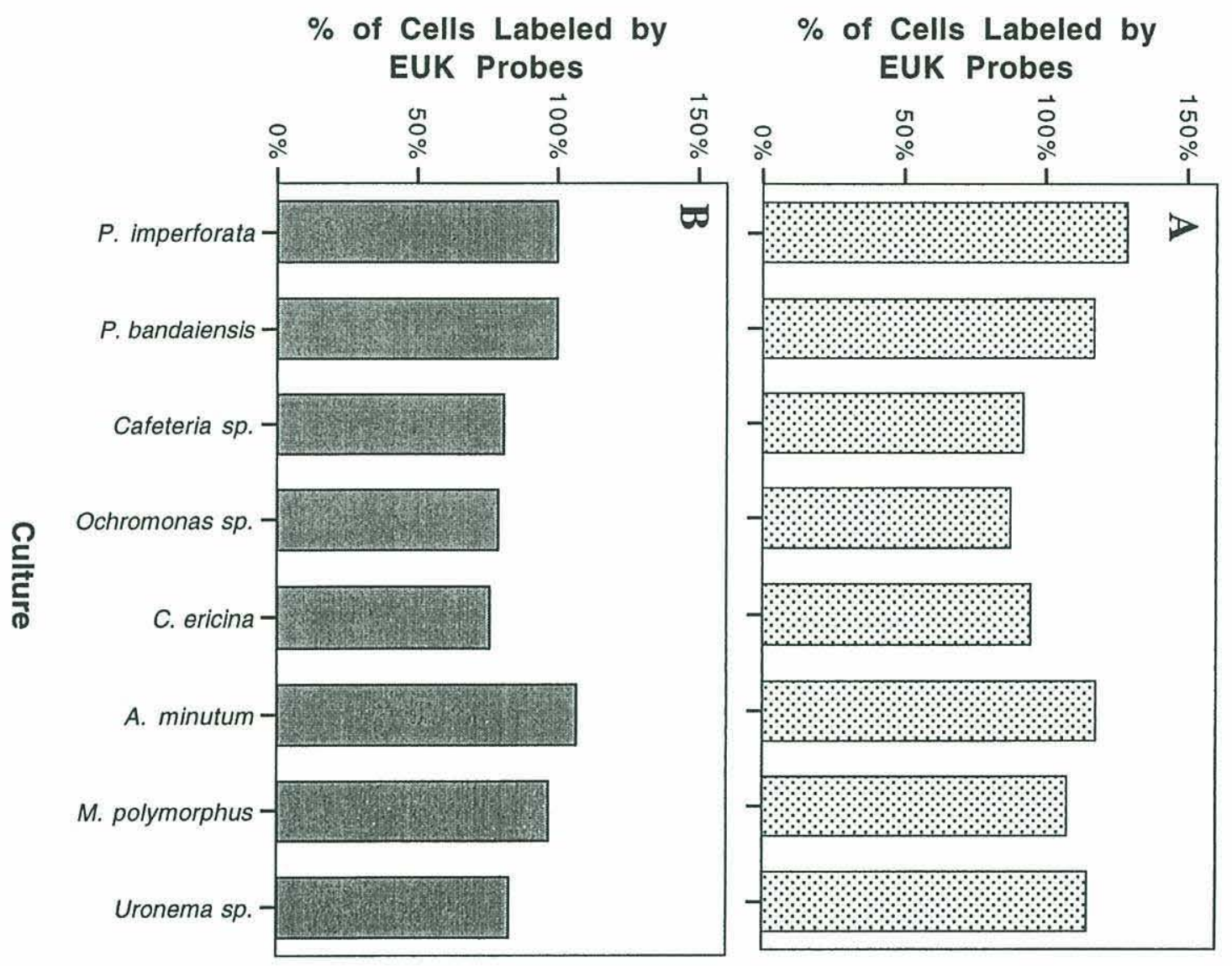


(ii) Field samples. The ability of the probe hybridization method to provide accurate counts of mixed assemblages of protists relative to DAPI and acridine orange counts was examined with water samples collected from a variety of environments. The nanoplankton assemblages in the oligotrophic freshwater (Deep Pond) and seawater (Sargasso Sea) samples as well as the Woods Hole coastal water sample were mainly dominated by small protists approximately $2 \mu \mathrm{m}$ in diameter. Nanoplanktonic protists in the Sippiwissett Marsh samples on the other hand were predominantly photosynthetic dinoflagellates approximately 15 to $18 \mu \mathrm{m}$ in size.

TNAN counts obtained from samples stained with $5 \mu \mathrm{g} \mathrm{ml}^{-1}$ of DAPI were similar to counts from samples stained with $50 \mu \mathrm{g} \mathrm{ml}^{-1}$ of DAPI (data not shown). Estimates of TNAN using 0.4 and $0.8 \mu \mathrm{m}$ filters also were not different. In the Eel Pond water sample, TNAN abundances estimated using $0.4 \mu \mathrm{m}$ and $0.8 \mu \mathrm{m}$ filters were $1.34 \times 10^{3} \pm$ $0.20 \mathrm{ml}^{-1}$ and $1.36 \times 10^{3} \pm 0.27 \mathrm{ml}^{-1}$, respectively, and in the algal culture, $9.03 \times$ $10^{4} \pm 0.16 \mathrm{ml}^{-1}$ and $9.31 \times 10^{4} \pm 0.20 \mathrm{ml}^{-1}$, respectively. The density of TNAN in all the field samples enumerated by in situ hybridization was similar to or higher than TNAN densities obtained using DAPI or AO staining (Fig. 4). The greatest difference observed was in the Woods Hole water sample. Probe counts of TNAN in this water sample was approximately 2 times greater than TNAN densities obtained using DAPI and AO staining.

(iii) Mesocosm experiment. The additions of DOC and DIN in the mesocosm treatments stimulated the growth of the bacterial and algal assemblages and, subsequently, other organisms at higher trophic levels as they responded to the elevated production. The abundance of heterotrophic nanoplankton (comprised largely of bacterivorous flagellates) increased probably in response to the elevated bacterial densities while the photosynthetic nanoplankton bloomed presumably as a result of the inorganic nutrient additions. This experiment was ideal for testing the in situ 
Figure 4. Total nanoplankton densities in a freshwater sample (Deep Pond), and three seawater samples determined by DAPI staining, AO staining and eukaryote-specific probes. Error bars represent $\pm 1 \mathrm{SD}$ of the mean of triplicate counts. 


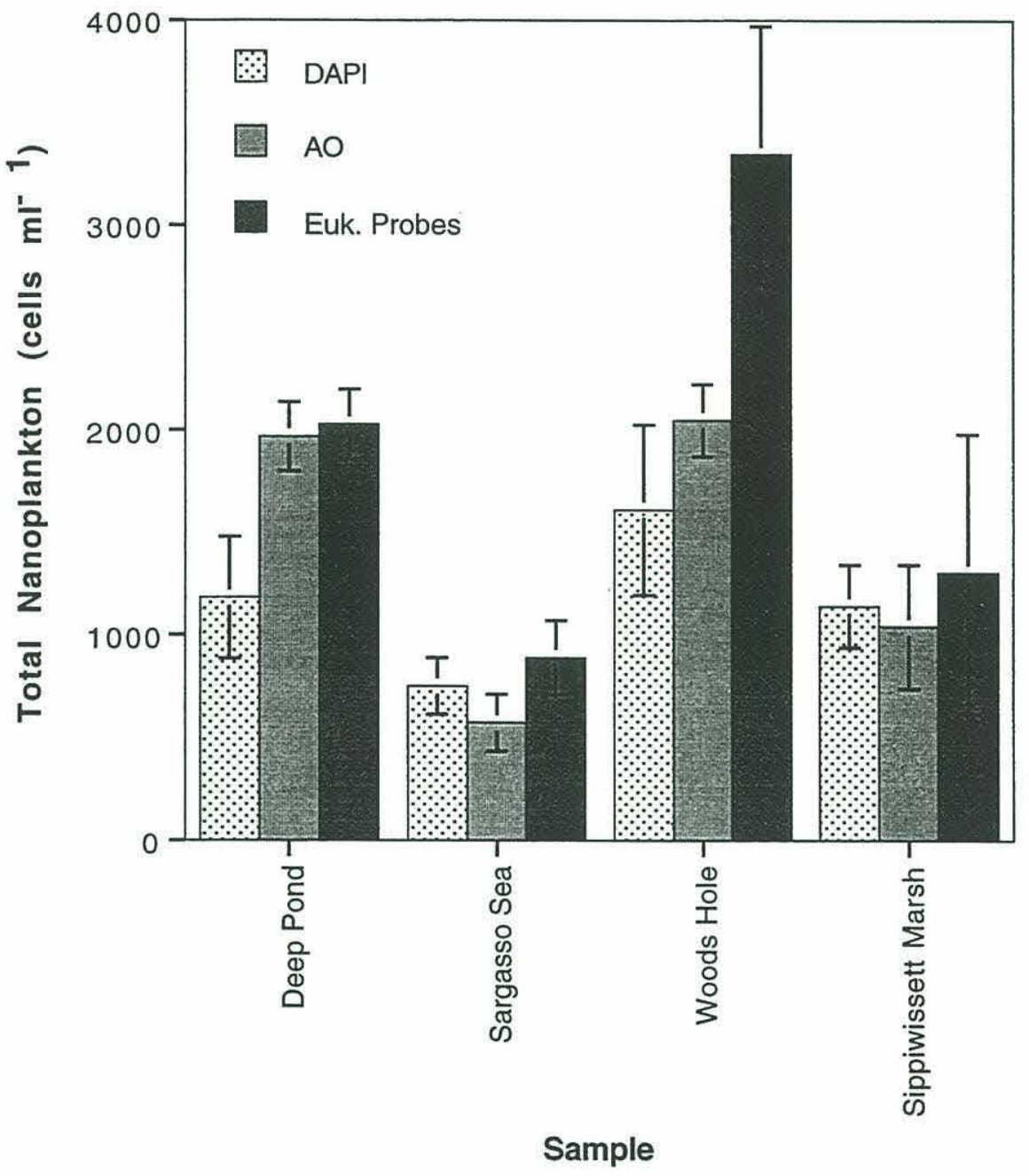


hybridization method under a field setting because the various DOC and DIN additions resulted in a range of TNAN abundances during the 10 day sampling period.

TNAN concentrations in the three enriched treatments (DOC, DIN, and DOC + DIN) increased dramatically relative to the control treatment during the first 10 days of the experiment (Fig. 5). TNAN abundance in the control treatment was 2 -fold higher at the end of the experiment than its initial value. In contrast, TNAN abundances in the DOC, DIN, and DOC + DIN treatments increased by approximately 10 -fold during the 10 day period.

TNAN counts obtained by probe hybridization were consistently higher than DAPI counts of TNAN in all four treatments over the 10 day period (Fig. 5). Probe counts at the beginning of the experiment were nearly 2 -fold greater than DAPI counts (average of $t=0$ samples from all four treatments), and ranged from approximately 1.3 to 3.3 times the DAPI counts over the duration of the experiment. By day 10, probe counts of TNAN remained approximately 2 -fold greater than the corresponding DAPI counts in the control, DOC and DIN treatments, but were more than 3 -fold greater than the DAPI counts in the DOC + DIN treatment. These results indicated that the probes consistently detected a portion of the nanoplankton assemblage that were not detected by DAPI in all the treatments. This difference was greatest for the DOC + DIN enrichment.

TNAN densities determined by AO staining on day 10 were comparable to DAPI counts in the control, DOC, and DIN treatments, but were approximately 1.5 times higher than DAPI counts in the DOC + DIN treatment. Nevertheless, all TNAN abundances determined using $\mathrm{AO}$ were lower than estimates obtained using the probe hybridization method. 
109 
Figure 5. Changes in total nanoplankton densities as measured by eukaryote-specific probes, DAPI and AO staining in 4 treatments of a mesocosm experiment. The treatments were: unamended seawater (CONTROL); dissolved organic carbon (DOC) addition; dissolved inorganic nutrient (DIN) additions, and DOC and DIN (DOC + DIN) additions. 


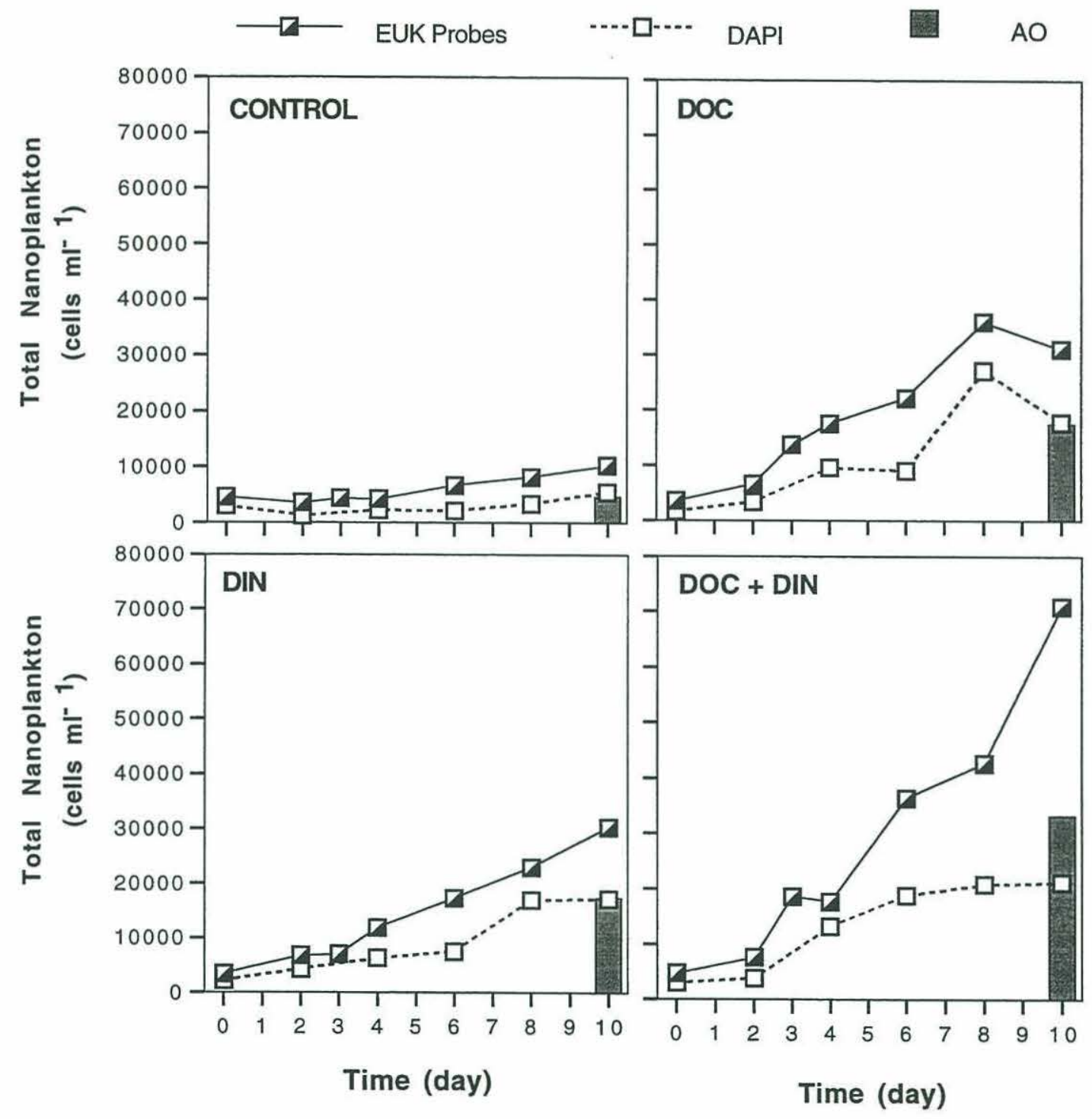




\section{Discussion}

A major goal in the application of molecular approaches in ecological studies has been the identification and enumeration of individual species of microorganisms in their natural environment. The quantitative in situ hybridization technique described in this study is a significant step towards this goal. The method permits direct enumeration of both cultured and naturally occurring protists using in situ hybridization with oligonucleotide probes. In addition, the method has wide applicability for conducting in situ hybridization to identify and enumerate other microbial cells in aquatic samples.

Hybridization experiments performed in this study with several cultures of nanoplanktonic protists demonstrated that the method provided accurate cell counts in comparison to the conventionally employed DAPI and AO methods for enumerating protists (Fig. 3). Because cultures do not present many of the difficulties associated with field samples (diverse species assemblages resulting in a range of cell types, sizes, physiological states and aggregations), they served as simple controls for testing the reliability of oligonucleotide probes and of the hybridization procedure for quantifying nanoplanktonic protists. We have shown that, for the species tested in this study, the quantitative in situ hybridization method gave estimates comparable to the fluorochrome staining techniques.

Our quantification of mixed assemblages of protists with eukaryote probes has also provided an independent means other than conventional staining methods to examine the natural abundance of nanoplanktonic protists. In a survey of water samples collected from four environments of differing trophic status, probe counts of TNAN were up to 2fold greater than counts obtained using DAPI or AO staining (Fig. 4). This observation was further supported by results from the mesocosm experiment which demonstrated 
that TNAN abundances obtained using probe hybridization ranged from 1.3 to 3.3 times (average of 2) higher than DAPI counts of TNAN in all four enrichment regimes over a 10 day period (Fig. 5). If the probe counts of TNAN are assumed to be an accurate estimate of TNAN in these water samples, our results indicate that DAPI or AO staining failed to detect a portion of the nanoplanktonic assemblage constituting approximately $25 \%$ to $70 \%$ of the TNAN assemblage.

The differences observed in TNAN abundances among samples treated with probes, DAPI or AO may be explained by the presence of nanoplanktonic cells that were obscured in detrital aggregates or poorly stained by DAPI or AO, but readily detectable by in situ hybridization with oligonucleotide probes. We have observed that the nuclei of some cultured species of protists as well as the nuclei of some protists in natural water samples are not well-stained by DAPI. A prevalence of such cells in water samples collected in this study could have contributed to an underestimation of TNAN densities in the DAPI stained samples. Water samples collected from Deep Pond, Sargasso Sea and Woods Hole at the time of this study also contained many small nanoplanktonic cells. Small nanoplanktonic cells, typically those about $2 \mu \mathrm{m}$ in size are often extremely difficult to distinguish when stained with DAPI or acridine orange. DAPI stains primarily the nucleus; therefore, the nuclei of $2 \mu \mathrm{m}$ protists often appear as small, bright dots that can be confused with stained bacteria (arrow in Fig. 2e). Probes, on the other hand, bind to ribosomes that are dispersed in the cytoplasm. As a result, protists are more uniformly stained and thus easier to visualize (arrow in Fig $2 \mathrm{f}$ ). Tiny $(\approx 2$ $\mu \mathrm{m})$ cells were routinely observed in samples examined using the in situ hybridization method during this study.

The low estimates of TNAN obtained from DAPI counts may also be caused by bacteria and aggregate material interfering with nanoplankton counts, particularly in the DOC + DIN treatment of the mesocosm experiment. Enrichment of the water sample 
in the mesocosm experiment with DOC + DIN resulted in the greatest difference between DAPI counts and probe counts of TNAN (Fig. 5). Macro- and microscopic aggregates composed primarily of phytodetrital aggregates and filamentous bacteria were particularly extensive in the DOC + DIN treatment as a result of elevated phytoplankton and bacterial abundances. The high concentration of bacteria and aggregate material may have been responsible for the underestimation of TNAN in DAPI-stained samples because DAPI (as well as AO) stained the bacteria and detrital material intensely, and as a result, masked the fluorescence of stained protists within aggregates. Figures $2 \mathrm{e}$ and $2 \mathrm{~g}$ show DAPI and AO stained protists, respectively, that were not associated with detrital aggregates and were reasonably easy to enumerate. However, in aggregates stained by AO (Fig. 2h) or DAPI (Fig. 2i), the fluorescence of detrital material and aggregated bacteria masked the fluorescence of the protists associated with the aggregates. These attached protists, in contrast, were easily distinguished when treated with oligonucleotide probes because the probes and FITC-avidin labeled the protists but not the detrital material and bacteria (Fig. 2j, same field of view as Fig. $2 \mathrm{i}$, but showing FITC fluorescence of probed cells).

We have demonstrated in this study that counts of cultured protists obtained by probe hybridization were comparable to DAPI and AO counts, and that counts of TNAN in field samples obtained using probes were frequently higher than DAPI or AO counts of TNAN. It is difficult to assess whether probes provide accurate determinations of the abundance of TNAN in natural, mixed assemblages, but the results of our study indicate that in situ hybridization with probes gave estimates that are at least as high as (and in some cases higher than) counts obtained using commonly employed fluorochrome stains.

Identification of a variety of microorganisms in diverse habitats using rRNAbased phylogenetic identification techniques have greatly enhanced our understanding of species diversity and distribution ( 3 , and references therein). Knowledge of the species 
composition in a particular environment, in turn, can be used to relate community structure to various aspects of community function and biogeochemical activity. Similarly, demonstration of specific taxa in an environment can be indicative of particular physiologies within the assemblage. However, in order to estimate the importance of these processes in the environment, it is necessary to quantify the abundance of the microorganisms responsible for them. The quantitative in situ hybridization method that we have developed provides an effective means to enumerate the total assemblage of nanoplanktonic protists in environmental samples. Our laboratories have also recently developed oligonucleotide probes specific to several ecologically important species of heterotrophic flagellates common in aquatic environments (manuscript in preparation). With the availability of these probes and the quantitative method described here, it should now be possible to gather data on the abundance and distribution of different taxonomic groups of protists and to measure the contribution of these species to energy flow in aquatic ecosystems.

\section{Acknowledgements}

This study was supported by NSF Grants OCE-9216270 (D.A.C.) and OCE9218523 (E.F.D.) and by an Independent Study Award (from the Woods Hole Oceanographic Institution to D.A.C.). We thank Chuck Hopkinson, John Hobbie, Joe Vallino and other participating members of the Marine Biological Laboratories Ecosystems Center for samples from the mesocosm experiment. The mesocosm study was partially supported by NSF LMER Grant OCE-9214461 (C.H.). We also thank Andy Solow for advice on statistical analysis, Carol Kosman and Mark Dennett for technical 
assistance, and Jacqueline Eccleston, Gaspar Taroncher-Oldenburg and John Waterbury who provided cultures.

\section{References}

1. Amann, R. I., B. J. Binder, S. W. Olson, R. Devereux and D. A. Stahl. 1990. Combination of 16S rRNA-targeted oligonucleotide probes with flow cytometry for analyzing mixed microbial populations. Appl. Environ. Microbiol. $56: 1919-1925$.

2. Amann, R. I., L. Krumholz and D. A. Stahl. 1990. Fluorescentoligonucleotide probing of whole cells for determinative, phylogenetic, and environmental studies in microbiology. J. Bacteriol. 172:762-770.

3. Amann, R. I., W. Ludwig and S. K-H. 1995. Phylogenetic identification and in situ detection of individual microbial cells without cultivation. Microbiol. Rev. 59:143-169.

4. Azam, F., T. Fenchel, J. G. Field, J. S. Gray, L. A. Meyer-Reil and F. Thingstad. 1983. The ecological role of water-column microbes in the sea. Mar. Ecol. Prog. Ser. 10:257-263.

5. Berninger, U.-G., D. A. Caron, R. W. Sanders and B. J. Finlay. 1991. Heterotrophic flagellates of planktonic communities, their characteristics and methods of study, p. 39-56. In D. J. Patterson and J. Larsen (ed.), The biology of free-living heterotrophic flagellates. vol. Special Volume 45. Clarendon Press, Oxford. 
6. Caron, D. A. 1991. Evolving role of protozoa in aquatic nutrient cycles, p. 387415. In P. C. Reid, C. M. Turley and P. H. Burkill (ed.), Protozoa and their role in marine processes. vol. 25. Springer-Verlag, Berlin.

7. Caron, D. A. 1994. Protozoan links in food webs, p. 125-130. In K. Hausmann and N. Hülsmann (ed.), Progress in Protozoology, Proceedings of the IX International Congress of Protozoology, Berlin 1993. Gustav Fischer Verlag, Stuttgart.

8. Caron, D. A. and J. C. Goldman. 1990. Protozoan nutrient regeneration, p. 283-306. In G. M. Capriulo (ed.), Ecology of marine protozoa. Oxford University Press, New York.

9. Caron, D. A., E. L. Lim, G. Miceli, J. B. Waterbury and F. W. Valois. 1991. Grazing and utilization of chroococcoid cyanobacteria and heterotrophic bacteria by protozoa in laboratory cultures and a coastal plankton community. Mar. Ecol. Prog. Ser. 76:205-212.

10. DeLong, E. F., F. S. Wickham and N. R. Pace. 1989. Phylogenetic stains: ribosomal RNA-based probes for the identification of single cells. Science 243:1360-1363.

11. Devereux, R., M. D. Kane, J. Windrey and D. A. Stahl. 1992. Genus- and group-specific hybridization probes for determinative and environmental studies of sulfate-reducing bacteria. Systematic and Applied Microbiology 15:601-609.

12. DiChristina, T. J. and E. F. DeLong. 1993. Design and application of rRNAtargeted oligonucleotide probes for the dissimilatory iron- and manganese-reducing bacterium Shewanella putrefaciens. Appl. Environ. Microbiol. 59:4152-4160.

13. Giovannoni, S. J., E. F. DeLong, G. J. Olsen and N. R. Pace. 1988. Phylogenetic group-specific oligodeoxynucleotide probes for identification of single microbial cells. J. Bacteriol. 170:720-726. 
14. Guillard, R. R. L. 1975. Culture of phytoplankton for feeding marine invertebrates, p. 29-60. In W. L. Smith and M. H. Chanley (ed.), Culture of marine invertebrate animals. Plenum Publishing, New York.

15. Hicks, R. E., R. I. Amann and D. A. Stahl. 1992. Dual staining of natural bacterioplankton with 4',6-diamidino-2-phenylindole and fluorescent oligonucleotide probes targeting kingdom-level 16S rRNA sequences. Appl. Environ. Microbiol. 58:2158-2163.

16. Hobbie, J. E., R. J. Daley and S. Jaspar. 1977. Use of Nuclepore filters for counting bacteria by fluorescence microscopy. Appl. Environ. Microbiol. 33:1225-1228.

17. Lee, S. and P. F. Kemp. 1994. Single-cell RNA content of natural marine planktonic bacteria measured by hybridization with multiple 16S rRNA-targeted fluorescent probes. Limnol. Oceanogr. 39:869-879.

18. Lim, E. L., L. A. Amaral, D. A. Caron and E. F. DeLong. 1993. Application of rRNA-based probes for observing marine nanoplanktonic protists. Appl. Environ. Microbiol. 59:1647-1655.

19. Malone, T. C. 1971. The relative importance of nannoplankton and netplankton as primary producers in tropical oceanic and neritic phytoplankton communities. Limnol. Oceanogr. 16:633-639.

20. Manz, W., R. Amann, R. Szewzyk, U. Szewzyk, T.-A. Stenström, P. Hutzler and K.-H. Schleifer. 1995. In situ identification of Legionellaceae using 16S rRNA-targeted oligonucleotide probes and confocal laser scanning microscopy. Microbiology 141:29-39.

21. Patterson, D. J. and J. Larsen. 1991. The biology of free-living heterotrophic flagellates. Clarendon Press, Oxford 
22. Raskin, L., L. K. Poulsen, D. R. Noguera, B. E. Rittmann and D. A. Stahl. 1994. Quantification of methanogenic groups in anaerobic biological reactors by oligonucleotide probe hybridization. Appl. Environ. Microbiol. $60: 1241-1248$.

23. Sambrook, J., E. F. Fritsch and T. Maniatis. 1989. Molecular cloning: a laboratory manual. Cold Spring Harbor Laboratory Press, Cold Spring Harbor.

24. Sherr, B. F., E. B. Sherr and R. D. Fallon. 1987. Use of monodispersed, fluorescently labeled bacteria to estimate in situ protozoan bacterivory. Appl. Environ. Microbiol. 53:958-965.

25. Sherr, E. B., D. A. Caron and B. F. Sherr. 1993. Staining of heterotrophic protists for visualization via epifluorescence microscopy, p. 213-227. In P. Kemp, J. Cole, B. Sherr and E. Sherr (ed.), Handbook of methods in aquatic microbial ecology. Lewis Publishers, Boca Raton.

26. Sherr, E. B., B. F. Sherr and J. McDaniel. 1991. Clearance rates of $<6 \mu \mathrm{m}$ fluorescently labeled algae (FLA) by estuarine protozoa: potential grazing impact of flagellates and ciliates. Mar. Ecol. Prog. Ser. 69:81-92.

27. Simon, N., N. LeBot, D. Marie, F. Partensky and D. Vaulot. 1995. Fluorescent in situ hybridization with rRNA-targeted oligonucleotide probes to identify small phytoplankton by flow cytometry. Appl. Environ. Microbiol. 61:2506-2513.

28. Sogin, M. L. and J. H. Gunderson. 1987. Structural diversity of eukaryotic small subunit ribosomal RNAs. Ann. N.Y. Acad. Sci. 503:125-139.

29. Stahl, D. A. and R. Amann. 1991. Development and application of nucleic acid probes, p. 205-248. In E. Stackebrandt and M. Goodfellow (ed.), Nucleic acid techniques in bacterial systematics. John Wiley \& Sons Ltd., Chichester, England. 
30. Vørs, N. 1992. Heterotrophic amoebae, flagellates and heliozoa from the Tvärminne area, Gulf of Finland, in 1988-1990. Ophelia 36:1-109. 


\section{Chapter IV}

The Ecology of Paraphysomonas imperforata based on Studies Employing Oligonucleotide Probe Identification of Cells in Coastal Water Samples and Enrichment Cultures 


\section{Abstract}

The geographical distribution and seasonal abundance of the cosmopolitan heterotrophic flagellate, Paraphysomonas imperforata in coastal waters was examined using species-specific oligonucleotide hybridization probes which target small subunit ribosomal RNA. Despite previous records of $P$. imperforata as an abundant and widely distributed species, results from this study showed that $P$. imperforata occurred at extremely low abundances in coastal environments. Similarly, the seasonal abundance of P. imperforata examined at one sampling site remained consistently low and constituted no more than $1 \%$ of the total nanoplankton over a 17 -month sampling period. In contrast to the low abundances observed in natural water samples, $P$. imperforata often dominated the nanoplankton in heterotrophic enrichment cultures prepared from these same samples, comprising up to $98 \%$ of the total nanoplankton. Based on these findings, I conclude that $P$. imperforata is an opportunistic species capable of growing rapidly to high abundances when prey concentrations are high. Water temperature appeared to play a role in the seasonal differences observed in $P$. imperforata dominance. Experiments with enrichment cultures also suggest that the absolute abundance of $P$. imperforata and nanoplankton grazers can influence the degree to which $P$. imperforata dominates the HNAN assemblage of enrichment cultures. Seasonal changes in water temperature may also affect these factors and as a consequence indirectly control $P$. imperforata populations. Finally, these results suggest that enrichment cultivation or perhaps incubations in general can select for species such as $P$. imperforata that may not be representative of oceanic nanoplanktonic protists that are abundant. 


\section{Introduction}

Heterotrophic protists play a major role in the flow of energy in planktonic food webs as the primary grazers of bacteria and other picoplankton $(3,11,14,30,31)$. These heterotrophs are also potential sources of nutrients and dissolved organic material which are regenerated as a result of their grazing activities $(5,16)$. Although our understanding of the role of small protists in aquatic ecosystems has improved considerably, very little still is known about the spatial and temporal abundance and dynamics of individual species in the water column. Several investigators have recently begun to document the diversity and distribution of small heterotrophic protists in different marine waters but such studies have not focused on obtaining quantitative information about individual species (35-37).

Studies documenting the diversity and distribution of small heterotrophic protists have not been quantitative because identification of these taxa usually involve enrichment cultivation and/or electron microscopy. To observe cells by electron microscopy, samples must be concentrated or enriched because nanoplanktonic protists do not usually occur in sufficient densities naturally to prepare for electron microscopy. As a result, the number of cells present in electron microscopical preparations are either biased (e.g. in enrichment cultures) or no longer representative of their original densities due to cell loss during preparation (e.g. electron microscopy).

An approach that enables simultaneous identification and enumeration of specific taxa in water samples without isolation and culture is in situ hybridization of whole cells with rRNA-targeted oligonucleotide probes $(2,21,34)$. Oligonucleotide probes are designed to bind to short, complementary sequence regions of the rRNA that are unique to the taxa of interest. These probes are labeled with fluorescent dyes (either 
directly or indirectly via a secondary reporter molecule) so that cells hybridized with probes may be directly observed by epifluorescence microscopy, confocal laser scanning microscopy or flow cytometry $(1,10,22,25,32)$. When used in combination with a recently developed quantitative in situ hybridization method, oligonucleotide probes were also shown to be applicable for detecting and quantifying small protists in field samples by epifluorescence microscopy (23).

P. imperforata is a heterotrophic, free-living flagellate within the Class Chrysophyceae. The cells are typically spherical in shape and range in size from 4 to 18 $\mu \mathrm{m}$ in diameter. This species and other members of the genus are identified by the silica scales that cover the organism. P. imperforata was chosen for this study because it has been found commonly in enrichment cultures established from a wide variety of environmental water samples in all seasons, and both the freshwater and marine forms appear to be cosmopolitan $(36,37)(27,29)$. Many laboratory studies have used Paraphysomonas as an experimental organism, representative of the heterotrophic nanoplankton, in ecological studies, and thus, extensive physiological information exists for this organism $(6,7,11,12,16,17,19)$.

The occurrence of $P$. imperforata in plankton communities, and the factors which may control its abundance and distribution in coastal marine environments were examined with species-specific oligonucleotide probes developed for $P$. imperforata (8) in this study. P. imperforata was found to occur at low densities in coastal waters, constituting no more than $1 \%$ of TNAN in all the samples examined, and did not vary seasonally. Although such low abundances were observed in field samples, $P$. imperforata often dominated the nanoplankton in natural samples enriched with bacteria. Water temperature, small differences in the absolute abundances of $P$. imperforata and nanoplankton grazers appeared to play a role in determining whether $P$. imperforata dominated enrichment cultures. 
directly or indirectly via a secondary reporter molecule) so that cells hybridized with probes may be directly observed by epifluorescence microscopy, confocal laser scanning microscopy or flow cytometry $(1,10,22,25,32)$. When used in combination with a recently developed quantitative in situ hybridization method, oligonucleotide probes were also shown to be applicable for detecting and quantifying small protists in field samples by epifluorescence microscopy (23).

P. imperforata is a heterotrophic, free-living flagellate within the Class Chrysophyceae. The cells are typically spherical in shape and range in size from 4 to 18 $\mu \mathrm{m}$ in diameter. This species and other members of the genus are identified by the silica scales that cover the organism. P. imperforata was chosen for this study because it has been found commonly in enrichment cultures established from a wide variety of environmental water samples in all seasons, and both the freshwater and marine forms appear to be cosmopolitan $(36,37)(27,29)$. Many laboratory studies have used Paraphysomonas as an experimental organism, representative of the heterotrophic nanoplankton, in ecological studies, and thus, extensive physiological information exists for this organism $(6,7,11,12,16,17,19)$.

The occurrence of $P$. imperforata in plankton communities, and the factors which may control its abundance and distribution in coastal marine environments were examined with species-specific oligonucleotide probes developed for $P$. imperforata (8) in this study. P. imperforata was found to occur at low densities in coastal waters, constituting no more than $1 \%$ of TNAN in all the samples examined, and did not vary seasonally. Although such low abundances were observed in field samples, $P$. imperforata often dominated the nanoplankton in natural samples enriched with bacteria. Seasonal changes in water temperature, small differences in the absolute abundances of $P$. imperforata and nanoplankton grazers appeared to play a role in determining whether $P$. imperforata dominated enrichment cultures. 


\section{Materials and methods}

Sampling sites and sampling schedule. Water samples were collected from several coastal environments to examine the geographical distribution and abundance of $P$. imperforata among the nanoplankton. The sampling locations were Vineyard Sound (Falmouth) and Great Harbor (Woods Hole) in Massachusetts, from seven estuarine sampling sites on Long Island (Orient Harbor, West Neck Bay, Coecles Harbor, Northwest Creek, Northwest Harbor, Quantuck Creek and Quantuck Canal) in New York, and from Ferry Reach, Bermuda. The Massachusetts and Bermuda water samples were mesotrophic while the Long Island water samples were eutrophic and contained high algal biomass. At each site, samples were collected at a depth of approximately $0.1-0.2 \mathrm{~m}$ and preserved with formaldehyde to a final concentration of $3.7 \%$. Samples were stored at $4^{\circ} \mathrm{C}$ and processed within a week of collection.

The seasonal abundance of $P$. imperforata was examined by sampling at the Vineyard Sound site over a period of 17 months beginning from June 1995. Water samples were collected on the 1st and the 15th of every month (except for the June 2 and August 16, 1995 sampling days) as described above. Samples from June 1995 were preserved as whole seawater samples, but subsequent samples were filtered through 20 $\mu \mathrm{m}$ Nitex screening to remove larger plankton and detrital material before preservation in formaldehyde.

Experiments with enrichment cultures. Vineyard Sound seawater from the same samples collected for analysis of $P$. imperforata seasonal abundance were used 
for heterotrophic nanoflagellate enrichments twice a month over the 17-month sampling period. These enrichments cultures were established to assess the effect of enrichment on $P$. imperforata abundance compared to the TNAN. Yeast extract was added directly to $250 \mathrm{ml}$ of Vineyard Sound seawater at a final concentration of $0.005 \%$ (to promote growth of the natural bacterial assemblage) and incubated in the dark at $20^{\circ} \mathrm{C}$. These enrichments were sampled 4 days later for enumeration of total nanoplankton and P. imperforata. This incubation period allowed peak nanoplankton abundances to be obtained (data not shown). Eight of the enrichment cultures established over the 17month period were also sampled on day 2 and 3 in order to follow changes in the TNAN and $P$. imperforata abundances over the 4 day period. All the enrichments were performed in duplicate except for those established from June 1995 to January 1996.

Three experiments with enrichment cultures were conducted in parallel to the routine enrichment cultures to assess whether food limitation, initial $P$. imperforata abundance or grazing by nanoplankton consumers affected the success of $P$. imperforata in enrichment cultures. Water samples used in these experiments were taken from the same water samples collected for monitoring the seasonal abundance of $P$. imperforata in Vineyard Sound and for establishing the routine enrichment cultures.

In the first experiment, I hypothesized that the absolute abundance of $P$. imperforata might affect the degree to which $P$. imperforata dominated enrichment cultures. To test this hypothesis, $P$. imperforata (Clone VS1) was added to enrichment cultures to increase the initial density of $P$. imperforata relative to their natural densities on two occasions (Aug. 15 and Sept. 1, 1996). The concentration of $P$. imperforata added was approximately $3 \%$ of the TNAN (Aug. 15) or $<1$ and $1 \%$ of the TNAN (Sept. 1). Each addition was performed in duplicate. All the enrichment cultures were sampled on the first day of enrichment and on day 3 and 4 for enumeration of TNAN and $P$. imperforata. 
In the second experiment, I examined whether grazing by nanoplankton consumers might play a role in determining $P$. imperforata dominance. Grazing experiments with enrichment cultures were conducted using Vineyard Sound seawater collected on three occasions (April 15, May 15 and June 15, 1996). Water samples were divided into 3 treatments, each consisting of 0.5 liter of seawater contained in 1 liter polycarbonate bottles, performed in duplicate: whole seawater, $20 \mu \mathrm{m}$ filtrate of whole seawater and $5 \mu \mathrm{m}$ filtrate of whole seawater. The $5 \mu \mathrm{m}$ filtrate presumably excluded larger-sized plankton that could feed on $P$. imperforata and contained only small protists and picoplanktonic cells. Yeast extract was added to each bottle at a concentration of $0.005 \%$. All the treatments were incubated in the dark at $20^{\circ} \mathrm{C}$ and sampled on the first day of enrichment and on day 4,6 and 7 for counts of TNAN and $P$. imperforata.

The effect of food limitation on $P$. imperforata dominance in enrichment cultures was assessed on two occasions (September 15 and October 1,1996). In each experiment, one set of enrichment cultures was supplemented with bacteria (after heterotrophic nanoplankton in the cultures had significantly removed the original enriched bacterial population) and compared to another set of enrichment cultures that were not supplemented with bacteria. The bacterial concentrate was prepared by growing bacteria in a 1 liter filtrate (Whatman GF/F filters) of Vineyard Sound seawater on $0.5 \%$ yeast extract for 2 days, pelleting the bacteria by centrifugation (10,000 rpm for $15 \mathrm{~min}$.$) and then, resuspending the bacteria in approximately 50 \mathrm{ml}$ of sterile Vineyard Sound seawater. Seven $\mathrm{ml}$ of this bacterial concentrate was added to the enrichment cultures in duplicate beginning on day 3 (when the flagellates reached late exponential growth), and everyday thereafter until day 6. The final concentration of bacteria in the cultures was estimated to be approximately $10^{8}$ cells $\mathrm{ml}^{-1}$ after the 
additions. The enrichment cultures were sampled on day 1, 2 and/or 3, 4, 5 and 7 for enumeration of TNAN and $P$. imperforata.

\section{Oligonucleotide probe preparation, detection and enumeration of $P$.} imperforata and total nanoplankton. Oligonucleotides were synthesized with an amino group or a biotin at the $5^{\prime}$ terminus (Operon Technologies, Inc., Alameda, CA; Eppendorf, Madison, WI; Oligos Etc. Inc., Wilsonville, OR). The amino groups of aminomodified oligonucleotides were coupled with biotin (Molecular Probes Inc., Eugene, OR), purified through Sephadex G-25 columns and finally purified by polyacrylamide gel electrophoresis as previously described (22).

Detection and enumeration of TNAN were performed using oligonucleotide probes complementary to regions on the small subunit (SSU) ribosomal RNA that are conserved for all eukaryotes. The probes were as follows (the numbers correspond to Escherichia coli SSU rRNA base positions): EUK 1209 (5'-GGG CAT CAC AGA CCT G-3') (15), EUK 502 (5'-ACC AGA CTT GCC CTC C-3') (1), and EUK 309 (5'-TCA GGC TCC CTC TCC GG3') (33).

Probes specific for $P$. imperforata were designed based on SSU rRNA sequences obtained from clonal cultures of $P$. imperforata originally isolated from Vineyard Sound seawater (8). A combination of three oligonucleotide probes with the following sequences were used for enumeration of $P$. imperforata (the numbers also correspond to E. coli SSU rRNA base positions): PIMP 635 (5'-TGA GGG GCG GAC CGG TCG CC-3'), PIMP 663 (5'-GGA CGC AGA GAC CAG GTG CAC A-3') and PIMP 1683 (5'-CCA AGC CGC AGT CCG AGA-3'). The specificity of each probe was tested against several clones of $P$. imperforata and a variety of closely and distantly related protists in slot blot hybridization experiments (8). The $P$. imperforata clones used for probe testing originated from Vineyard Sound and Waquoit Bay, MA; Sakonnet River, RI; Santa Barbara 
Channel, CA; and England. Wash temperatures for appropriate specificity were determined empirically by slot blot and whole cell hybridizations. The $P$. imperforata probes were also tested against three other species of Paraphysomonas, $P$. bandaiensis, P. vestita, and P. butcheri; thirteen other species of chrysophytes spanning 6 families; one species of prasinophyte, dinoflagellate, red alga, bodo and ciliate; two species of synurophytes, prymnesiophytes and diatoms; three species of green algae.

Total nanoplankton and $P$. imperforata were enumerated by the quantitative in situ hybridization method using biotinylated probes and fluorescein (FITC)-labeled avidin (23). Briefly, samples were vacuum-filtered onto $0.4 \mu \mathrm{m}$ polycarbonate filters of Transwell tissue culture inserts (Costar), dehydrated in a series of ethanol washes and prehybridized in hybridization buffer (10X Denhardt's solution, $0.1 \mathrm{mg} \mathrm{m}^{-1}$ of polyadenylic acid, $5 X$ SET buffer $[750 \mathrm{mM} \mathrm{NaCl}, 100 \mathrm{mM}$ Tris- $\mathrm{HCl}\{\mathrm{pH} 7.8\}, 5 \mathrm{mM}$ EDTA], $0.1 \%$ sodium dodecyl sulfate) for at least $45 \mathrm{~min}$. at $40^{\circ} \mathrm{C}$. Oligonucleotide probes were then added to the samples and hybridized overnight at $40^{\circ} \mathrm{C}$. Each probe was used at a final concentration of $2.5 \mathrm{ng} \mu^{-1}$ in all the hybridizations. Following hybridization, samples were washed at $45^{\circ} \mathrm{C}$ in $0.2 \mathrm{X}$ SET buffer $(30 \mathrm{mM} \mathrm{NaCl}, 4 \mathrm{mM}$ Tris- $\mathrm{HCl}\{\mathrm{pH} 7.8\}, 0.2 \mathrm{mM}$ EDTA) for $10 \mathrm{~min}$, incubated with FITC-labeled avidin (20

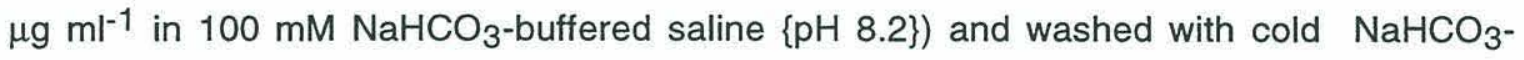
buffered saline to remove unincorporated FITC-avidin. Control hybridizations incubated with FITC-avidin only were also performed for all the samples examined to check for background binding. Filters were finally cut out of the Transwells and mounted on glass slides for observation by epifluorescence microscopy.

The volume of unenriched seawater samples filtered for counts of total nanoplankton and $P$. imperforata ranged from 15 to $25 \mathrm{ml}$ for Vineyard Sound seawater and 3 to $10 \mathrm{ml}$ for Long Island seawater. A volume of $50 \mathrm{ml}$ was filtered for the sample collected from Bermuda. The volumes of enriched seawater samples filtered ranged from 
0.5 to $5 \mathrm{ml}$ depending on the cell density of the TNAN. One hybridization was carried out for each sample. Fluorescence observation and enumeration of FITC-labeled cells were performed at $630 \mathrm{X}$ magnification with a Zeiss Axioskop using a BP450-490 exciter filter and an LP520 barrier filter. Approximately 15 to 30 fields were observed for enumeration of total nanoplankton in unenriched seawater samples but $P$. imperforata cell counts were always obtained from a total of 50 fields. The number of fields observed for enumeration of cells in enrichment samples ranged from 10 to 30 fields. Epifluorescence micrographs of the samples were taken with a Zeiss MC100 camera with Ektachrome 200 ASA color film.

\section{Results}

Abundances and distribution of $P$. imperforata. P. imperforata was either undetectable or at very low abundances in all the coastal water samples examined in this study (Table 1). Samples in which $P$. imperforata was not detected were denoted as $<3-5$ cells $\mathrm{ml}^{-1}$ for Vineyard Sound and Bermuda samples, and as $<13 \mathrm{cells} \mathrm{ml}^{-1}$ for Long Island water samples. These values represented the limit of detection for $P$. imperforata based on the volume of sample filtered, magnification and area counted. The highest abundance of $P$. imperforata detected, $\approx 400$ cells $\mathrm{ml}^{-1}$, originated from the Quantuck Canal sampling site on Long Island, New York. However, typical abundances of $P$. imperforata in all the samples examined were $\leq 50$ cells $\mathrm{ml}^{-1}$. In all the samples, $P$. imperforata represented $\leq 1 \%$ of the total nanoplankton.

Seasonal abundances of $P$. imperforata and TNAN in Vineyard Sound seawater. Total nanoplankton abundances in Vineyard Sound seawater during the 17- 


\begin{tabular}{lccc}
\hline \multicolumn{1}{c}{ Location } & $\begin{array}{c}\text { Total Nanoplankton } \\
\left(\text { cells } \mathrm{ml}^{-1}\right)\end{array}$ & $\begin{array}{c}\boldsymbol{P} \text {. imperforata } \\
\left(\text { cells } \mathrm{ml}^{-1}\right)\end{array}$ & $\%$ of TNAN \\
\hline $\begin{array}{l}\text { Vineyard Sound, MA } \\
\text { (34 sampling days) }\end{array}$ & $1.96 \times 10^{3}-1.28 \times 10^{4}$ & $<5.00 \times 10^{0}-4.93 \times 10^{1}$ & $\leq 1 \%$ \\
Great Harbor, MA & $4.51 \times 10^{3}$ & & $<1 \%$ \\
& & $2.10 \times 10^{1}$ & \\
Long Island, NY & $1.32 \times 10^{4}-1.17 \times 10^{5}$ & $<1.30 \times 10^{1}-4.03 \times 10^{2}$ & $\leq 1 \%$ \\
(7 sampling sites) & & & $<1 \%$ \\
Bermuda & & & \\
\hline
\end{tabular}

Table 1. Abundances of total nanoplankton (TNAN) and $P$. imperforata in coastal waters of Massachusetts, Long Island, NY and Bermuda. 
Figure 1. Seasonal abundance of $P$. imperforata and total nanoplankton in Vineyard Sound seawater. The symbol " $\downarrow "$ denotes the detection limit of $P$. imperforata based on the volume of sample filtered and the magnification and area counted. 


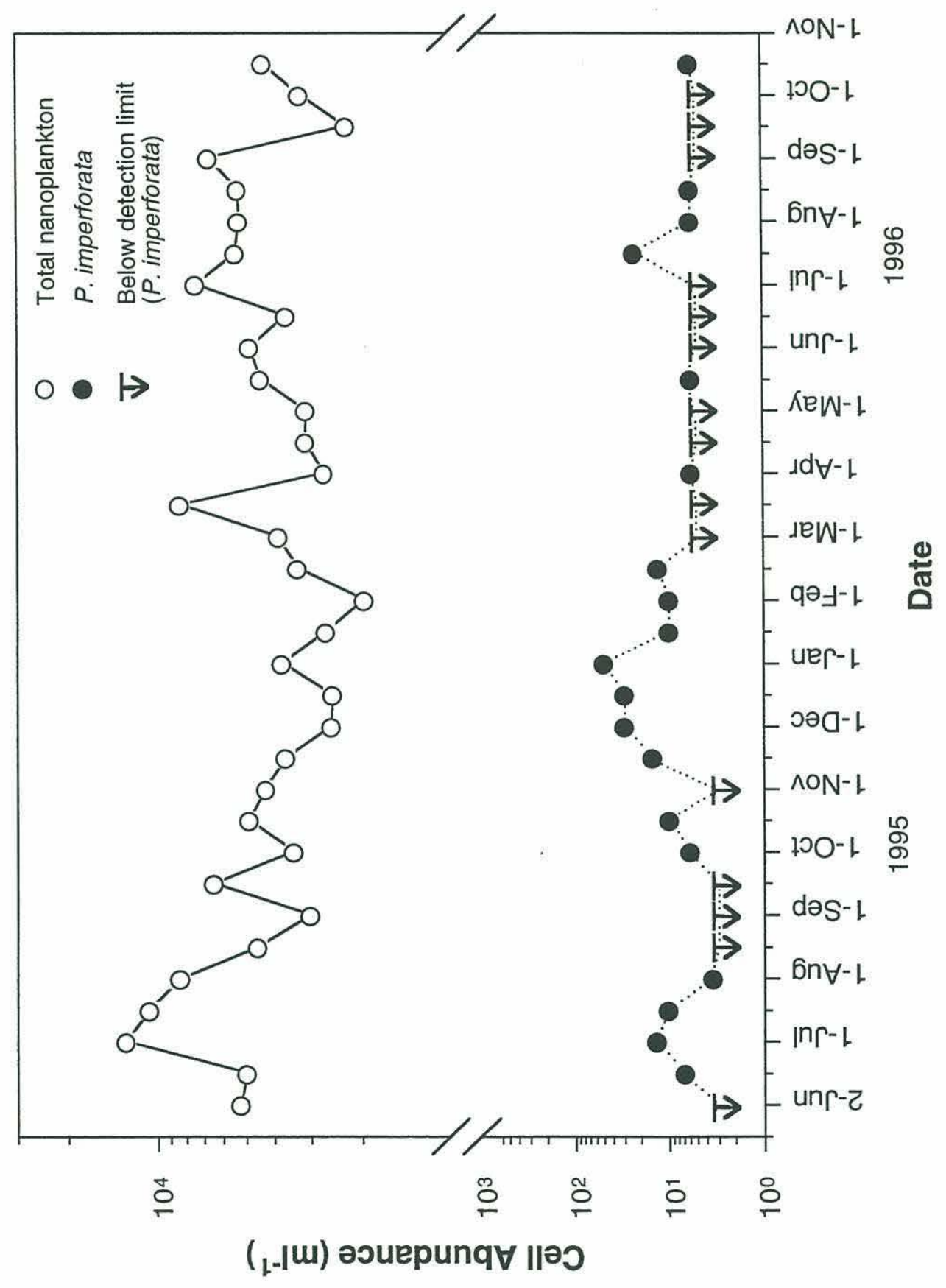


month sampling period oscillated between $2 \times 10^{3}-1 \times 10^{4}$ cells $\mathrm{ml}^{-1}$ (Table 1 and Fig. 1). P. imperforata was often not detected in the water samples, but given that the detection limit of the counting procedure employed was 3-5 cells $\mathrm{ml}^{-1}$ (denoted with the symbol $\downarrow$ in Fig. 1), it was not possible to determine whether $P$. imperforata was actually absent or at very low abundances. When detected, typical abundances of $P$. imperforata were $\approx 10$ cells $\mathrm{ml}^{-1}$ or less, and the highest abundance observed was 49 cells $\mathrm{ml}^{-1}$. These abundances represented $1 \%$ or less of the TNAN in Vineyard Sound seawater. The abundances of heterotrophic nanoplankton (HNAN) were not enumerated in this study (HNAN could not be distinguished from the photosynthetic nanoplankton because ethanol washes during sample preparation bleached photosynthetic pigments), but it is unlikely that $P$. imperforata constituted a large percentage of the HNAN either. Previous studies of HNAN in Vineyard Sound indicated that they are typically $\approx 50 \%$ of the TNAN abundances (4), thus, $P$. imperforata would have constituted $\approx 2 \%$ of the HNAN at most.

\section{Seasonal abundances of $P$. imperforata and TNAN in enrichment}

cultures. The addition of yeast extract to natural seawater samples stimulated growth of the bacterial assemblage within 24 hours. The enriched bacterial concentrations, approximately $10^{8}$ cells $\mathrm{ml}^{-1}$, were two orders of magnitude higher than natural concentrations. Heterotrophic nanoplankton which consisted largely of flagellated protozoa grew in response to the elevated bacterial concentrations, and by the 4th day of incubation, nanoplankton abundances ranged between $5 \times 10^{4}$ and $7 \times 10^{5}$ cells $\mathrm{ml}^{-1}$ over the entire sampling period (Fig. 2).

P. imperforata abundances in enrichment cultures of winter and spring months (from Nov. 1995 to Jun. 1996) constituted a significant fraction of the TNAN abundances and reached densities above $10^{5}$ cells $\mathrm{ml}^{-1}$ (Fig. 2 and 3). The lowest 
Figure 2. Seasonal abundance of $P$. imperforata and total nanoplankton in enrichment cultures started from Vineyard Sound seawater. 


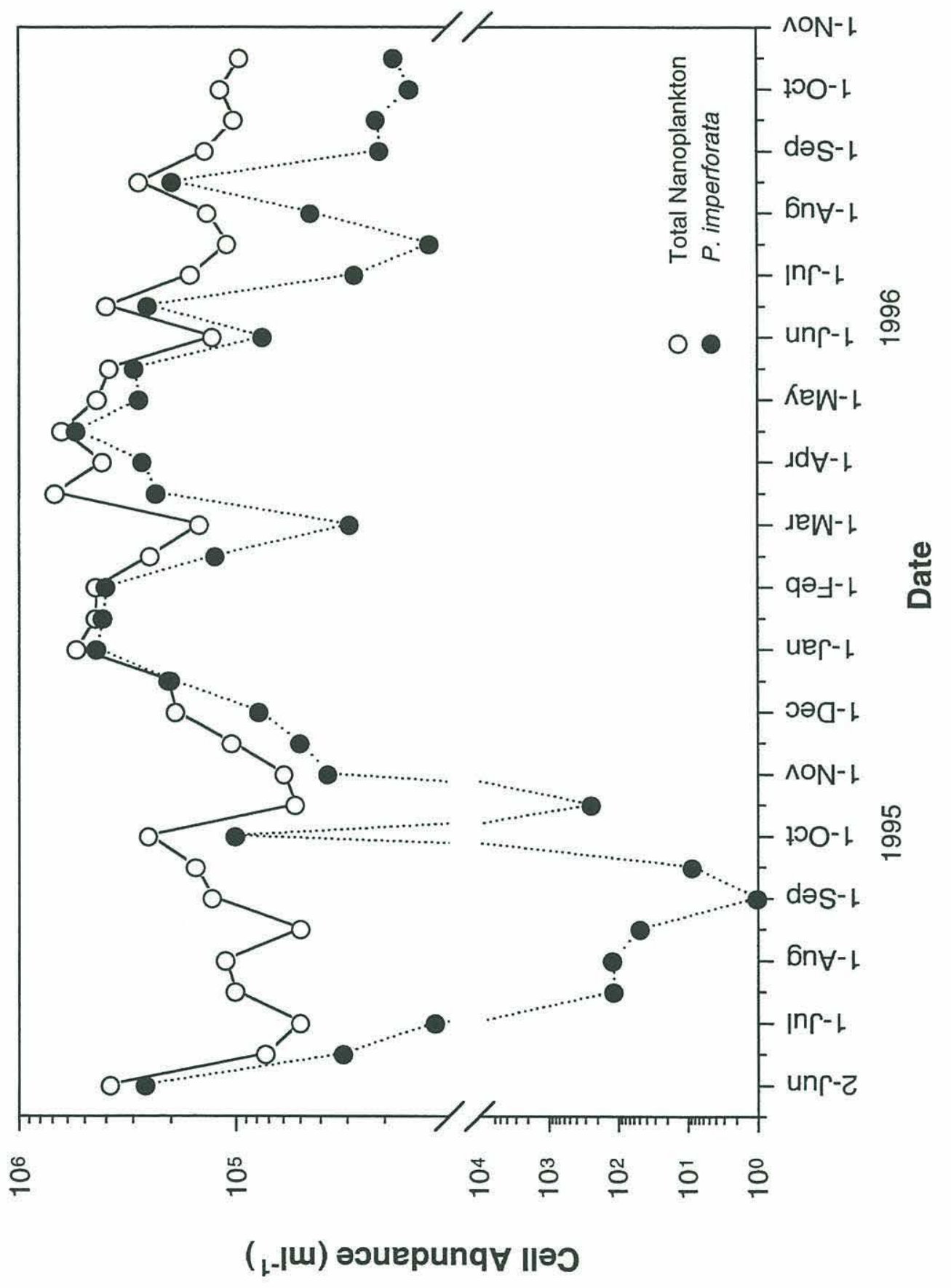


Figure 3. Epifluorescence micrographs of $P$. imperforata in enrichment cultures. $A$ and B: $P$. imperforata cells hybridized with $P$. imperforata-specific probes showing FITC fluorescence. Flagellates and ciliates (oblong cells in B) that were not labeled by the $P$. imperforata probes can be distinguished by their light, yellow autofluorescence. 


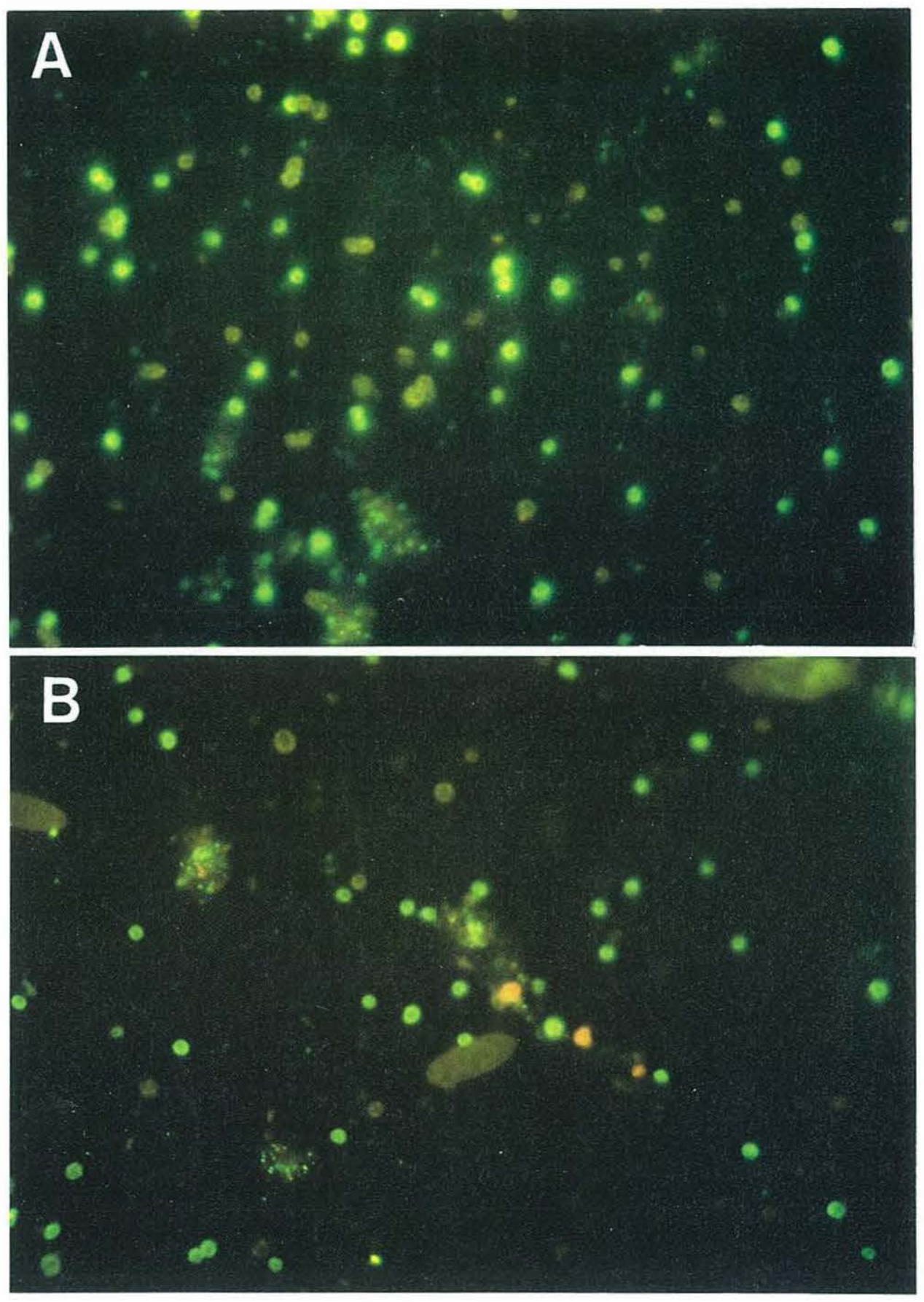


abundances of $P$. imperforata were observed in enrichments cultures of summer and fall of 1995 and 1996 (from Jul. to Oct. of each year). $P$. imperforata abundances were $\leq 2 \times 10^{2}$ cells $\mathrm{ml}^{-1}$ and approximately $2 \times 10^{4}$ cells $\mathrm{ml}^{-1}$ during this period in 1995 and 1996, respectively (with the exception of one sampling day in each year).

In general, the highest $P$. imperforata abundances were obtained in enrichments begun with water samples that were $10^{\circ} \mathrm{C}$ or colder (Fig. 4). Five out of six enrichment cultures in which $P$. imperforata comprised more than $75 \%$ of the TNAN (up to $98 \%$ of the TNAN) were established with water samples in this temperature range. $P$. imperforata averaged less than $1 \%$ and $20 \%$ of TNAN in enrichment cultures during the late summer and fall of 1995 and 1996, respectively (Fig. 4). These periods of low $P$. imperforata coincided with the warmest ambient water temperatures of each year, beginning in July when water temperature approached $20^{\circ} \mathrm{C}$, through October 15 when the water temperature fell to about 15 to $18^{\circ} \mathrm{C}$. Overall, the water temperature during the summer and fall of 1996 (maximum temperature $=21^{\circ} \mathrm{C}$ ) was lower than during 1995 (maximum temperature $=24.5^{\circ} \mathrm{C}$ ).

Changes in population abundances of nanoplankton and $P$. imperforata (also expressed as a $\%$ of TNAN) were monitored everyday (except for day 1) for 4 days on 8 of the 34 sampling dates. The population changes measured on Dec. 15, 1995 and Jan. 15, Sept. 1 and Oct. 15, 1996 are shown in Fig. 5, and are representative of the types of changes observed in other enrichment cultures. Abundances of nanoplankton and $P$. imperforata reached maximum densities on the third or fourth day of incubation. The maximum density of $P$. imperforata in these enrichment cultures also coincided with the highest percentage of $P$. imperforata. These abundances were usually maintained through day 4 (Fig. 5: Dec. 15, 1995 and Jan. 15, Sept. 1, 1996), but in some cases fell dramatically by the fourth day (Fig. 5: Oct. 15, 1996). The decrease in TNAN and $P$. 
143 
Figure 4. Seasonal abundance of $P$. imperforata in absolute cell densities and as a percentage of total nanoplankton (TNAN) in enrichment cultures and seasonal water temperature in Vineyard Sound, MA. 


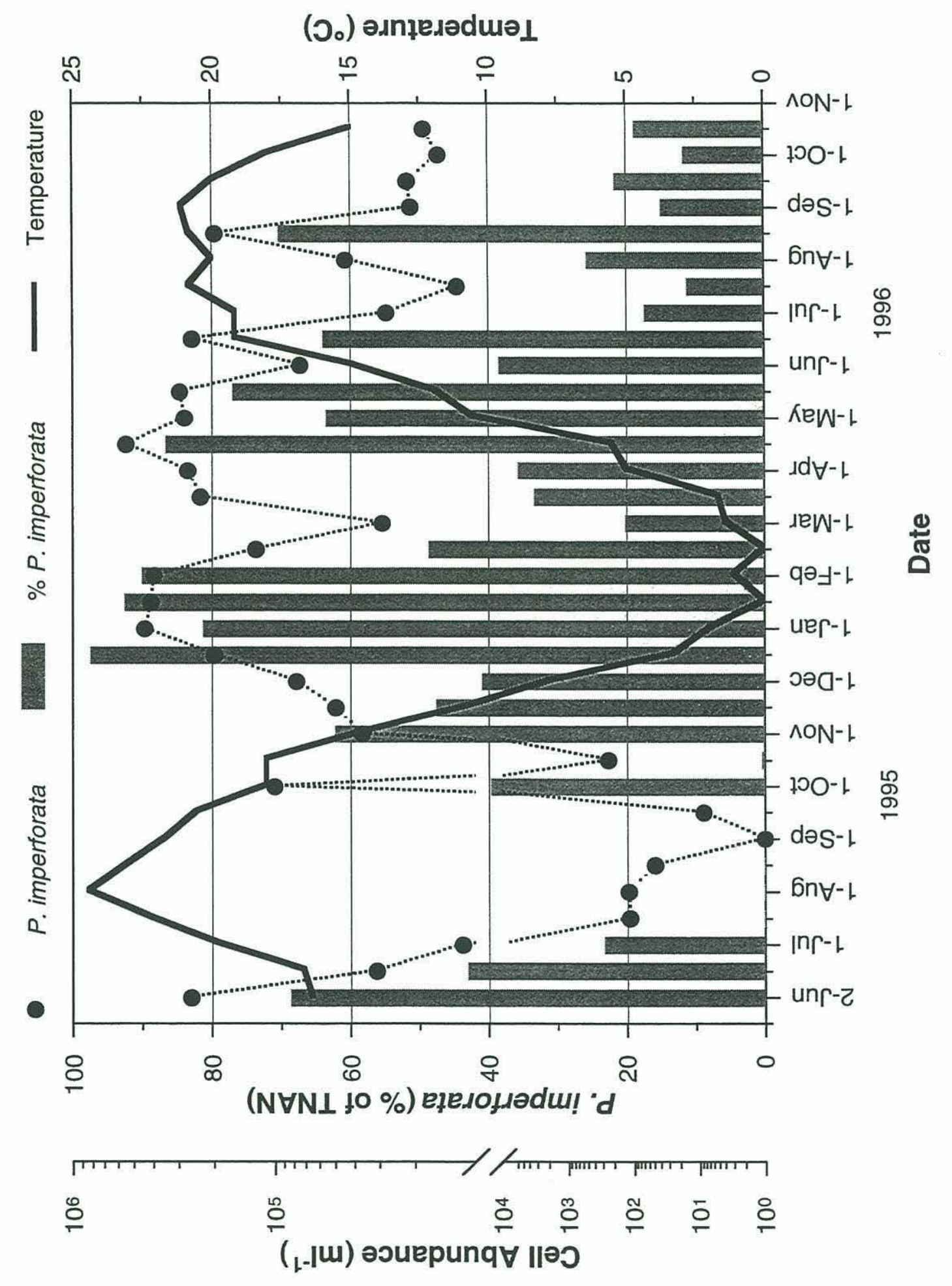


Figure 5. Examples of changes in the abundance of $P$. imperforata and total nanoplankton (TNAN) represented by enrichment cultures started on Dec. 15, 1995, Jan. 15, Sept. 1 and Oct. 15, 1996. Error bars represent the standard error of the mean from duplicate treatments. 


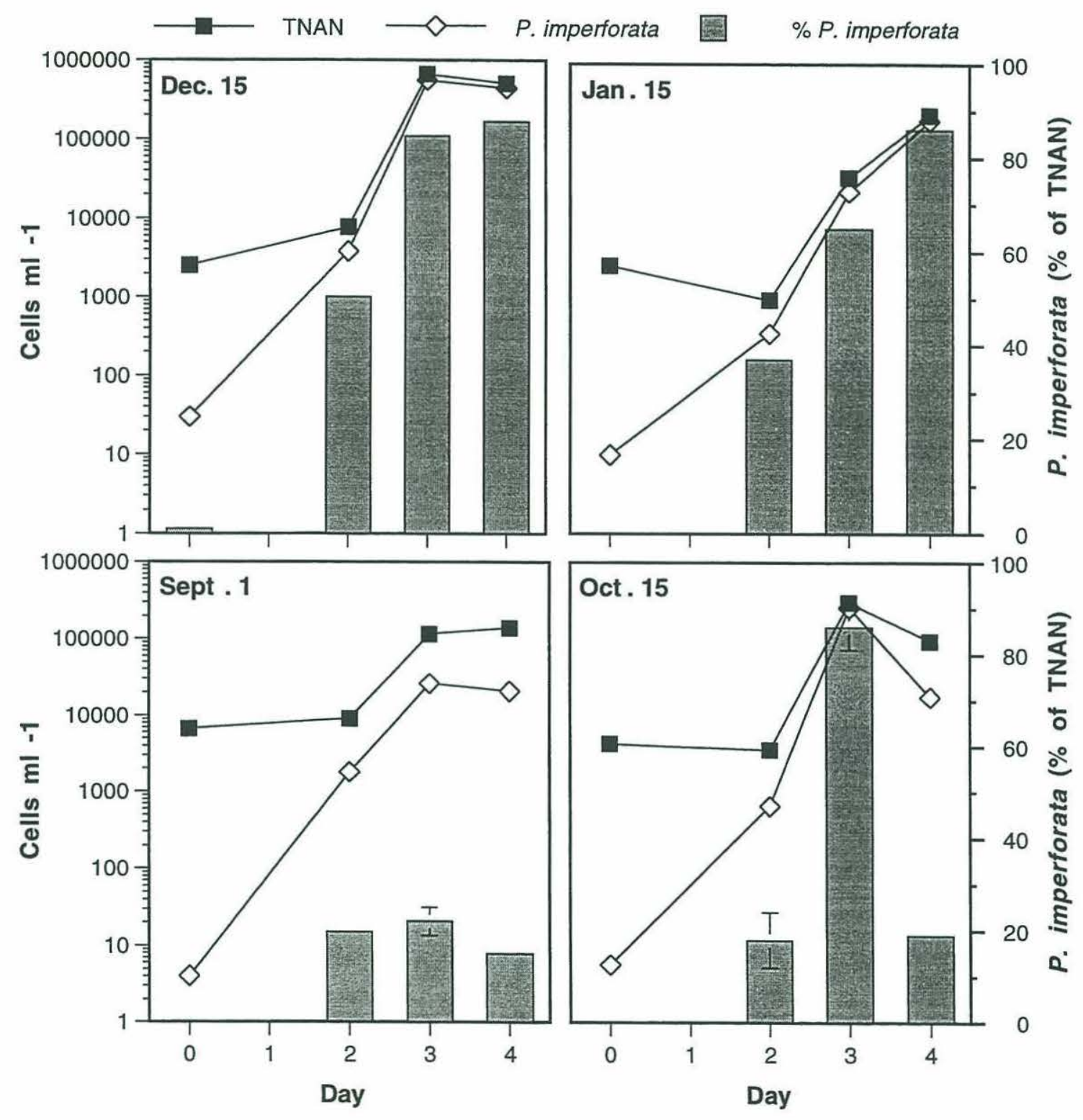


imperforata abundances between the third and fourth day of enrichment was not anticipated based on previous observations of enrichment cultures from Vineyard Sound.

Growth rates of $P$. imperforata in the enrichment cultures were calculated so that they could be compared to values reported for $P$. imperforata in the literature. This comparison was one way to obtain independent confirmation that the probes were accurately detecting $P$. imperforata in the enrichment cultures. The growth rates of $P$. imperforata in the seasonal study were calculated based on changes in abundances over 4 days. However, the time used for growth rate calculations was 3 days based on the assumption that $P$. imperforata, on average, reached their peak abundance on day 3 and remained at that abundance through day 4 (Fig. 5). Growth rates of $P$. imperforata in enrichment cultures started throughout the seasonal study ranged from 2.1 to $3.9 \mathrm{~d}^{-1}$ and averaged approximately $3.1 \mathrm{~d}^{-1}$, with the exception of the summer/fall 1995 period when $P$. imperforata abundances were lowest and their growth rate averaged less than 1 $d^{-1}$.

Effect of initial $P$. imperforata abundance on $P$. imperforata dominance. The importance of initial $P$. imperforata abundance in determining its dominance of enrichment cultures was examined by comparing enrichment cultures with various starting densities of $P$. imperforata. $P$. imperforata from a laboratory culture (Clone VS 1) was added to enrichment cultures to increase the initial abundance of $P$. imperforata relative to their natural densities. Natural densities of $P$. imperforata before enrichment was $\leq 5$ cells $\mathrm{ml}^{-1}(<1 \%$ of the TNAN). Following additions of $P$. imperforata Clone VS1, the initial abundance of $P$. imperforata on Aug. 15, 1996 was $\approx 180$ cells $\mathrm{ml}^{-1}\left(3 \%\right.$ of the TNAN), and on Sept. $1,1996, \approx 10$ cells $\mathrm{ml}^{-1}(<1 \%$ of the TNAN) and $\approx 90$ cells $\mathrm{ml}^{-1}(1 \%$ of the TNAN).

Enrichment cultures with higher initial $P$. imperforata densities were dominated by $P$. imperforata to a greater extent than enrichment cultures with lower 
initial $P$. imperforata densities during the 4 days of incubation (Fig. 6). The maximum densities of $P$. imperforata in treatments with $P$. imperforata Clone VS1 added were approximately 2 - to 5 -fold higher than in enrichment cultures without $P$. imperforata added. In the Aug. 15 experiment, $P$. imperforata constituted up to $95 \%$ of the TNAN in the treatments supplemented with $P$. imperforata compared to $75 \%$ of the TNAN in enrichment cultures without $P$. imperforata added. In the Sept. 1 experiment where starting concentrations of $P$. imperforata were $<5$ cells $\mathrm{ml}^{-1}$ (natural abundance), 15 cells $\mathrm{ml}^{-1}$ and 90 cells $\mathrm{ml}^{-1}, P$. imperforata constituted $22 \%, 79 \%$ and $90 \%$ of TNAN, respectively.

\section{Effect of nanoplankton grazers on $P$. imperforata dominance.} Enrichment cultures were performed with whole seawater, $<20 \mu \mathrm{m}$ fractionated seawater and $<5 \mu \mathrm{m}$ fractionated seawater to test whether nanoplankton grazers controlled the degree to which $P$. imperforata dominated the enrichment cultures. The whole seawater and the $<20 \mu \mathrm{m}$ enrichment cultures were expected to contain zooplankton larger than $5 \mu \mathrm{m}$ that could potentially consume $P$. imperforata but the $<5$ $\mu \mathrm{m}$ enrichment cultures should only contain small protists like $P$. imperforata .

Increases in the TNAN among whole seawater, $<20 \mu \mathrm{m}$ and $<5 \mu \mathrm{m}$ fractions were similar after 4 days of enrichment in all three experiments conducted on April 15, May 15 and June 15, 1996 (Fig 7). P. imperforata comprised similar percentages of the TNAN in the $<5 \mu \mathrm{m}$ fractions, $<20 \mu \mathrm{m}$ fractions and the whole seawater enrichment cultures on day 4. Removal of nanoplankton, microzooplankton and macrozooplankton grazers therefore did not affect growth of the TNAN or the ability of $P$. imperforata to dominate the TNAN during the first 4 days of enrichment. However, differences in TNAN and $P$. imperforata abundances were apparent between the $<5 \mu \mathrm{m}$ and the $<20 \mu \mathrm{m}$ fractions or whole seawater treatments on day 6 in two of the experiments, and on day 7 
Figure 6. Changes in the abundance of $P$. imperforata and total nanoplankton (TNAN) in enrichment cultures with and without additions of $P$. imperforata Clone VS1. Experiments were performed with enrichment cultures started on Aug. 15 and Sept. 1, 1996. The dotted bars and line represent changes in $P$. imperforata abundance in enrichment cultures that were supplemented with $P$. imperforata to a final density of 10 cells $\mathrm{ml}^{-1}$. Error bars represent the standard error of the mean from duplicate treatments. 

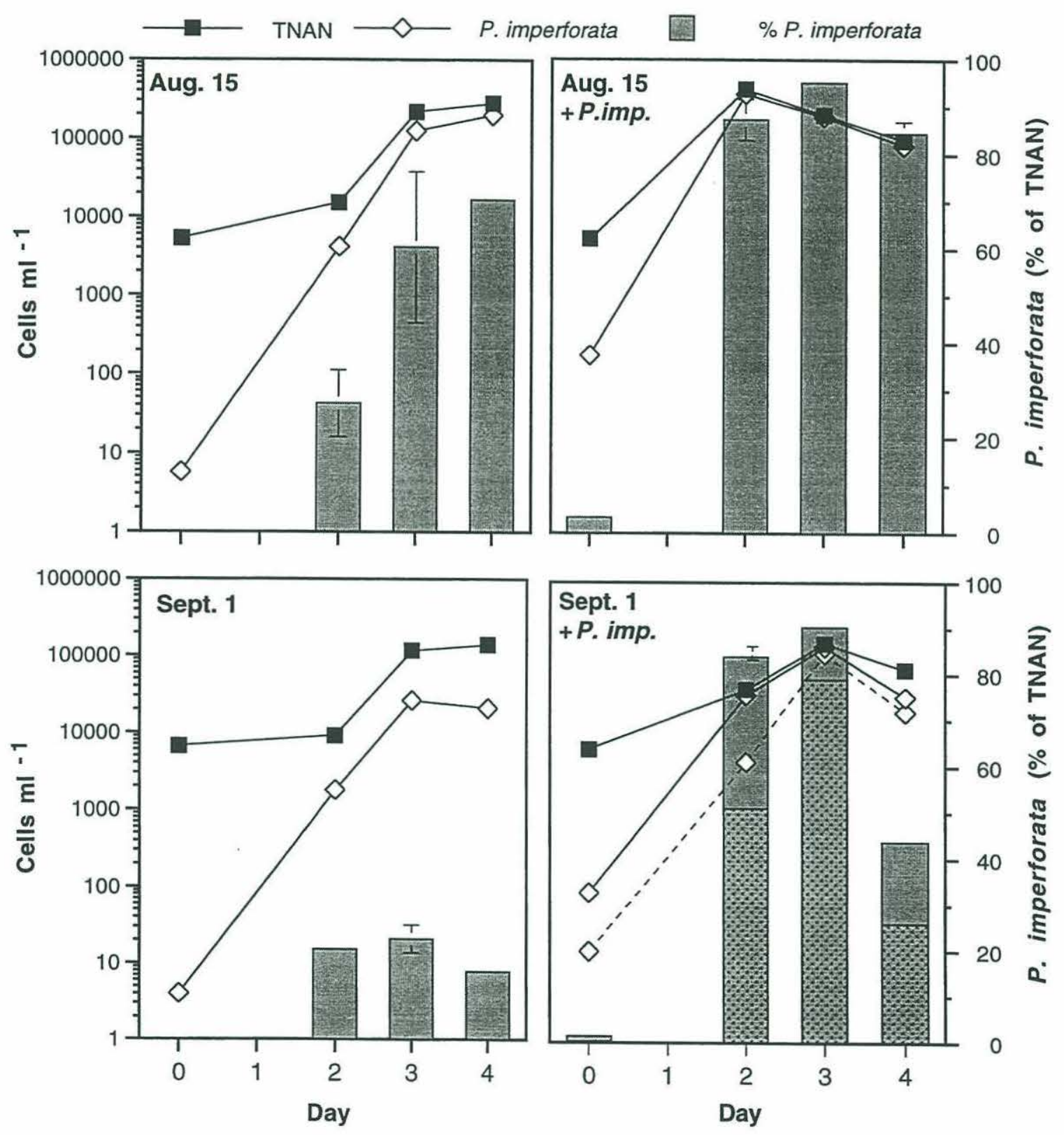
Figure 7. Changes in the abundance of total nanoplankton (TNAN) and P. imperforata in whole seawater (WSW), $<20 \mu \mathrm{m}$ and $<5 \mu \mathrm{m}$ treatments of grazing experiments conducted with enrichment cultures started on Apr. 15, May 15 and June 15, 1996. The $<20 \mu \mathrm{m}$ and $<5 \mu \mathrm{m}$ treatments contained seawater prefiltered through $20 \mu \mathrm{m}$ and 5 $\mu \mathrm{m}$ Nitex screening, respectively. Error bars represent the standard error of the mean from duplicate treatments. 

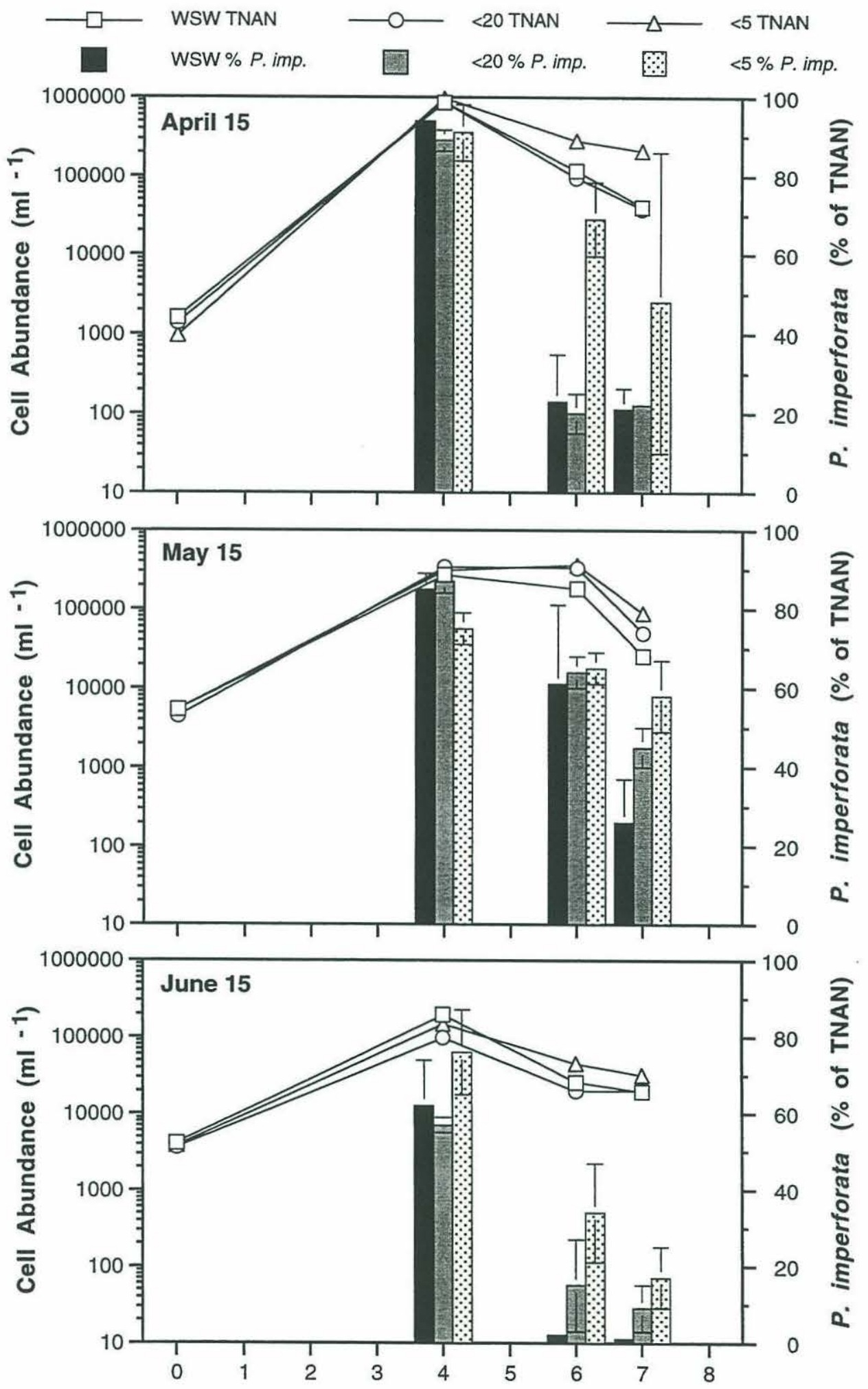

Time (d) 
in all three experiments. By day $7, P$. imperforata constituted a higher percentage of the TNAN in the $<5 \mu \mathrm{m}$ fractions than the $<20 \mu \mathrm{m}$ fractions or whole seawater in all three experiments. Differences in $P$. imperforata abundances were also greater between the $<5 \mu \mathrm{m}$ and whole seawater enrichment cultures than between the $<5 \mu \mathrm{m}$ and $<20 \mu \mathrm{m}$ treatments during the May 15 and June 15 experiments, presumably because prefiltration with $20 \mu \mathrm{m}$ Nitex screening removed micro- and macrozooplankton grazers of the nanoplankton including $P$. imperforata.

The effect of food availability on $P$. imperforata dominance. Bacteria were added to enrichment cultures after 72 hours (3 days) of incubation and every 24 hours thereafter until day 6 in order to examine whether food limitation affected $P$. imperforata dominance. TNAN abundances increased to approximately $2 \times 10^{5}$ cells ml-1 and $P$. imperforata constituted approximately $60 \%$ of the TNAN on day 3 , following the initial enrichment. TNAN in the enrichment cultures remained constant (Sept. 15 experiment) or increased slightly (Oct. 1 experiment) from day 3 to day 7 when bacteria were added daily, but TNAN in the enrichment cultures without addition of bacteria decreased by approximately 10 -fold during this period (Fig. 8).

The abundances $P$. imperforata ( $\%$ of the TNAN) in enrichment cultures with and without the addition of bacteria, however, decreased dramatically between day 3 and day 7 in both experiments. P. imperforata decreased to about 20 to $30 \%$ of the TNAN after the fourth day of incubation and was no longer detected by day 6 of the experiments despite the availability of bacteria. These results indicated that food supply was not important for maintaining $P$. imperforata dominance in enrichment cultures after the onset of stationary growth . 
155 
Figure 8. Changes in the abundance of total nanoplankton (TNAN) and $P$. imperforata in enrichment cultures started on Sept. 15 and Oct. 1, 1996, with and without bacteria added. Bacteria were added to the treatments on day $3,4,5$ and 6 on both sampling dates. 

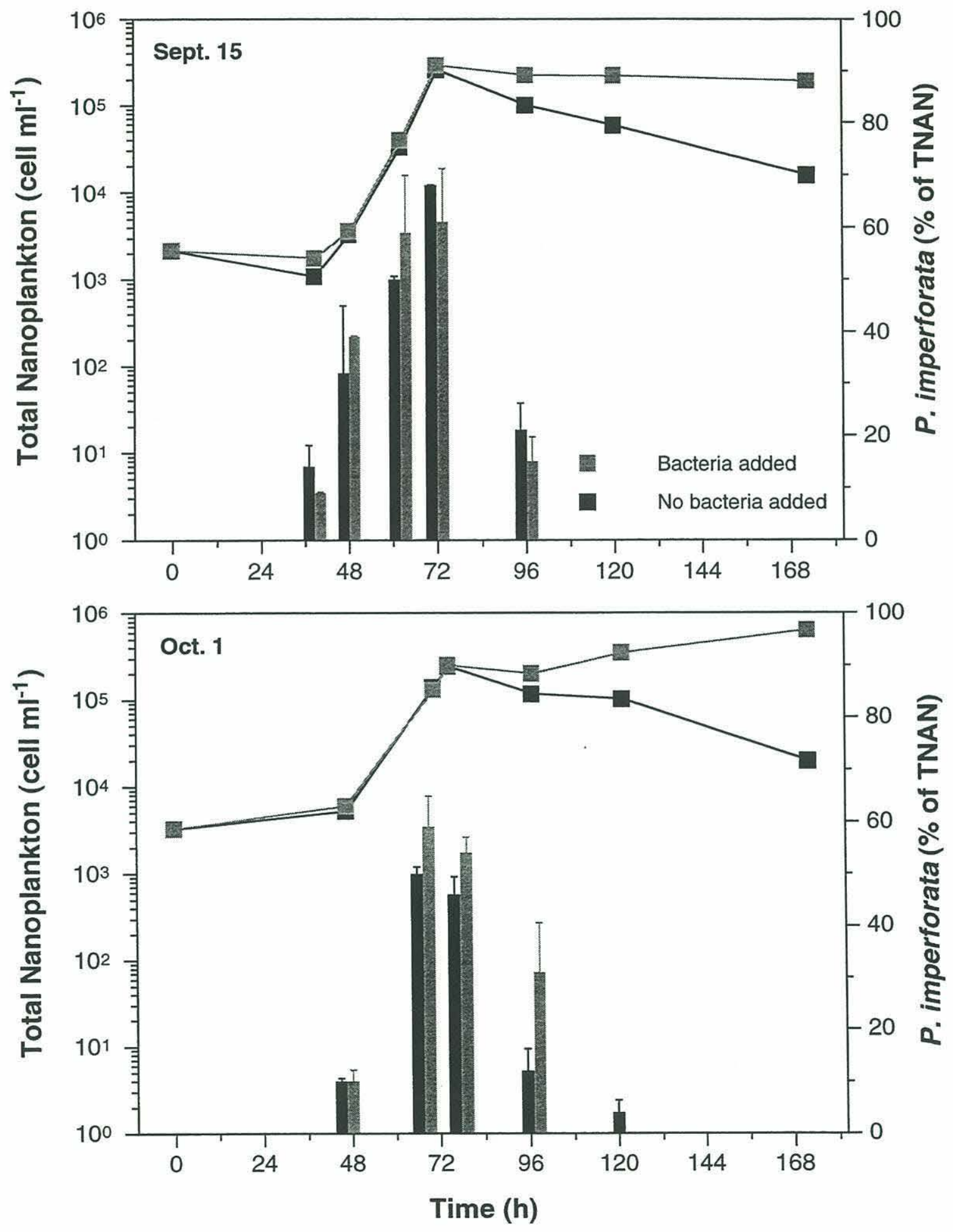


\section{Discussion}

A simple and efficient method that can be used routinely for documenting the quantitative occurrence of different species is required in order to study the population abundances and distribution of small protists in aquatic environments. Oligonucleotide hybridization probes which target the rRNA provide a means to directly measure the abundance of species or groups of organisms in cultures as well as in natural water samples. In this study, the spatial and temporal variability of $P$. imperforata abundance in coastal environments was examined using a combination of three eukaryote-specific probes and three $P$. imperforata-specific probes for detecting and enumerating TNAN and P. imperforata populations, respectively. Hybridization with eukaryote-specific probes has been found to yield counts of TNAN in natural water samples that were comparable to cell counts obtained by conventional 4', 6-diamidino-2-phenylindole (DAPI) (26) and acridine orange staining (18) (23). Counts of TNAN obtained from hybridizations with eukaryote probes were also essential for evaluating the efficieny of hybridizations throughout this study.

Natural abundances of $P$. imperforata in coastal water samples were extremely low irrespective of the location or the time of year. $P$. imperforata abundances in the eutrophic coastal waters of Long Island, NY did not differ greatly from abundances found in more mesotrophic, coastal waters such as Vineyard Sound and Great Harbor, MA, with the exception of Quantuck Canal, Long Island (Table 1). The highest abundance of $P$. imperforata (400 cells $\mathrm{ml}^{-1}$ ) was measured at Quantuck Canal but at this site, $P$. imperforata still constituted only $1 \%$ of the TNAN. The low abundances of $P$. imperforata therefore appear to be a common phenomenon based on the coastal water samples examined in this study. Similarly, seasonal abundances of $P$. imperforata examined at 
the Vineyard Sound sampling site remained consistently low and constituted no more than $1 \%$ of TNAN over a 17-month sampling period (Table 1, Fig. 1).

It is possible that fluorescent in situ hybridization with $P$. imperforata probes either under- or overestimated the abundances of $P$. imperforata in field samples. The abundances of $P$. imperofrata enumerated by probe hybridization could have been lower than actual abundances if the rRNA content of $P$. imperforata cells in field populations were low. Low rRNA content would affect probe binding, and thus, fluorescence signal so that target cells were below the limit of detection. $P$. imperforata abundances could also have been underestimated if different clones of $P$. imperforata in natural samples varied in their sequences at the target sites of the probes and prevented probe binding. An overestimation of $P$. imperforata abundances, on the other hand, might be caused by nonspecific binding of the probes to species other than $P$. imperforata.

Several lines of evidence indicate that the $P$. imperforata probes and the in situ hybridization method for enumerating nanoplanktonic protists were giving accurate estimates of $P$. imperforata in field samples: 1) these probes detected clones of $P$. imperforata isolated from several different marine habitats in slot blot hybridizations and whole cell hybridizations ( see section in "material and methods" for $P$. imperforata clones tested in specificity studies; 8); 2) probes gave predicted abundances of $P$. imperforata in seawater samples inoculated with known concentrations of $P$. imperforata (Fig. 6); 3) the growth rate of $P$. imperforata in the Aug. 15 and Sept. 1 enrichment cultures supplemented with $P$. imperforata averaged $3.1 \mathrm{~d}^{-1}$ and was the same as $P$. imperforata growth rates in cultures without $P$. imperforata added (Fig. 6); 4) $P$. imperforata was detected with these specific probes using the same quantitative in situ hybridization technique that has been shown to give accurate estimates of TNAN with eukaryote-specific probes (23). 
While there are no studies in the literature with which to compare the $P$. imperforata abundances obtained, a study by Fenchel (14) provides some data on the quantitative occurrence of the major groups of heterotrophic flagellates in a coastal marine environment based on identifications of broad, group-specific diagnostic features with epifluorescence microscopy. Estimates of Paraphysomonas spp. abundance by Fenchel during a 30 day period ranged from less than 10 to 200 cells $\mathrm{ml}^{-1}$, and a most probable number (MPN) estimate of Paraphysomonas spp. on one of the sampling days gave a density of 40 cells $\mathrm{ml}^{-1}$. These estimates fall within the range of $P$. imperforata abundances enumerated by hybridization probes and agree with our observation that $P$. imperforata abundances were low in coastal waters. The estimates by Fenchel, however, must be considered with some caution because naked and scaled chrysomonads cannot be properly distinguished by epifluorescence microscopy, nor can the different species of Paraphysomonas.

The low abundances of $P$. imperforata in coastal water samples were in stark contrast to the ability of this species to dominate the nanoplankton in the same water samples enriched with bacteria (Fig. 2). $P$. imperforata grew rapidly in most of the enrichment cultures once bacteria became available and dominated the TNAN. The prevalence of $P$. imperforata in enrichment cultures is also supported by observations from a number of taxonomic studies which documented $P$. imperforata as a common species in marine habitats. Water samples in these studies were often subjected to some form of enrichment cultivation before they were prepared for observation by electron microscopy $(20,24,36,37)$.

The ability of $P$. imperforata to initiate growth and division rapidly once prey organisms became available may be an ecologically important survival strategy that allows $P$. imperforata to exploit short-lived food supplies present in heterogeneous environments such as marine snow particles in oligotrophic waters or in coastal areas 
with periodic or seasonal influx of nutrients. Fenchel also proposed encystment, which maximizes the survival period, as an alternative behavior determining the fitness of a protist, but $P$. imperforata, unlike a number of other heterotrophic flagellates, has never been observed to form cysts $(13,28)$. The "feast and famine" existence may indeed confer a higher fitness for $P$. imperforata than encystment and partly explain the cosmopolitan distribution of this species.

Seasonal differences in the abundance of $P$. imperforata and the extent to which they dominated enrichment cultures were also observed (Fig. 4). P. imperforata tended to dominate enrichment cultures established in the winter/spring months but not in the summer/fall months (Fig. 4). Temperature appears to play role in determining the seasonal dominance of $P$. imperforata in these enrichment cultures. All the enrichment cultures in the seasonal study were incubated at $20^{\circ} \mathrm{C}$. Consequently, cells in water samples collected during the winter/spring months (average water temperature was $\approx 5^{\circ} \mathrm{C}$ ) were subjected to greater temperature shifts than cells in water samples collected during the later summer/fall (when water temperature averaged $\approx 18$ to $20^{\circ} \mathrm{C}$ ). The success of $P$. imperforata in enrichment cultures started during the winter/spring months therefore might simply be due to the ability of $P$. imperforata to survive the drastic change in temperature better than other flagellates in cold water samples. Flagellates which were not tolerant of drastic temperature shifts (especially from cold to warm water) could have survived in enrichment cultures established during the late summer/fall months to outcompete $P$. imperforata. Alternatively, species which preferred warm water and could outcompete $P$. imperforata might be dominant at that time of the year, especially in the late summer/fall of 1995 when the average water temperature was much warmer than in 1996.

The timing of sampling the enrichment cultures was also likely to have caused some of the variability observed in $P$. imperforata dominance in the seasonal study. 
Enrichment cultures from the seasonal study were sampled after 4 days of incubation, which was when TNAN and $P$. imperforata typically reached stationary growth phase and when $P$. imperforata constituted the maximum \% of TNAN (Fig. 5 and 6). However, there were also instances when $P$. imperforata abundances decreased dramatically between the third and fourth day of incubation so that abundances (absolute numbers and as a $\%$ of TNAN) on the fourth day did not reflect their maximum abundances (Fig. 5: Oct. 15; Fig. 6: Sept.1+P. imp.; Fig. 7). It is not possible to determine which sampling dates were affected by such a decrease, but the Sept. 1 enrichment culture demonstrated that the low abundances of $P$. imperforata were not always caused by declines in $P$. imperforata abundances by the time of sampling on day 4 (Fig. 5 and 6). $P$. imperforata in the Sept. 1 enrichment culture was never the dominant species and only constituted a low $\%$ of TNAN throughout the 4 days of incubation.

Enrichment cultures supplemented with $P$. imperforata cells demonstrated that initial cell densities affected the ability of $P$. imperforata to dominate enrichment cultures (Fig. 6). Cultures started with higher densities of $P$. imperforata were consistently dominated by $P$. imperforata to a greater extent than those with lower initial $P$. imperforata densities. In the Sept. 1 enrichment culture, the initial $P$. imperforata density was less than 5 cells $\mathrm{ml}^{-1}$ and $P$. imperforata never constituted more than $20 \%$ of the TNAN. However, increasing the density of $P$. imperforata (by adding cultured $P$. imperforata Clone VS1) to just 10 cells $\mathrm{ml}^{-1}$ allowed $P$. imperforata to dominate the enrichment culture, constituting almost $80 \%$ of the TNAN. Based on these results, it appears that small differences in the absolute abundance of $P$. imperforata at the beginning of the enrichment cultures was sufficient to allow $P$. imperforata to outgrow flagellate competitors and eventually dominate the enrichment cultures, or vice versa. 
Nano- to macrozooplankton-sized grazers did not have any effect on $P$. imperforata dominance during the first 4 days of the enrichment cultures. TNAN abundances and the \% of TNAN that was comprised of $P$. imperforata were essentially the same in the $<5 \mu \mathrm{m},<20 \mu \mathrm{m}$ and whole seawater treatments after 4 days of growth, suggesting that grazing by plankton larger than $5 \mu \mathrm{m}$ did not play an important role in controlling the abundance of $P$. imperforata during the initial period of enrichment. These grazers, however, did affect the $P$. imperforata and nanoplankton population after day 4. The TNAN and $P$. imperforata decreases in the $<5 \mu \mathrm{m}$ treatments represented cell mortality presumably due to food limitation for all the treatments. Decreases in TNAN and $P$. imperforata abundances in the whole seawater and $<20 \mu \mathrm{m}$ treatments, however, were greater than in the $<5 \mu \mathrm{m}$ treatment. This result indicates the presence of nano- to macrozooplankton-sized grazers of $P$. imperforata in the water samples. In general, the larger grazers present in whole seawater appeared to be more important as grazers of $P$. imperforata because $P$. imperforata decreased more dramatically in the whole seawater than in the $<20 \mu \mathrm{m}$ treatment which excluded the microzooplankton and macrozooplankton grazers. This result is not unexpected because the size of $P$. imperforata is likely to have made them more readily consumed by the micro- or macrozooplankton than nanoplanktonic grazers.

Prey abundance was also not important in maintaining $P$. imperforata dominance even though it was likely a major influence during the initial enrichment and allowed $P$. imperforata to increase by up to two orders of magnitude (Fig. 8). $P$. imperforata in most of the enrichment cultures responded quickly to increased prey concentrations and depleted the bacteria by the third or fourth day of incubation. The subsequent addition of bacteria, however, did not prevent $P$. imperforata abundances from decreasing dramatically. The cause of the rapid disappearance of $P$. imperforata in the enrichment cultures is not clear. $P$. imperforata is capable of cannibalism but it seems unlikely 
that $P$. imperforata had resorted to cannibalism because it is normally a behavior in response to starvation (16), and the enrichment cultures had been continuously supplied with bacteria soon after they were depleted. The bacteria provided as food $(H$. halodurans) is also a species that is readily consumed by laboratory cultures of $P$. imperforata (9). P. imperforata might also have resorted to cannibalism in response to cell-to-cell contact when it reached peak abundances but no evidence of this behavior was observed in the cultures. Nanoplanktonic grazers were perhaps the most likely cause of $P$. imperforata disappearance (Fig. 7) but this would imply that the grazers were selectively feeding on $P$. imperforata. Nevertheless, no obvious grazers such as ciliates or dinoflagellates that might have been voraciously feeding on $P$. imperforata were actually observed at that time, and it is not known whether or not selective grazers of $P$. imperforata exists. Waste accumulation was possibly a major factor that caused $P$. imperforata decreases during the "late" stages of enrichment cultures as well. Based on the results of these experiments, it is clear however, that the rapid decrease of $P$. imperforata between the third and seventh day of the enrichment cultures was not due to food limitation.

Perhaps the most important finding of this study is that enrichment cultures can select for species that may not be representative of oceanic nanoplanktonic protists that are abundant, and are not indicative of the quantitative importance of the species. The enrichment culture method for heterotrophic protists favors the growth of bacterivorous species that are amenable to culture conditions. The fact that cultivable species may not necessarily represent numerically dominant or abundant species in nature is a phenomenon that has been known among bacteriologists for some time $(2$, and references therein). In this study, $P$. imperforata was found to be in low abundance in coastal waters, but because enrichment culture conditions presented a transient period of elevated prey concentrations, opportunistic species such as $P$. imperforata which can 
respond quickly to favorable growth conditions prevailed in many of the enrichment cultures.

Our present knowledge of how physical and biological factors affect the abundance, distribution and diversity of protists in aquatic environments is still very limited. This shortcoming in our understanding of protistan ecology is largely a result of the difficulties associated with identifying and enumerating small protists simultaneously in mixed natural assemblages using existing techniques. In situ hybridization with oligonucleotide probes enables direct measurements of the abundance of flagellate species in natural water samples. The use of this approach in the present study has demonstrated the potential of using molecular biological approaches to address fundamental ecological questions that have been technically difficult to study. More importantly, the data obtained in this study is a step towards elucidating the factors that control the abundance and distribution of these species. In future, the use of oligonucleotide probes to target a variety of species or species groups will provide a more complete picture of diversity and their role in an environment. Information on protistan species composition, abundance and their variability is ultimately necessary in order to describe biogeochemical processes that are important to ecosystem function.

\section{Acknowledgements}

This study was supported by National Science Foundation grant OCE-9216270. 


\section{References}

1. Amann, R. I., B. J. Binder, S. W. Olson, R. Devereux and D. A. Stahl. 1990. Combination of 16S rRNA-targeted oligonucleotide probes with flow cytometry for analyzing mixed microbial populations. Appl. Environ. Microbiol. $56: 1919-1925$.

2. Amann, R. I., W. Ludwig and S. K-H. 1995. Phylogenetic identification and in situ detection of individual microbial cells without cultivation. Microbiol. Rev. 59:143-169.

3. Azam, F., T. Fenchel, J. G. Field, J. S. Gray, L. A. Meyer-Reil and F. Thingstad. 1983. The ecological role of water-column microbes in the sea. Mar. Ecol. Prog. Ser. 10:257-263.

4. Caron, D. A. 1983. Technique for enumeration of heterotrophic and phototrophic nanoplankton, using epifluorescence microscopy, and comparison with other procedures. Appl. Environ. Microbiol. 46:491-498.

5. Caron, D. A. and J. C. Goldman. 1990. Protozoan nutrient regeneration, p. 283-306. In G. M. Capriulo (ed.), Ecology of marine protozoa. Oxford University Press, New York.

6. Caron, D. A., J. C. Goldman, O. K. Andersen and M. R. Dennett. 1985. Nutrient cycling in a microflagellate food chain. II. Population dynamics and carbon cycling. Mar. Ecol. Prog. Ser. 24:243-254.

7. Caron, D. A., J. C. Goldman and M. R. Dennett. 1986. Effect of temperature on growth, respiration, and nutrient regeneration by an omnivorous microflagellate. Appl. Environ. Microbiol. 52:1340-1347. 
8. Caron, D. A., E. L. Lim, C. Kosman, M. R. Dennett and E. F. DeLong. in prep. Oligonucleotide probe design and phylogenetic position of the heterotrophic nanoflagellate genus Paraphysomonas based on small subunit ribosomal RNA sequences for species.

9. Caron, D. A., E. L. Lim, G. Miceli, J. B. Waterbury and F. W. Valois. 1991. Grazing and utilization of chroococcoid cyanobacteria and heterotrophic bacteria by protozoa in laboratory cultures and a coastal plankton community. Mar. Ecol. Prog. Ser. 76:205-212.

10. DeLong, E. F., F. S. Wickham and N. R. Pace. 1989. Phylogenetic stains: ribosomal RNA-based probes for the identification of single cells. Science 243:1360-1363.

11. Fenchel, T. 1982. Ecology of heterotrophic microflagellates. I. Some important forms and their functional morphology. Mar. Ecol. Prog. Ser. 8:211-223.

12. Fenchel, T. 1982. Ecology of heterotrophic microflagellates. II. Bioenergetics and growth. Mar. Ecol. Prog. Ser. 8:225-231.

13. Fenchel, T. 1982. Ecology of heterotrophic microflagellates. III. Adaptations to heterogeneous environments. Mar. Ecol. Prog. Ser. 9:25-33.

14. Fenchel, T. 1982. Ecology of heterotrophic microflagellates. IV. Quantitative occurrence and importance as bacterial consumers. Mar. Ecol. Prog. Ser. 9:3542.

15. Giovannoni, S. J., E. F. DeLong, G. J. Olsen and N. R. Pace. 1988. Phylogenetic group-specific oligodeoxynucleotide probes for identification of single microbial cells. J. Bacteriol. 170:720-726.

16. Goldman, J. C. and D. A. Caron. 1985. Experimental studies on an omnivorous microflagellate: implications for grazing and nutrient regeneration in the marine microbial food chain. Deep-Sea Res. 32:899-915. 
17. Goldman, J. C., D. A. Caron, O. K. Andersen and M. R. Dennett. 1985. Nutrient cycling in a microflagellate food chain: I. Nitrogen dynamics. Mar. Ecol. Prog. Ser. 24:231-242.

18. Hobbie, J. E., R. J. Daley and S. Jaspar. 1977. Use of Nuclepore filters for counting bacteria by fluorescence microscopy. Appl. Environ. Microbiol. 33:1225-1228.

19. Landry, M. R., J. M. Lehner-Fournier, J. A. Sundstrom, V. L. Fagerness and K. E. Selph. 1991. Discrimination between living and heatkilled prey by a marine zooflagellate, Paraphysomonas vestita (Stokes). J. Exp. Mar. Biol. Ecol. 146:139-151.

20. Larsen, J. and D. J. Patterson. 1990. Some flagellates (Protista) from tropical marine sediments. J. Nat. His. 24:801-937.

21. Lim, E. L. 1996. Molecular identification of nanoplanktonic protists based on small subunit ribosomal RNA gene sequences for ecological studies. J. Euk. Microbiol. 43:101-106.

22. Lim, E. L., L. A. Amaral, D. A. Caron and E. F. DeLong. 1993. Application of rRNA-based probes for observing marine nanoplanktonic protists. Appl. Environ. Microbiol. 59:1647-1655.

23. Lim, E. L., D. A. Caron and E. F. DeLong. 1996. Development and field application of a quantitative method for examining natural assemblages of protists with oligonucleotide probes. Appl. Environ. Microbiol. 62:1416-1423.

24. Lucas, I. A. N. 1967. Two new marine species of Paraphysomonas. J. Mar. Biol. Assoc. U.K. 47:329-334.

25. Manz, W., R. Amann, R. Szewzyk, U. Szewzyk, T.-A. Stenström, P. Hutzler and K.-H. Schleifer. 1995. In situ identification of Legionellaceae 
using 16S rRNA-targeted oligonucleotide probes and confocal laser scanning microscopy. Microbiology 141:29-39.

26. Porter, K. G. and Y. S. Feig. 1980. The use of DAPI for identifying and counting aquatic microflora. Limnol. Oceanogr. 25:943-948.

27. Preisig, H. R. and D. J. Hibberd. 1982. Ultrastructure and taxonomy of Paraphysomonas (Chrysophyceae) and related genera 1. Nord. J. Bot. 2:397-420.

28. Preisig, H. R. and D. L. Hibberd. 1983. Ultrastructure and taxonomy of Paraphysomonas (Chrysophyceae) and related genera 3. Nord. J. Bot. 3:695-723.

29. Preisig, H. R., N. Vørs and G. Hällfors. 1991. Diversity of heterotrophic heterokont flagellates, p. 361-399. In D. J. Patterson and J. Larsen (ed.), The Biology of Free-living Heterotrophic Flagellates. vol. 45. Clarendon Press, Oxford.

30. Sieburth, J. M. 1984. Protozoan bacterivory in pelagic marine waters, p. 405-444. In J. E. Hobbie and P. J. I. Williams (ed.), Heterotrophic activity in the sea. Plenum Press, New York.

31. Sieburth, J. M. and P. G. Davis. 1982. The role of heterotrophic nanoplankton in the grazing and nurturing of planktonic bacteria in the Sargasso and Caribbean Sea. Ann. Inst. Océanogr., Paris 58(S):285-296.

32. Simon, N., N. LeBot, D. Marie, F. Partensky and D. Vaulot. 1995. Fluorescent in situ hybridization with rRNA-targeted oligonucleotide probes to identify small phytoplankton by flow cytometry. Appl. Environ. Microbiol. $61: 2506-2513$.

33. Sogin, M. L. and J. H. Gunderson. 1987. Structural diversity of eukaryotic small subunit ribosomal RNAs. Ann. N.Y. Acad. Sci. 503:125-139.

34. Stahl, D. A. and R. Amann. 1991. Development and application of nucleic acid probes, p. 205-248. In E. Stackebrandt and M. Goodfellow (ed.), Nucleic acid techniques in bacterial systematics. John Wiley \& Sons Ltd., Chichester, England. 
35. Vørs, N. 1992. Heterotrophic amoebae, flagellates and heliozoa from the Tvärminne area, Gulf of Finland, in 1988-1990. Ophelia 36:1-109.

36. Vørs, N. 1993. Heterotrophic amoebae, flagellates and heliozoa from Arctic marine waters (North West Territories, Canada and West Greenland). Polar Biol. 13:113-126.

37. Vørs, N. 1993. Marine heterotrophic amoebae, flagellates and heliozoa from Belize (Central America) and Tenerife (Canary Islands), with descriptions of new species, Luffisphaera bulbochaete N. Sp., L. longihastis N. Sp., L. turriformis N. Sp. and Paulinella intermedia N. Sp. Journal of Eukaryotic Microbiology 40:272287. 


\section{Conclusions}


The work described in this thesis has demonstrated that SSU rRNA-based identification techniques are applicable and extremely useful for identifying and quantifying nanoflagellates in pure cultures as well as in natural, mixed assemblages. The potential of using molecular biological approaches to address fundamental ecological questions that had been technically difficult to study in the past, was illustrated by using studies the heterotrophic flagellate, Paraphysomonas imperforata as a model organism. Overall, the work in this thesis has provided some new insights on the biology and ecology of heterotrophic nanoflagellates.

The first chapter examined the use of RFLP analysis to discriminate isolates of heterotrophic flagellates. Restriction digests of PCR-amplified SSU rDNA from these isolates proved to be a rapid and reliable method for discriminating flagellate taxa. The differentiation of isolates by the PCR-RFLP method was in good agreement with established morphological classification at the specific and generic level. In addtion, RFLP analysis could detected morphologically and genetically polymorphic forms of $P$. imperforata among the isolates tested. This result is significant in that it confirmed the common knowledge among flagellate taxonomists that scaled chrysophytes such as those in the genus Paraphysomonas are extremely polymorphic and that species distinction among certain taxa, for example, may not be valid. A surprising result of this study was perhaps the intraspecific variability found in the SSU rRNA gene sequence of $P$. imperforata. The extent of sequence heterogeneity could not be adequately examined in this study because of the limited number of isolates available, but remains an important issue for future studies. Based on the isolates examined, this work established two novel and important points concerning heterotrophic nanoflagellates: 1) there is sufficient variability in the SSU rDNA of chrysomonad flagellates to allow development of genusor species-specific probes; 2) molecular information can provide an independent 
criterion to evaluate the validity of species distinctions (or lack of) when morphological characteristics are unclear or atypical.

Chapter II and Chapter III addressed the feasibility of using oligonucleotide probes for the detection and quantification of nanoplanktonic protists especially in field samples. The use of multiple biotinylated probes with FITC-avidin as the secondary label was found to be necessary in order to obtain sufficient signal amplification for detecting field populations of nanoplanktonic protists. A quantitative in situ hybridization procedure that enables direct enumeration of protists on polycarbonate filters was subsequently developed so that oligonucleotide probes could be used to examine natural assemblages of protists from environmental water samples. With this method, I found that probes could detect small nanoplanktonic cells that might be missed by fluorochrome stains. Cells attached to or embedded in aggregates were also difficult to distinguish when stained by fluorochrome dyes but not by probes. As a result, probe counts of total nanoplankton by the quantitative in situ hybridization procedure were in many cases higher than counts obtained by fluorochrome staining. The data obtained from this work suggest that nanoplankton in certain water samples may actually be present at higher abundances than previously thought, especially in water samples where small cells persist or in eutrophic water samples with high concentrations of detrital material.

In the final chapter of this thesis, I used $P$. imperforata as a model organism to demonstrate the applicability of species-specific probes for addressing some fundamental ecological questions concerning many taxa of small protists: What is their natural abundance? Does their abundance vary spatially and temporally? What are the factors controlling their distribution? P. imperforata was found to constitute $1 \%$ or less of the total nanoplankton (TNAN) in samples examined over a 17-month period. Although such low abundances were observed in natural water samples, $P$. imperforata 
often dominated the nanoplankton (up to $98 \%$ of TNAN) when water samples were enriched with bacteria. I conclude that $P$. imperforata is an opportunistic species capable of growing to high abundances under favorable culture conditions rather than a truly dominant species. Water temperature, small differences in the absolute abundance of $P$. imperforata, and possibly nanoplankton grazers all appeared to play a role in determining whether $P$. imperforata dominated the enrichment cultures. These results represent new and unexpected insights into the ecology of a species that was mostly considered to be common and abundant based on observations of enriched water samples. More importantly, the results also suggest that enrichment cultures or perhaps incubations in general can promote growth of species that may not be representative of nanoflagellates that are abundant in the ocean.

Information on the ecology of specific populations of small flagellates in aquatic environments is beginning to materialize using molecular biological approaches. The work described in this thesis is a step towards characterizing the biogeography of natural assemblages of small protists and elucidating the factors that control the abundance and distribution of these species. Knowledge of protistan species composition, abundance and variability in an environment can ultimately be used to relate community structure to various aspects of community function and biogeochemical activity. New technologies will likely continue to emerge in the field of molecular biology to help advance our ability to study the ecology of small protists and characterize their diversity in aquatic habitats. 


\section{Appendix}

\section{Molecular Identification of Nanoplanktonic Protists based on Small Subunit Ribosmoal RNA Gene Sequences for Ecological Studies 1}

1 This paper was originally presented as part of the symposium on "Protistan Molecular Ecology and Systematics," July 29, 1995, during the 48th Annual Meeting of the Society of Protozoologists, University of Alabama, Tuscaloosa, AL. J. Euk. Microbiol., 43(2): pp. 101-106. 
ABSTRACT

Nanoplanktonic protists are comprised of a diverse assemblage of species which are responsible for a variety of trophic processes in marine and freshwater ecosystems. Current methods for identifying small protists by electron microscopy do not readily permit both identification and enumeration of nanoplanktonic protists in field samples. Thus, one major goal in the application of molecular approaches in protistan ecology has been the detection and quantification of individual species in natural water samples. Sequences of small subunit ribosomal RNA (SSU rRNA) genes have proven to be useful towards achieving this goal. Comparison of sequences from clone libraries of protistan SSU rRNA genes amplified from natural assemblages of protists by the polymerase chain reaction (PCR) can be used to examine protistan diversity. Furthermore, oligonucleotide probes complementary to short sequence regions unique to species of small protists can be designed by comparative analysis of rRNA gene sequences. These probes may be used to either detect the RNA of particular species of protists in total nucleic acid extracts immobilized on membranes, or the presence of target species in water samples via in situ hybridization of whole cells. Oligonucleotide probes may also serve as primers for the selective amplification of target sequences from total population DNA by PCR. Thus, molecular sequence information is becoming increasingly useful for identifying and enumerating protists, and for studying their spatial and temporal distribution in nature. Knowledge of protistan species composition, abundance and variability in an environment can ultimately be used to relate community structure to various aspects of community function and biogeochemical activity. 
Free-living protists in the nanoplankton size class $(2-20 \mu \mathrm{m})$ are comprised primarily of a diverse assemblage of heterotrophic and photosynthetic flagellates [31, $32,44,45]$. Protists in this size category numerically dominate the eukaryotic plankton and are responsible for a variety of trophic processes in planktonic food webs $[3,5$, and references therein]. Photosynthetic protists often constitute a significant fraction of primary production in aquatic ecosystems while heterotrophic species are the major consumers of picoplankton-sized microorganisms (prokaryotic and eukaryotic cells 0.2 to $2 \mu \mathrm{m}$ in size) $[9,28,38,39]$. The grazing activities of these heterotrophs also result in the release of nutrients and dissolved organic material which are utilized by bacteria and microalgae $[6,8]$. In addition, by virtue of their size and ability to efficiently graze minute microorganisms, protists serve as an important trophic link between the picoplankton and metazoan zooplankton which can capture protists but are unable to consume picoplanktonic cells efficiently [7].

Despite their abundance and vital position in the trophic structure of microbial food webs, relatively little information is available on the population structure and diversity of the nanoplankton assemblage in the water column. Virtually nothing is known about the seasonal and temporal abundance of most species, and the geographical distribution of individual species is also poorly understood. Measurements of nanoplankton production and grazing rates in ecological studies are routinely performed without concomitant identification of the species responsible for these processes. Individual species often are not recognized as functionally and physiologically unique entities but are grouped together by size. This simplistic treatment of protistan community structure is largely a result of difficulties associated with identifying and enumerating small protists in mixed, natural assemblages using existing techniques.

Until recently, electron microscopy has been the most informative method for identifying small protists because of its high resolution. Information on ultrastructural 
organization based on flagella systems, scale morphology, and the structure of mitochondria and chloroplasts for example, has been used for taxonomy and phylogeny. However, electron microscopy is labor-intensive, impractical for analyses of large numbers of samples and has limited applicability for cell enumeration. As a result, the method is not routinely used for processing environmental water samples and for viewing natural assemblages of microorganisms. One of the major goals in the application of molecular biological approaches in ecological studies thus, is to provide a new tool that allows both identification and enumeration of small protists in natural water samples.

An approach for examining microbial diversity that has begun to gain wide application in recent years is the use of SSU rRNA sequences and rRNA-based phylogenetic identification techniques [2, 47]. Ribosomal RNA molecules are suitable molecular markers because they are universally distributed, highly conserved, and functionally and evolutionarily homologous across kingdom lines [29, 41]. The molecule is interspersed with conserved and variable regions which are useful for sequence alignment and differentiation of compared organisms, respectively. The gene (and gene product) is relatively easy to isolate and characterize, and appears not to undergo lateral gene transfer between species. At present, the SSU rRNA database contains approximately 3000 aligned sequences, of which more than 400 are eukaryotic sequences [30]. The database provides a source of sequence information for comparative sequence analysis and the design of oligonucleotide primers and probes. Oligonucleotides of varying specificity ranging from kingdom- to subspecies-level have been designed for numerous microorganisms for use as primers and probes, indicating that the SSU rRNA molecule may be a suitable target to design protistan probes. Another important advantage of working with the rRNA molecule is that the relatively high cellular content of rRNA provides abundant target sites for probe binding. 
Ribosomal RNA sequences and phylogenetic identification techniques have mostly been employed for the detection and identification of a variety of prokaryotes [2]. These techniques have enabled bacteriologists to characterize species in cultures as well as in environmental samples by direct sequence analysis, restriction fragment length polymorphism (RFLP) analyses or by oligonucleotide hybridization probes. The use of PCR to amplify rRNA genes from single cells or minute amounts of template DNA, together with auto-sequencing techniques, have made the identification of microbial cells using molecular biological techniques more effective and expedient than traditional culture methods.

The purpose of this paper is to provide a conceptual framework for applying rRNA-based phylogenetic identification techniques to examine free-living nanoplankton diversity and ecology. The ecology of these protists has been examined using rRNA-based techniques in only a few recent studies $[16,25,37,40]$. The extensive molecular work of aquatic bacteriologists has served as a model for how these methods can be applied to analyze natural nanoplankton populations, and still serves this role. An overview of these methodological approaches will be given, together with their potential applications to protistan ecology. Finally, a quantitative procedure using fluorescent in situ hybridization will be described which demonstrates the effectiveness of molecular biological techniques for studying the ecology of small protists. The method involves the use of specific oligonucleotide probes for detecting and enumerating natural assemblages of nanoplanktonic protists. 
EXAMINING THE DIVERSITY OF NANOPLANKTONIC PROTISTS AND IDENTIFYING SPECIFIC POPULATIONS

Examining Community Diversity. An approach that relies on the sequencing of multiple clones from gene libraries of PCR-amplified SSU rRNA provides a method to study the population structure and diversity of natural microbial assemblages without the selective bias of cultivation and isolation of clonal cultures. The approach has been increasingly used to characterize natural bacterial communities in diverse habitats $[4,12,19,20,35,42]$, and has the potential for direct application to nanoplanktonic protists (Fig. 1A). Because it is based on PCR amplification of SSU rRNA genes, it is particularly suitable for analyzing environmental water samples in which the concentration of target DNA may be low.

Diversity analyses of small protists can follow a similar approach as has been performed with natural bacterial assemblages because small protistan assemblages can be collected and processed similarly to bacteria. Natural populations of nanoplankton $(<20 \mu \mathrm{m})$ are collected and concentrated into a cell pellet for extraction of bulk nucleic acids. Extracted nucleic acids are then used as template for amplification of rRNA genes by PCR. Primers specific for the $5^{\prime}-$ and $3^{\prime}-$ end of eukaryotic rRNA genes are used in PCR amplifications in order to selectively amplify protistan rDNA. Clone libraries of protistan SSU rRNA genes amplified from natural populations of nanoplanktonic protists by PCR may be subsequently prepared. Because some clones are likely to contain similar inserts (i.e. cloned rDNA from the same species), restriction fragment length polymorphism (RFLP) can be used to screen the inserts and group clones with the same RFLP patterns. Representative clones are sequenced by the dideoxy chain termination method using universal or eukaryote-specific rRNA sequencing primers. Approximately 1800 nucleotides of sequence information can be obtained for each clone 
181 
Figure 1. Flow chart showing the different steps involved in examining community diversity of nanoplanktonic protists (A), samples. 


\section{A. Examining Community Diversity}

Collect natural

population of cells

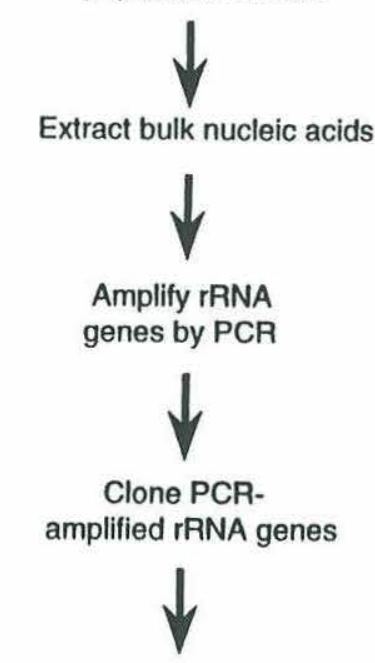

Screen and group rDNA clones by RFLP

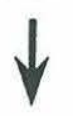

Sequence representative rDNA clones

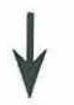

Phylogenetic analysis of sequences

\section{B. Identifying Specific Populations}

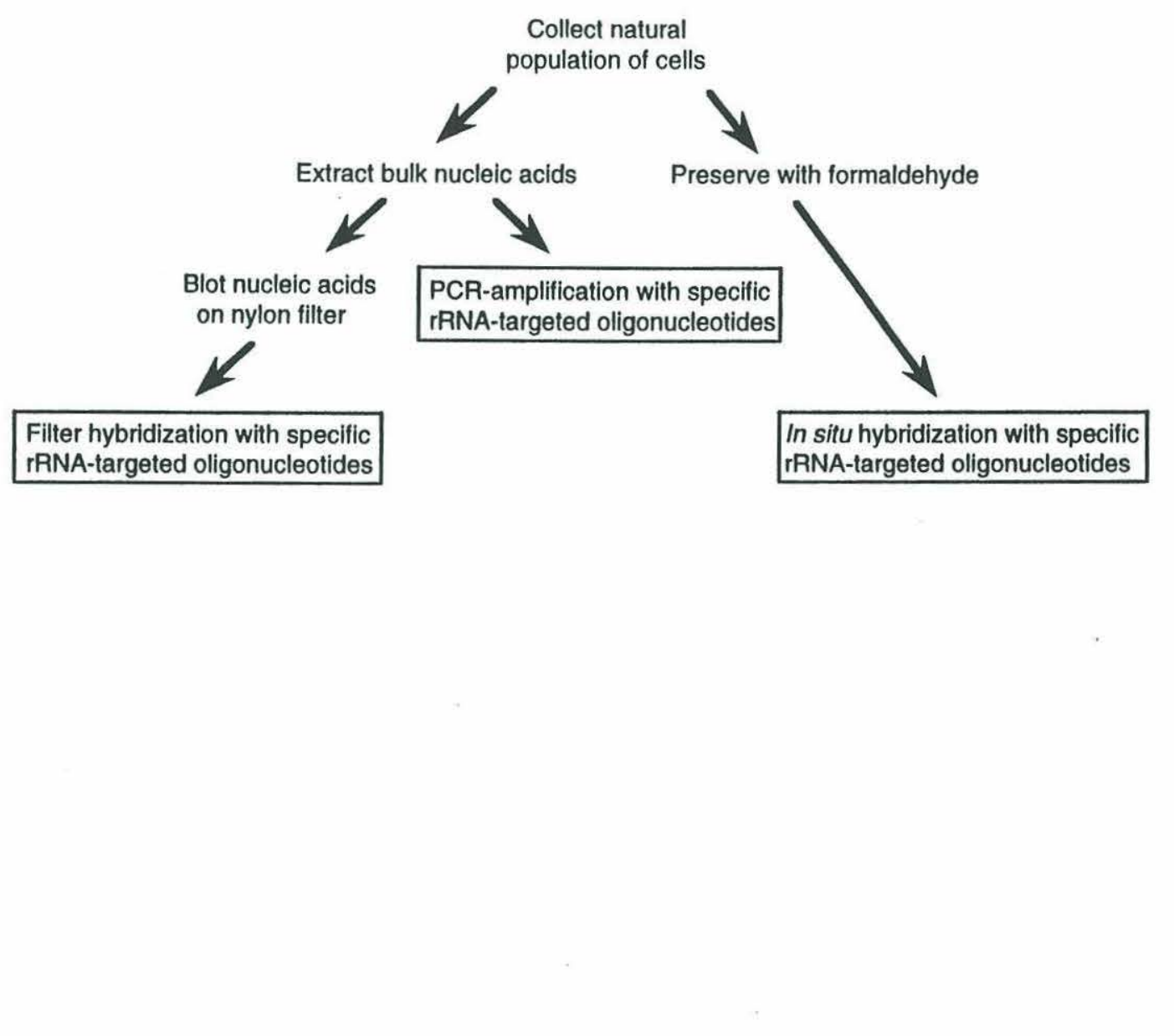


sequenced. Sequences are aligned and compared with sequences of identified microorganisms retrieved from the rRNA database for phylogenetic analysis [27].

Identification of a particular species is based on a match between a cloned sequence and an identified sequence in the database. If sequences obtained are from unknown or uncultivable organisms, the similarity of those sequences with identified sequences in the database may suggest possible phylogenetic affiliations which may in turn indicate biochemical function based on the properties of close relatives. Phylogenetic analysis of rDNA clones provides a potentially comprehensive method to assess species composition and community diversity in natural water samples. The usefulness of this approach, however, depends on the presence of sequences of previously identified species or closely related species in the database in order to establish the species identity or phylogenetic affinity of the sequences. This approach also has the potential for introducing some selectivity due to biases in sampling, differential cell lysis, nucleic acid extraction efficiency, DNA amplification or rDNA cloning efficiency $[15,23,33,34]$.

Identifying Specific Populations. A more direct and rapid approach for detecting and identifying nanoplanktonic protists employs the use of specific rRNAtargeted oligonucleotides (Fig. 1B). Ribosomal RNA-targeted oligonucleotides are short DNA fragments, usually 15 to 25 base pairs in length, which complement and bind to regions of the rRNA molecule. The more conserved regions of the rRNA molecule are suitable for discerning broader phylogenetic relationships such as kingdom-level relationships, while the variable regions of the molecule are suitable for designing oligonucleotides to discriminate organisms at the subspecies-, species- or genus-level [2, and references therein]. 
Oligonucleotides are designed by comparative analysis of aligned rRNA sequences from species of interest and of closely and distantly related taxa. Sequence segments, approximately 20 base pairs in length, characteristic of the species or taxonomic group of interest are identified by visual inspection of the aligned sequences, and oligonucleotides complementary to these signature sequences are synthesized. Hybridization and wash temperatures for these oligonucleotides are then empirically determined, and their specificity confirmed by hybridization of the oligonucleotides to rRNA from a variety of species [43].

Oligonucleotides may be used as PCR amplification primers or as hybridization probes for detecting the presence of specific rRNA sequences (or the cells that contain them) in a water sample without prior isolation and culture. Cells are collected and concentrated for extraction of bulk nucleic acids or directly preserved with formaldehyde (Fig. 1B). Targeted protistan populations in the extracted nucleic acid samples are detected using specific rRNA-targeted oligonucleotides either as primers for the selective amplification of target sequences by PCR, or as probes in filter hybridizations. Selective amplification by PCR is achieved by using a pair of primers specific for the target group, or a primer specific for the taxonomic group of interest in combination with a eukaryote-specific primer. Extracted nucleic acids are used as template for amplification of target DNA sequences by PCR according to standard protocols. Following amplification, PCR products are visualized by agarose gel electrophoresis. Positive amplifications, which contain amplified DNA fragments that correspond to the size of the DNA encompassed by the primer set used, indicate the presence of the target organism or group in the samples. This result should be confirmed by sequencing the amplified fragment to ensure that the sequence matches that of the target organism. Alternatively, RFLP analysis is a rapid way of checking that the correct DNA fragment has been amplified. 
PCR has been shown to be a very specific and sensitive method for the detection of pathogens in clinical samples and for the identification of some aquatic microorganisms $[10,14,16]$. When group-specific probes are used as PCR amplification primers, the technique offers a simple and rapid method to detect and identify the organism of interest from very small amounts of DNA. In addition, numerous samples can be analyzed simultaneously, making the approach suitable for studies which involve broad sampling schemes as in examining the biogeography of small protistan species.

Target protistan populations in bulk nucleic acids can alternatively be detected using specific rRNA-targeted oligonucleotides as probes [11-13, 20]. By this method, extracted nucleic acids are blotted onto nylon filters, immobilized, and hybridized with oligonucleotide probes. Probes used in filter-bound, nucleic acid hybridizations are usually radioactively labeled with $32 \mathrm{P}$ because of the sensitivity that $32 \mathrm{P}$ provides. Probes hybridized to target sequences on the filters are detected by autoradiography. Probing nucleic acids on filters may also be used for estimating the relative abundance of target populations in water samples. Extracted nucleic acids and rRNA from known standards are serially diluted, loaded onto filters, and hybridized with the targetspecific probe as well as a eukaryote-specific probe (on separate filters). Autoradiographic signals from these hybridizations are quantified, and the percentage of target-specific rRNA is estimated from the slope of the amount of target-specific probe bound per unit of rRNA relative to the amount of eukaryote-specific probe bound per unit of rRNA.

A more direct approach for detecting small protists using oligonucleotide probes involves in situ hybridization of whole cells in preserved water samples. Probes for in situ hybridizations are most commonly labeled with fluorescent dyes either directly or indirectly via secondary reporter molecules. In situ hybridizations may be performed on cells immobilized on gelatin-coated glass slides, polycarbonate filters or "in 
solution" [1, 21, 26]. The protocol for performing in situ hybridizations are slightly modified to accommodate these different cell preparations. Discussion in this section will be restricted to performing in situ hybridizations using cells attached to glass slides, and fluorescent detection by epifluorescence microscopy. Hybridization of protists concentrated onto polycarbonate filters is detailed in the following section along with results from experiments applying oligonucleotide probes for enumerating protists in field samples. "In solution" hybridization techniques and identification of small, marine photosynthetic protists by flow cytometry have recently been described and will not be discussed in this paper [40].

Nanoplanktonic protists are detected by fluorescent in situ hybridization in water samples (10 to $50 \mathrm{mls}$ of coastal water) that have been preserved, concentrated, and spotted onto gelatin- and Teflon-coated slides [25]. The cell spots are dried and subsequently dehydrated in a series of ethanol washes. Hybridization buffer and probes are added to each sample, and allowed to hybridize for 2 to 24 hours in a sealed, moist chamber to avoid evaporation. Following hybridization, the samples are washed (and secondary labels are added, if necessary) and processed according to the manufacturer's protocols. Samples are mounted in a glycerol-based solution and viewed by immediately epifluorescence microscopy. The cytoplasm of probed, target cells will appear uniformly stained while the nucleus and food vacuoles of heterotrophic protists usually appear as dark, unlabeled circles.

A common problem with fluorescence-based, whole cell in situ hybridizations for bacteria is low detection signal (fluorescence). However, this problem is not as great for large protists, and often can be circumvented for small protists by the use of biotinylated probes and a fluorochrome-avidin conjugate as a secondary label. The use of multiple, biotinylated probes that are specific for different sites on the ribosome of the target cell has also been shown to significantly amplify hybridization signal and permit 
visualization of probed protists and some bacteria in field samples [24, 25, 46]. Preserved samples should be processed as soon as possible because cross-linking of formaldehyde over time reduces cell permeability, and degradation of target sequences may also be a problem.

The use of fluorescent probes for in situ hybridization simplifies the detection of target cells in water samples because it excludes the need for nucleic acid extraction. Moreover, whole cell, in situ hybridization with oligonucleotide probes permits detected cells to be visualized intact. Another key advantage of in situ hybridization using oligonucleotide probes and fluorescent detection is the ability to detect and quantify the absolute abundance of target cells. The application of oligonucleotide probes for quantifying the natural abundances of protists in field samples is described in the following section.

\section{APPLICATION OF OLIGONUCLEOTIDE PROBES FOR QUANTIFYING NATURAL ASSEMBLAGES OFPROTISTS.}

Two of the major obstacles in the application of in situ hybridization and oligonucleotide probes for ecological studies has been the ability to detect cells in natural samples and quantifying them. Signal amplification achieved by using multiple, biotinylated probes, as mentioned above, has now made it possible to detect small protistan cells in natural water samples. However, finding a hybridization technique that allows quantification of probed microorganisms has been more difficult. This difficulty is mainly due to the problem of cell loss when washing and concentrating cells in the hybridization protocol. 
A new quantitative method was recently developed for in situ hybridization and detection of marine and freshwater protists using oligonucleotide probes [26]. The key to this quantitative technique is the use of Transwell cell culture chamber inserts (Costar Corp., Cambridge, MA). The Transwell is a polystyrene dish, $25 \mathrm{~mm}$ in diameter, that has a polycarbonate membrane filter as its base. These Transwells serve as filtration cups in which samples can be concentrated and processed without cell loss due to rinsing. The Transwells are used directly without pretreatment of the filters with Irgalan Black to reduce background fluorescence, a routine procedure in epifluorescence microscopy [22]. Using a slight vacuum, preserved samples (2 to 25 $\mathrm{mls}$ ) are drawn down onto polycarbonate filters (25 $\mathrm{mm}, 0.4 \mu \mathrm{m}$ pore size) of Transwells placed on top of fritted glass filtration bases. Transwells containing the concentrated samples are then transferred to 6-well tissue culture plates (in which the Transwells come) where wash solutions are added directly to the filters. Solutions are drawn away by vacuum filtration between each wash or incubation. Following hybridization, filters are prepared for examination using epifluorescence microscopy by cutting them out of the Transwells and mounting them on glass slides.

The ability of the in situ hybridization method using biotinylated eukaryotespecific probes and FITC-avidin to provide accurate counts of nanoplanktonic protists relative to counts obtained by conventional nanoplankton staining with $4^{\prime}, 6$-diamidino2-phenylindole (DAPI) and acridine orange (AO) was examined with culture and field samples. Cell counts obtained by the in situ hybridization method of several cultures of protists representing a range of sizes and taxonomic groups were not significantly different from counts obtained by DAPI and AO staining (data not shown). However, total nanoplankton (TNAN) abundances obtained by in situ hybridization for several natural water samples were consistently higher than nanoplankton abundances obtained using DAPI or AO staining (Table 1). The largest difference was observed between the probe 
Table 1. Total nanoplankton (TNAN) counts determined using DAPI and AO staining as a percentage of TNAN counts obtained using eukaryote-specific probes from a variety of freshwater and seawater samples.

\begin{tabular}{lcc}
\hline & DAPI & AO \\
\cline { 2 - 3 } \multicolumn{1}{c}{ Sample } & (\% of TNAN counts determined by probes) \\
\hline Deep Pond (fw) & 58 & 97 \\
Sargasso Sea (sw) & 85 & 65 \\
Woods Hole (sw) & 48 & 61 \\
Sippiwissett Marsh (bw) & 88 & 80 \\
\hline fw = freshwater, sw = seawater, bw = brackish water.
\end{tabular}


counts and DAPI counts of TNAN. DAPI detected only $48 \%$ to $88 \%$ of TNAN densities obtained by eukaryote-specific probes.

Total nanoplankton abundances were also examined in samples collected from a mesocosm experiment designed to examine the impact of dissolved organic carbon (DOC) and dissolved nutrients (DIN) on coastal food webs. Total nanoplankton enumerated using DAPI staining in the control and the three enriched treatments (DOM, DIN and DOM+DIN) were consistently lower than TNAN counts obtained by probe hybridization over a 10 day sampling period (Table 2). On average, DAPI counts were $47 \%$ of probe counts of TNAN in the control. Enrichment of the water samples did not result in dramatic changes: DAPI staining in these treatments only labeled an average of $53 \%$ to $59 \%$ of the TNAN determined using probes. The greatest difference observed between probe counts and DAPI counts was in the DOC + DIN treatment during the last day of sampling (day 10): only $30 \%$ of the nanoplankton detected by probes were labeled by DAPI (data not shown). TNAN in all four treatments were also counted by AO staining but only on day 10. Acridine orange counts of TNAN in these samples were also lower than probe counts, ranging from $45 \%$ to $57 \%$ of TNAN abundances obtained by probe hybridization.

The underestimation of TNAN abundances in samples stained with DAPI or AO was attributed to the existence of small nanoplanktonic cells that could be detected using probes but not DAPI or AO, and the difficulty associated with distinguishing DAPI- or AO-stained protists attached to or embedded in aggregates. Because probes bind to ribosomes which are dispersed in the cytoplasm, cells are often more uniformly stained and easier to visualize and count than cells stained with DAPI (which primarily stains the nucleus). Bacteria and aggregate material which were abundant in the enriched treatments also interfered with nanoplankton counts because DAPI and AO stain bacteria and detrital material intensely, and as a result, masked the fluorescence of stained 
Table 2. Total nanoplankton (TNAN) counts determined using DAPI and AO staining as a percentage of TNAN counts obtained using eukaryote-specific probes averaged over a 10 day sampling period from a mesocosm experiment.

\begin{tabular}{|c|c|c|}
\hline \multirow[b]{2}{*}{ Treatment } & DAPI ${ }^{*}$ & $\mathrm{AO}^{\dagger}$ \\
\hline & \multicolumn{2}{|c|}{ ( $\%$ of TNAN counts determined by probes) } \\
\hline Control & $47(32-65)$ & 45 \\
\hline DOC & $54(41-75)$ & 56 \\
\hline DIN & $59(43-73)$ & 57 \\
\hline $\mathrm{DOC}+\mathrm{DIN}$ & $53(30-75)$ & 47 \\
\hline
\end{tabular}


protists within aggregates. Fluorescence due to non-specific labeling in probed samples, on the other hand, was very low and probed cells could be clearly distinguished even within detrital aggregates. This study demonstrated that in situ hybridization using oligonucleotide probes can provide a method for enumerating natural nanoplankton that is as accurate or superior to conventional methods employing fluorochrome stains. When combined with species- or group-specific oligonucleotide probes, this approach should finally allow enumeration of individual taxa of small protists in samples containing natural, mixed assemblages.

\section{CONCLUSION}

Molecular biological techniques can be used to obtain information concerning the population structure and biodiversity of natural communities of nanoplanktonic protists or to detect and characterize specific microbial populations in diverse habitats. While most studies investigating the diversity of aquatic microbial communities have focused on prokaryotes, the methodologies involved are readily applicable to studying protistan ecology and diversity. At present, we are still far from characterizing the total biodiversity of natural assemblages of small protists, but new, molecular biological approaches are at hand to help accomplish that objective. The goal of identifying specific populations of small protists and fungi in the aquatic environment is beginning to materialize using these tools. This achievement is indicated by the increasing number of studies targeting small protists using molecular biological techniques $[17,18,25,26$, $36,40]$. New technologies will likely continue to emerge in the field of molecular biology to help advance our ability to study the ecology of small protists and characterize their diversity in aquatic habitats. 


\section{ACKNOWLEDGEMENTS}

Financial support from NSF Grant OCE-9216270 is acknowledged, as is travel support from the Society of Protozoologists and the Woods Hole Oceanographic Institution/ Massachusetts Institute of Technology Education Office.

\section{LITERATURE CITED}

1. Amann, R. I., Binder, B. J., Olson, S. W., Devereux, R. \& Stahl, D. A. 1990. Combination of $16 \mathrm{~S}$ rRNA-targeted oligonucleotide probes with flow cytometry for analyzing mixed microbial populations. Appl. Environ. Microbiol., 56:1919-1925.

2. Amann, R. I., Ludwig, W. \& K-H, S. 1995. Phylogenetic identification and in situ detection of individual microbial cells without cultivation. Microbiol. Rev., 59:143169.

3. Azam, F., Fenchel, T., Field, J. G., Gray, J. S., Meyer-Reil, L. A. \& Thingstad, F. 1983. The ecological role of water-column microbes in the sea. Mar. Ecol. Prog. Ser., 10:257-263.

4. Barns, S. M., Fundyga, R. E., Jeffries, M. W. \& Pace, N. R. 1994. Remarkable archaeal diversity detected in a Yellowstone National Park hot spring environment. Proc. Natl. Acad. Sci. USA, 91:1609-1613.

5. Berninger, U.-G., Caron, D. A., Sanders, R. W. \& Finlay, B. J. 1991. Heterotrophic flagellates of planktonic communities, their characteristics and methods

of study. In: Patterson, D. J. \& Larsen, J. (ed.), The biology of free-living heterotrophic flagellates. vol. Special Volume 45. Clarendon Press, Oxford, pp. 39-56. 
6. Caron, D. A. 1991. Evolving role of protozoa in aquatic nutrient cycles. In: Reid, P. C., Turley, C. M. \& Burkill, P. H. (ed.), Protozoa and their role in marine processes. vol. 25. Springer-Verlag, Berlin, pp. 387-415.

7. Caron, D. A. 1994. Protozoan links in food webs. In: Hausmann, K. \& Hülsmann, N. (ed.), Progress in Protozoology, Proceedings of the IX International Congress of Protozoology, Berlin 1993. Gustav Fischer Verlag, Stuttgart, pp. 125-130.

8. Caron, D. A. \& Goldman, J. C. 1990. Protozoan nutrient regeneration. In: Capriulo, G. M. (ed.), Ecology of marine protozoa. Oxford University Press, New York, pp. 283-306.

9. Caron, D. A., Lim, E. L., Miceli, G., Waterbury, J. B. \& Valois, F. W. 1991. Grazing and utilization of chroococcoid cyanobacteria and heterotrophic bacteria by protozoa in laboratory cultures and a coastal plankton community. Mar. Ecol. Prog. Ser., 76:205-212.

10. Cary, S. C., Warren, W., Anderson, E. \& Giovannoni, S. J. 1993. Identification and localization of bacterial endosymbionts in hydrothermal vent taxa with symbiontspecific polymerase chain reaction amplification and in situ hybridization techniques. Mol. Mar. Biol. Biotech., 2:51-62.

11. DeLong, E. F. 1992. Archaea in coastal marine environments. Proc. Natl. Acad. Sci. USA, 89:5685-5689.

12. DeLong, E. F., Franks, D. G. \& Alldredge, A. L. 1993. Phylogenetic diversity of aggregate-attached vs. free-living marine bacterial assemblages. Limnol. Oceanogr., 38:924-934.

13. DiChristina, T. J. \& DeLong, E. F. 1993. Design and application of rRNAtargeted oligonucleotide probes for the dissimilatory iron- and manganese-reducing bacterium Shewanella putrefaciens. Appl. Environ. Microbiol., 59:4152-4160. 
14. Eisenstein, B. I. 1990. The polymerase chain reaction: a new method of using molecular genetics for medical diagnosis. New England Journal of Medicine, $\quad 322: 178-$ 183.

15. Farrelly, V., Rainey, F. A. \& Stackebrandt, E. 1995. Effect of genome size and rrn gene copy number on PCR amplification of 16S rRNA genes from a mixture of bacterial species. Appl. Environ. Microbiol., 61:2798-2801.

16. Fell, J. W. 1993. Rapid identification of yeast species using three primers in a polymerase chain reaction. Mol. Mar. Biol. Biotech., 2:174-180.

17. Fell, J. W. \& Kurtzman, C. P. 1990. Nucleotide sequence analysis of a variable region of the large subunit rRNA for identification of marine-occurring yeasts. Current Microbiol., 21:295-300.

18. Fell, J. W., Statzell-Tallman, A., Lutz, M. J. \& Kurtzman, C. P. 1992. Partial rRNA sequences in marine yeasts: a model for identification of marine eukaryotes. Mol. Mar. Biol. Biotech., 1:175-186.

19. Fuhrman, J. A., McCallum, K. \& Davis, A. A. 1993. Phylogenetic diversity of subsurface marine microbial communties from the Atlantic and Pacific Oceans. Appl. Environ. Microbiol., 59:1294-1302.

20. Giovannoni, S. J., Britschgi, T. B., Moyer, C. L. \& Field, K. G. 1990. Genetic diversity in Sargasso Sea bacterioplankton. Nature, 345:60-63.

21. Giovannoni, S. J., DeLong, E. F., Olsen, G. J. \& Pace, N. R. 1988. Phylogenetic group-specific oligodeoxynucleotide probes for identification of single microbial cells. J. Bacteriol., 170:720-726.

22. Hobbie, J. E., Daley, R. J. \& Jaspar, S. 1977. Use of Nuclepore filters for counting bacteria by fluorescence microscopy. Appl. Environ. Microbiol., 33:12251228. 
23. Kopczynski, E. D., Bateson, M. M. \& Ward, D. M. 1994. Recognition of chimeric small-subunit ribosomal DNAs composed of genes from uncultivated microorganisms. Appl. Environ. Microbiol., 60:746-748.

24. Lee, S., Malone, C. \& Kemp, P. F. 1993. Use of multiple 16S rRNA-targeted fluorescent probes to increase signal strength and measure cellular RNA from natural planktonic bacteria. Mar. Ecol. Prog. Ser., 101:193-201.

25. Lim, E. L., Amaral, L. A., Caron, D. A. \& DeLong, E. F. 1993. Application of rRNA-based probes for observing marine nanoplanktonic protists. Appl. Environ. Microbiol., 59:1647-1655.

26. Lim, E. L., Caron, D. A. \& DeLong, E. F. 1995. Development and field application of a quantitative method for examining natural assemblages of protists using oligonucleotide probes. Appl. Environ. Microbiol., submitted:

27. Maidak, B. L., Larsen, N., McCaughey, M. J., Overbeek, R., Olsen, G. J., Fogel, K., Blandy, J. \& Woese, C. R. 1994. The Ribosomal Database Project. Nucleic Acids Res., 22:3485-3487.

28. Malone, T. C. 1971. The relative importance of nannoplankton and netplankton as primary producers in tropical oceanic and neritic phytoplankton communities. Limnol. Oceanogr., 16:633-639.

29. Olsen, G. J., Lane, D. J., Giovannoni, J. \& Pace, N. R. 1986. Microbial ecology and evolution: a ribosomal RNA approach. Ann. Rev. Microbiol., 40:337-365.

30. Olsen, G. J., Overbeek, R., Larsen, N., Marsh, T. L., McCaughey, M. J., Maciukenas, M. A., Kuan, W.-M., Macke, T. J., Xing, Y. \& Woese, C. R. 1992. The ribosomal RNA database project. Nucleic Acids Res., 20:2199-2200.

31. Patterson, D. J. 1993. The current status of the free-living heterotrophic flagellates. Journal of Eukaryotic Microbiology, 40:606-609. 
32. Patterson, D. J. \& Larsen, J. (ed.). 1991. The biology of free-living heterotrophic flagellates. Clarendon Press, Oxford.

33. Rainey, F. A., Ward, N., Sly, L. I. \& Stackebrandt, E. 1994. Dependence on the taxon composition of clone libraries for PCR amplified, naturally occurring 16S rDNA, on the primer pair and the cloning system used. Experientia, 50:796-797.

34. Reysenbach, A.-L., Giver, L. J., Wickham, G. S. \& Pace, N. R. 1992. Differential amplification of rRNA genes by polymerase chain reaction. Appl. Environ. Microbiol., 58:3417-3418.

35. Rochelle, P. A., Fry, J. C., Parkes, R. J. \& Weightman, A. J. 1992. DNA extraction for 16S rRNA gene analysis to determine genetic diveristy in deep sediment communities. FEMS Microbiol. Lett., 100:59-66.

36. Rowan, R. \& Powers, D. A. 1991. Molecular genetic identification of symbiotic dinoflagellates (Zooxanthellae). Mar. Ecol. Prog. Ser., 71:65-73.

37. Scholin, C. A. \& Anderson, D. M. 1994. Identification of group- and strainspecific genetic markers for globally distributed Alexandrium (Dinophyceae). 1. RFLP analysis of SSU rRNA genes. J. Phycol., 30:744-754.

38. Sherr, B. F., Sherr, E. B. \& Fallon, R. D. 1987. Use of monodispersed, fluorescently labeled bacteria to estimate in situ protozoan bacterivory. Appl. Environ. Microbiol., 53:958-965.

39. Sherr, E. B., Sherr, B. F. \& McDaniel, J. 1991. Clearance rates of $<6 \mu \mathrm{m}$ fluorescently labeled algae (FLA) by estuarine protozoa: potential grazing impact of flagellates and ciliates. Mar. Ecol. Prog. Ser., 69:81-92.

40. Simon, N., LeBot, N., Marie, D., Partensky, F. \& Vaulot, D. 1995. Fluorescent in situ hybridization with rRNA-targeted oligonucleotide probes to identify small phytoplankton by flow cytometry. Appl. Environ. Microbiol., 61:2506-2513. 
41. Sogin, M. L. \& Gunderson, J. H. 1987. Structural diversity of eukaryotic small subunit ribosomal RNAs. Ann. N.Y. Acad. Sci., 503:125-139.

42. Stackebrandt, E., Liesack, W. \& Goebel, B. M. 1993. Bacterial diversity in a soil sample from a subtropical Australian environment as determined by $16 \mathrm{~S}$ rDNA analysis. FASEB Journal, 7:232-236.

43. Stahl, D. A. \& Amann, R. 1991. Development and application of nucleic acid probes. In: Stackebrandt, E. \& Goodfellow, M. (ed.), Nucleic acid techniques in bacterial systematics. John Wiley \& Sons Ltd., Chichester, England, pp. 205-248.

44. Vørs, N. 1992. Heterotrophic amoebae, flagellates and heliozoa from the Tvärminne area, Gulf of Finland, in 1988-1990. Ophelia, 36:1-109.

45. Vørs, N. 1993. Marine heterotrophic amoebae, flagellates and heliozoa from Belize (Central America) and Tenerife (Canary Islands), with descriptions of new species, Luffisphaera bulbochaete N. Sp., L. longihastis N. Sp., L. turriformis N. Sp. and Paulinella intermedia N. Sp. Journal of Eukaryotic Microbiology, 40:272-287.

46. Wallner, G., Amann, R. \& Beisker, W. 1993. Optimizing fluorescent in situ hybridization of suspended cells with rRNA-targeted oligonucleotide probes specific for the genus Acinetobacter and its application for in situ monitoring in activated sludge. Cytometry, 14:136-143.

47. Ward, D. M., Bateson, M. M., Weller, R. \& Ruff-Roberts, A. L. 1992. Ribosomal RNA analysis of microorganisms as they occur in nature. Adv. Microb. Ecol., 12:219-286. 